University of Tennessee Health Science Center

UTHSC Digital Commons

\title{
Characterization of Novel CB2 Agonist SMM-295 and Its Effects in Ischemia/Reperfusion Injury
}

Jeffrey D. Pressly

University of Tennessee Health Science Center

Follow this and additional works at: https://dc.uthsc.edu/dissertations

Part of the Chemicals and Drugs Commons, and the Pharmaceutics and Drug Design Commons

\section{Recommended Citation}

Pressly, Jeffrey D. (http://orcid.org/0000-0003-2151-8864), "Characterization of Novel CB2 Agonist SMM-295 and Its Effects in Ischemia/Reperfusion Injury" (2020). Theses and Dissertations (ETD). Paper 519. http://dx.doi.org/10.21007/etd.cghs.2020.0502.

This Dissertation is brought to you for free and open access by the College of Graduate Health Sciences at UTHSC Digital Commons. It has been accepted for inclusion in Theses and Dissertations (ETD) by an authorized administrator of UTHSC Digital Commons. For more information, please contact jwelch30@uthsc.edu. 


\title{
Characterization of Novel CB2 Agonist SMM-295 and Its Effects in Ischemia/ Reperfusion Injury
}

\begin{abstract}
Acute kidney injury (AKI) is a major problem clinically affecting up to two-thirds of intensive care unit patients, and results in increased hospitalization time, the risk of developing chronic kidney disease, and mortality. Hallmarks of AKI include tubular cell death and a decrease in renal perfusion which leads to decreases in renal function following injury. For 20 years the pathophysiology of AKI has been well established. However, therapies for AKI have shown minimal to no success clinically. The work here describes our efforts to further categorize the effects of CB2 activation, a possible novel therapeutic target in AKI.

There is increasing importance associated with the understanding of the biological activity of the cannabinoid receptors following the increased acceptance in the medicinal purposes of cannabis and cannabis-related compounds. The endocannabinoid system is comprised of its cognate G-protein coupled receptors, cannabinoid type 1 and 2 receptors, endogenous lipid signaling molecules, $\mathrm{N}$ arachidonoyl ethanolamine (AEA) and 2-acylglycerol, and the enzymes involved in their biosynthesis and catabolism. In the kidney, the CB1 receptors consistently demonstrate deleterious effects on glomerular and tubular function in various acute and chronic forms of injury, while CB2 receptors have demonstrated the opposite effects.
\end{abstract}

This work will demonstrate the findings of studies that focus on the role of CB2 in the recovery from ischemia/reperfusion injury (IRI) and the effects of CB2 activation on both tubular cell death and renal hemodynamics. To study the effect of CB2 activation on renal damage following IRI, our scientific group tested a small molecule agonist, SMM-295 [3'-methyl-4-(2-(thiophen-2-yl) propan-2-yl) biphenyl-2,6-diol], in an investigation of the $\mathrm{CB} 2$ receptor as a potential therapeutic target in the prevention of tubular epithelial cell damage after AKI. To test this compound in AKI, we used a mouse model of renal bilateral ischemiareperfusion injury (IRI), which is a common experimental model to study $\mathrm{AKI}$, demonstrating considerable beneficial effects of SMM-295 following injury. Subsequently, we then investigated the possible mechanisms that undermine the effects of SMM-295, including initiation of antiapoptotic signaling cascades in tubular epithelium as well as increases in renal perfusion through a vascular effect demonstrating a multifunctional role for SMM-295 in the treatment of IRI.

Our findings demonstrate that CB2 activation by SMM-295 ameliorated the effects of IRI through decreased tubular cell death in proximal tubule cells along with an increase in renal perfusion through a direct vascular effect. These data indicate selective activation of the CB2 receptor by our novel CB2 agonist SMM-295 has therapeutic value in pre-clinical studies and may provide a new target for therapy in the treatment of AKI.

Document Type

Dissertation

Degree Name

Doctor of Philosophy (PhD)

Program

Pharmaceutical Sciences

Research Advisor

Frank Park, Ph.D. 


\section{Keywords}

Acute Kidney Injury, Cannabinoids, CB2, IRI, Kidney, Renal Hemodynamics

\section{Subject Categories}

Chemicals and Drugs | Medicine and Health Sciences | Pharmaceutics and Drug Design | Pharmacy and Pharmaceutical Sciences 


\section{Characterization of Novel CB2 Agonist SMM-295 and Its Effects in Ischemia/Reperfusion Injury}

Author:

Jeffrey D. Pressly
Advisor:

Frank Park, PhD

A Dissertation Presented for The Graduate Studies Council of

The University of Tennessee Health Science Center

in Partial Fulfillment of the Requirements for the

Doctor of Philosophy degree from

The University of Tennessee

in

Pharmaceutical Sciences: Pharmaceutics

College of Graduate Health Sciences

May 2020 
Chapters 2 and 3 C 2018 American Society for Pharmacology and Experimental Therapeutics.

Chapter 4 (C) 2019 Elsevier Inc.

All other material (C) 2020 by Jeffrey D. Pressly.

All rights reserved. 


\section{DEDICATION}

I dedicate this body of work to my friends and family who have always provided me with love and support. 


\section{ACKNOWLEDGEMENTS}

I would like to acknowledge my advisor and committee members for their compassion, understanding, expertise and support throughout my studies. My advisor Dr. Frank Park remained patient with me and allowed my expertise in science to expand, igniting my passion to study renal disease. Dr. Adebowale Adebiyi, Dr. Charles R. Yates, and Dr. Bob M. Moore opened the door to novel studies by collaborating with me enabling me to broaden my perspective field of study. Dr. Santosh Kumar provided me with valuable advice and mentored me in the art of teaching and leadership. Dr. Kafait Malik allowed me into his lab for lab meeting to discuss broader ranging topics including cardiorenal disease enabling me to become a better and more diverse scientist. My committee is an example of the exemplary work we can achieve when we collaborate and form a diverse group of successful scientists. It is only with their continued work and expertise that I was able to matriculate to this level in my career and will forever remember their impact on my life. 


\begin{abstract}
Acute kidney injury (AKI) is a major problem clinically affecting up to two-thirds of intensive care unit patients, and results in increased hospitalization time, the risk of developing chronic kidney disease, and mortality. Hallmarks of AKI include tubular cell death and a decrease in renal perfusion which leads to decreases in renal function following injury. For 20 years the pathophysiology of AKI has been well established. However, therapies for AKI have shown minimal to no success clinically. The work here describes our efforts to further categorize the effects of CB2 activation, a possible novel therapeutic target in AKI.
\end{abstract}

There is increasing importance associated with the understanding of the biological activity of the cannabinoid receptors following the increased acceptance in the medicinal purposes of cannabis and cannabis-related compounds. The endocannabinoid system is comprised of its cognate G-protein coupled receptors, cannabinoid type 1 and 2 receptors, endogenous lipid signaling molecules, $\mathrm{N}$-arachidonoyl ethanolamine (AEA) and 2acylglycerol, and the enzymes involved in their biosynthesis and catabolism. In the kidney, the CB1 receptors consistently demonstrate deleterious effects on glomerular and tubular function in various acute and chronic forms of injury, while CB2 receptors have demonstrated the opposite effects. This work will demonstrate the findings of studies that focus on the role of CB2 in the recovery from ischemia/reperfusion injury (IRI) and the effects of CB2 activation on both tubular cell death and renal hemodynamics.

To study the effect of CB2 activation on renal damage following IRI, our scientific group tested a small molecule agonist, SMM-295 [3'-methyl-4-(2-(thiophen-2yl) propan-2-yl) biphenyl-2,6-diol], in an investigation of the CB2 receptor as a potential therapeutic target in the prevention of tubular epithelial cell damage after AKI. To test this compound in AKI, we used a mouse model of renal bilateral ischemia-reperfusion injury (IRI), which is a common experimental model to study AKI, demonstrating considerable beneficial effects of SMM-295 following injury. Subsequently, we then investigated the possible mechanisms that undermine the effects of SMM-295, including initiation of antiapoptotic signaling cascades in tubular epithelium as well as increases in renal perfusion through a vascular effect demonstrating a multifunctional role for SMM295 in the treatment of IRI.

Our findings demonstrate that CB2 activation by SMM-295 ameliorated the effects of IRI through decreased tubular cell death in proximal tubule cells along with an increase in renal perfusion through a direct vascular effect. These data indicate selective activation of the CB2 receptor by our novel CB2 agonist SMM-295 has therapeutic value in pre-clinical studies and may provide a new target for therapy in the treatment of AKI. 


\section{TABLE OF CONTENTS}

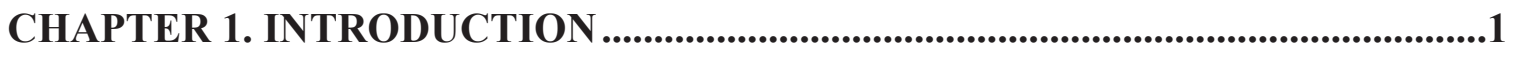

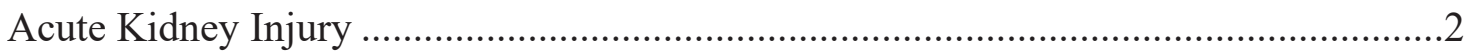

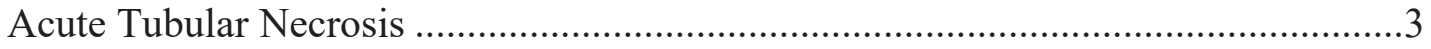

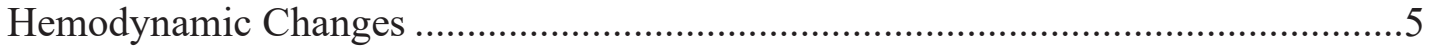

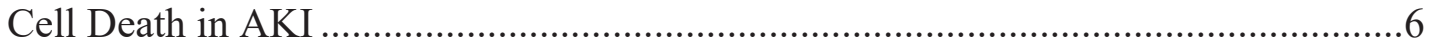

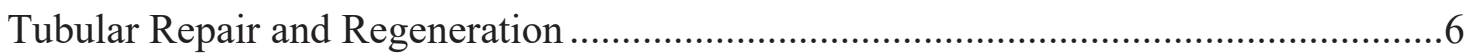

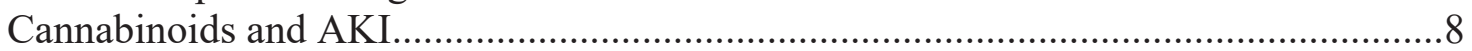

Cellular Mechanisms of CB2 Receptor Activation .................................................. 10

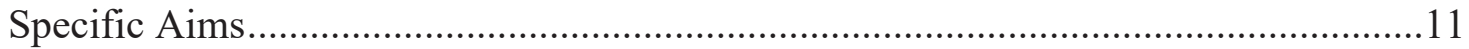

Aim 1: Determine the Effects of Novel Cannabinergic Drugs in a Mouse Model of IRI ...................................................................................................... 12

Aim 2: Categorize and Determine the Therapeutic Potential of SMM-295 in Treatment of IRI ..................................................................................... 12

Aim 3: Determine the Renal Hemodynamic Effects of CB2 Receptor Agonist

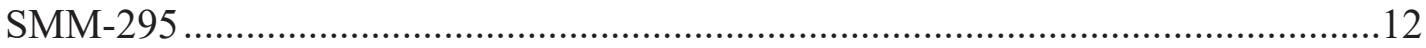

\section{CHAPTER 2. EFFECTS OF NOVEL CANNABINERGIC DRUGS IN A} MOUSE MODEL OF IRI ................................................................................................13

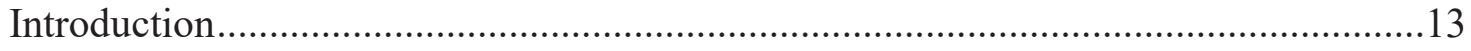

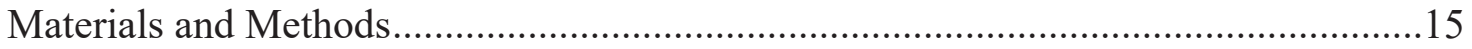

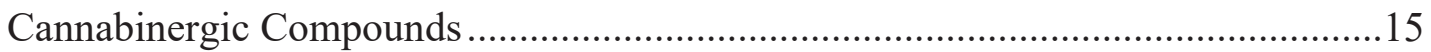

Renal Bilateral Ischemia-Reperfusion Injury .................................................. 15

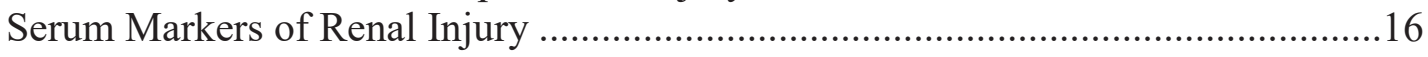

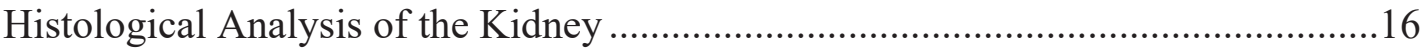

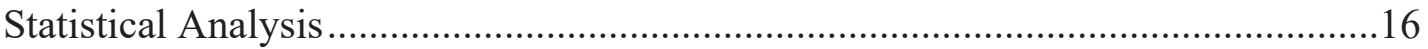

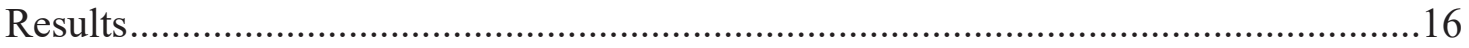

CB2 Receptor Activation Reduced Renal Injury Following Renal Bilateral

Ischemia-Reperfusion Injury ................................................................... 16

Effects of Novel CB2 Agonist, SMM-295, Compared to the "Gold Standard" Commercially Available CB2 Agonist, JWH-133 ...............................................19

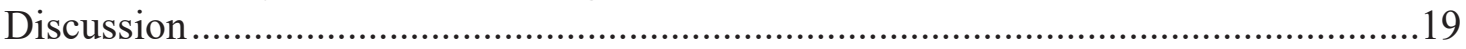

\section{CHAPTER 3. CHARACTERIZATION OF CB2 AGONIST SMM-295 AND ITS} EFFECTS IN IRI...........................................................................................................23

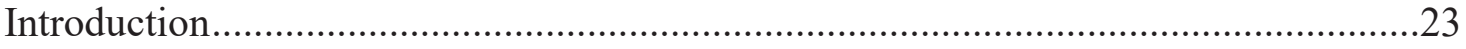

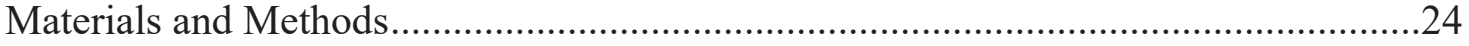

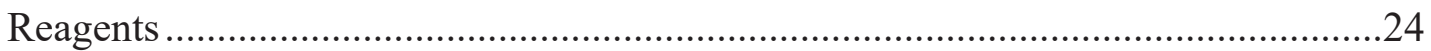

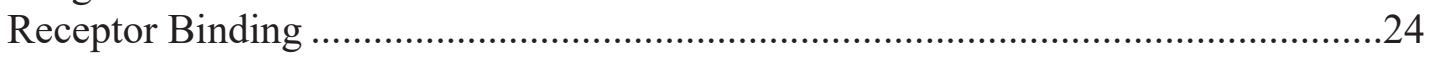

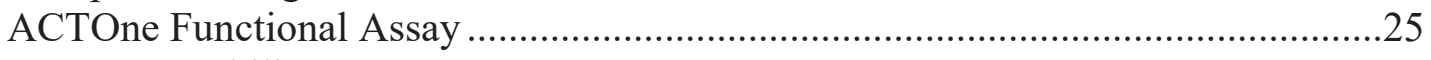

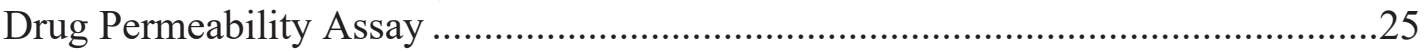

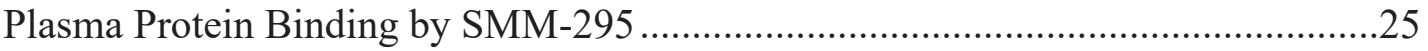

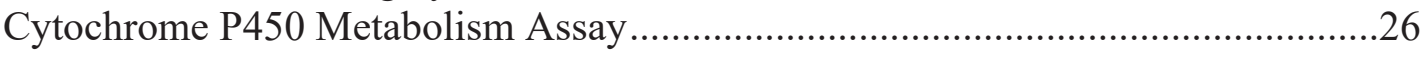


Human Ether-a-Go-Go-Related Gene Assay …………….......................................26

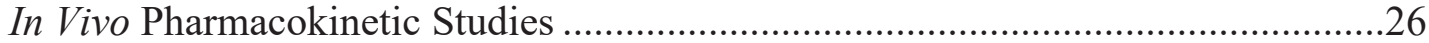

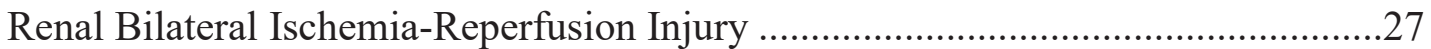

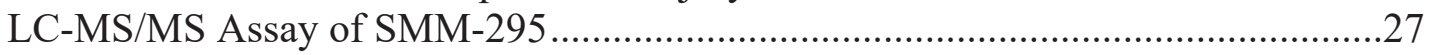

Reverse Transcription Polymerase Chain Reaction Analysis for CB2 Receptor

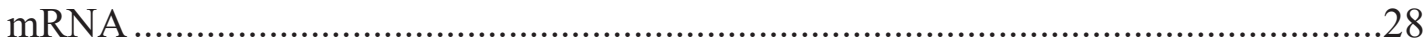

Hypoxia/Reoxygenation Injury in NRK-52E Cells .............................................28

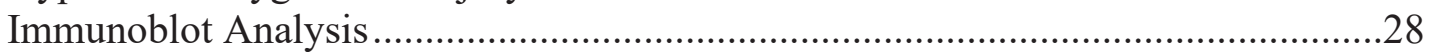

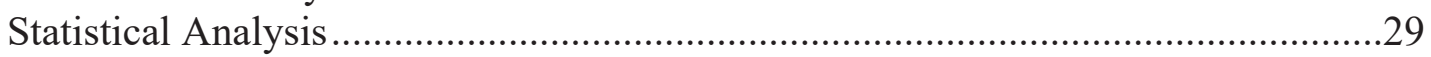

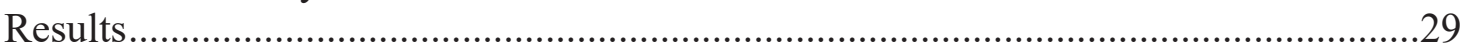

Physicochemical and Pharmacokinetic Properties of SMM-295 ...............................29

Receptor Binding and Functional Assays ..................................................................33

CB2 Receptor Upregulation in the Kidney Following Ischemia-Reperfusion

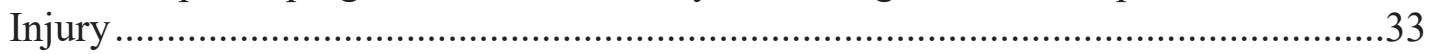

Upregulation of Anti-Apoptotic Pathways Following CB2 Receptor Activation in Kidney Lysates Obtained from Mice Following Renal Bilateral Ischemia-

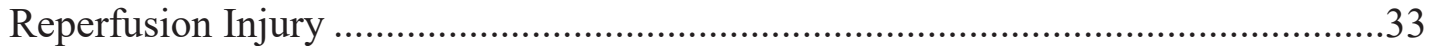

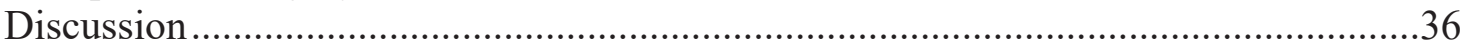

CHAPTER 4. RENAL HEMODYNAMIC EFFECTS OF CB2 ACTIVATION ......41

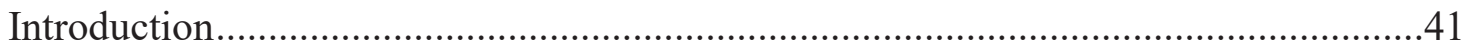

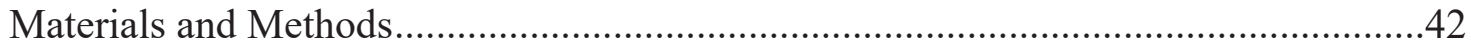

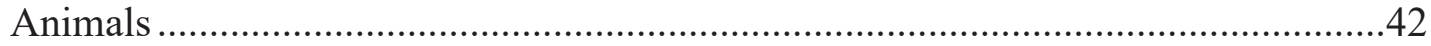

Chemicals and Assay Kits ..............................................................................42

Isolated Perfused Afferent Arteriole Measurement of Luminal Diameter .................42

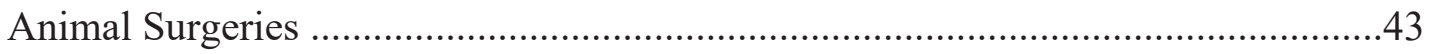

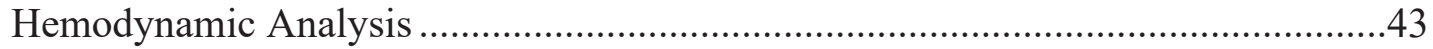

Calcitonin Gene-Related Peptide (CGRP) ELISA......................................................43

Bilateral Ischemia-Reperfusion Injury (IRI) …………........................................4

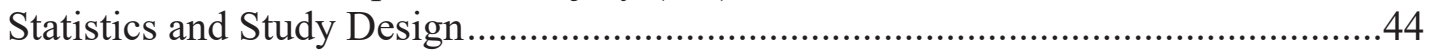

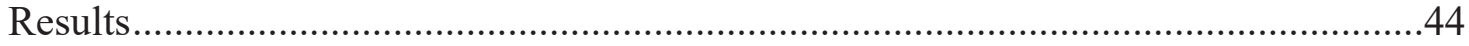

SMM-295 Effect on Cortical Renal Perfusion.......................................................4

CGRP Levels Following SMM-295 Infusion ........................................................46

Role of Cyclooxygenase and Nitric Oxide Synthase in CB2 Receptor Renal

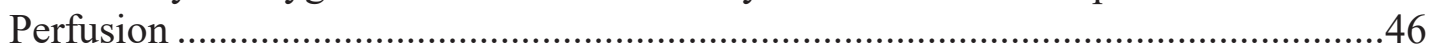

SMM-295 Increases Luminal Diameter of Afferent Arterioles..................................49

SMM-295 Effect on Cortical Renal Perfusion Following IRI...................................49

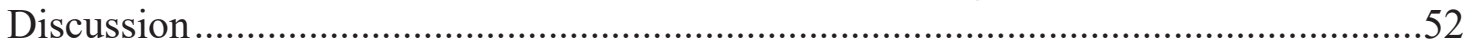

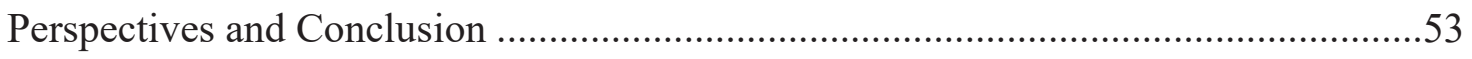

CHAPTER 5. DISCUSSION ...............................................................................................55

LIST OF REFERENCES .......................................................................................59

VITA 


\section{LIST OF TABLES}

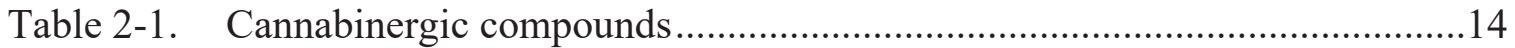

Table 3-1. Physiochemical and biochemical assays for SMM-295 .............................31

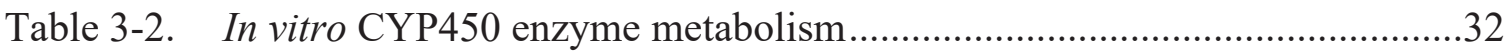




\section{LIST OF FIGURES}

Figure 2-1. Serum analysis from mice following bilateral ischemia-reperfusion injury in the presence or absence of CB2 activation

Figure 2-2. Tissue analysis from mice following bilateral ischemia-reperfusion injury in the presence or absence of CB2 activation

Figure 2-3. Comparison of novel CB2 agonist, SMM-295, compared to the "gold standard" CB2 agonist, JWH-133 ......................................................20

Figure 3-1. Chemical structure and in vivo pharmacokinetics of SMM-295 .................30

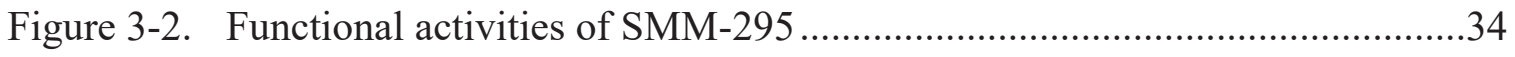

Figure 3-3. Increased steady-state levels of CB2 receptor mRNA in kidneys after

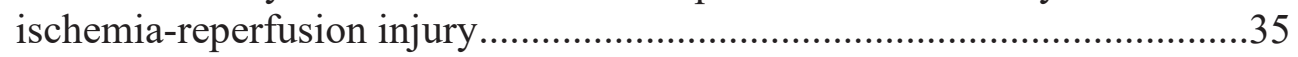

Figure 3-4. SMM-295 improved renal cell survival by reducing apoptotic signaling ....37

Figure 3-5. Analysis of cleaved caspase-3 levels in NRK-52E cells following hypoxic conditions in the presence of CB2 receptor activation...................38

Figure 4-1. CB2 receptor agonist, SMM-295, promotes increased renal cortical perfusion

Figure 4-2. Increased cortical renal perfusion is not through the CB1 receptor.

Figure 4-3. Renal afferent nerve activation is involved in CGRP release and increased cortical renal perfusion.

Figure 4-4. Endothelial derived factors COX and NOS are not involved with the increase in cortical renal perfusion following SMM-295 administration ....48

Figure 4-5. SMM-295 increases luminal diameter of pre-constricted isolated perfused afferent arterioles

Figure 4-6. Daily administration of SMM-295 prevented the reduction in renal cortical perfusion following bilateral renal IRI. 


\section{LIST OF ABBREVIATIONS}

$\begin{array}{ll}\text { ACE } & \text { Angiotensin converting enzyme } \\ \text { AEA } & \text { Anandamide } \\ \text { AGS3 } & \text { Accessory to G-protein signaling } 3 \\ \text { AKI } & \text { Acute Kidney Injury } \\ \text { Akt } & \text { Protein Kinase B } \\ \text { ANOVA } & \text { Analysis of variance } \\ \text { APJ } & \text { Apelin receptor } \\ \text { ATN } & \text { Acute tubular necrosis } \\ \text { ATP } & \text { Adenosine tri-phosphate } \\ \text { BCL-2 } & \text { B-cell lymphoma 2 protein } \\ \text { BCL-XL } & \text { B-cell lymphoma extra-large protein } \\ \text { BCP } & \text { B-caryophyllene } \\ \text { Bax } & \text { Bcl-2-associated X protein } \\ \text { cAMP } & \text { Cyclic adenosine monophosphate } \\ \text { CB1 } & \text { Cannabinoid receptor type 1 } \\ \text { CB2 } & \text { Cannabinoid receptor type 2 } \\ \text { Cbe } & \text { Endothelial cannabinoid receptor } \\ \text { CC3 } & \text { Cleaved caspase-3 } \\ \text { CGRP } & \text { Calcitonin gene related peptide } \\ \text { CKD } & \text { Chronic kidney disease } \\ \text { COX-2 } & \text { cyclooxygenase-2 } \\ \text { DMSO } & \text { Dimethylsulfoxide } \\ \text { DPBS } & \text { Dulbecco's phosphate-buffered saline } \\ \text { EDTA } & \text { Ethylenediaminetetraacetic acid } \\ \text { ELISA } & \text { Enzyme linked immunosorbent assay } \\ \text { ERK } & \text { Extracellular signal-regulated kinases } \\ \text { FBS } & \text { Fetal bovine serum } \\ \text { GDP } & \text { Guanosine-5'-diphosphate } \\ \text { GFR } & \text { Glomerular filtration rate } \\ \text { GIRK } & \text { G-protein coupled inwardly rectifying potassium channel } \\ \text { GPCR } & \text { G-Protein coupled receptor } \\ \text { GPR18 } & \text { G-Protein coupled receptor 18 } \\ \text { GPR55 } & \text { G-Protein coupled receptor 55 } \\ \text { GTP } & \text { Guanosine-5'-triphosphate } \\ \text { GTP } 5 & \text { Guanosine-5'-O-[gamma-thio]triphosphate } \\ \text { hERG } & \text { Human ether a-go-go related gene } \\ \text { HO-1 } & \text { Heme oxygenase-1 } \\ \text { HO-2 } & \text { Heme oxygenase-2 } \\ \text { HSP-27 } & \text { Heat shock protein 27 } \\ \text { HSP-70 } & \text { Heat shock protein 70 } \\ \text { HSP-72 } & \text { Heat shock protein 72 } \\ \text { HSP-90 } & \text { Heat shock protein 90 } \\ \text { IACUC } & \text { Institutional animal care and use committee } \\ & \end{array}$




$\begin{array}{ll}\text { IRI } & \text { Ischemia/reperfusion injury } \\ \text { LC-MS/MS } & \text { Liquid chromatography- mass spectrometry } \\ \text { L-NNA } & \text { Nomega-Nitro-L-arginine } \\ \text { LPS } & \text { Lipopolysaccharide } \\ \text { MAPK } & \text { Mitogen-activated protein kinase } \\ \text { NE } & \text { Norepinephrine } \\ \text { NGAL } & \text { Neutrophil gelatinase-associated lipocalin } \\ \text { NO } & \text { Nitric oxide } \\ \text { NOS } & \text { Nitric oxide synthase } \\ \text { P-gp } & \text { P-glycoprotein } \\ \text { PCNA } & \text { Proliferating cell nuclear antigen } \\ \text { PGD2 } & \text { Prostaglandin D2 } \\ \text { PGE2 } & \text { Prostaglandin E2 } \\ \text { PGF2 } & \text { Prostaglandin F2 } \\ \text { PGI2 } & \text { Prostaglandin I2 } \\ \text { PKA } & \text { Protein kinase A } \\ \text { PVDF } & \text { Polyvinylidene fluoride } \\ \text { RED } & \text { Rapid equilibrium dialysis } \\ \text { SAPK } & \text { Stress-activated protein kinase 3 } \\ \text { SEM } & \text { Standard error of the mean } \\ \text { TAL } & \text { Thick ascending limb } \\ \text { TxA2 } & \text { Thromboxane A2 } \\ \text { TRIP13 } & \text { Thyroid receptor interacting protein 13 } \\ \text { TRPV1 } & \text { Transient receptor potential vanilloid receptor 1 }\end{array}$




\section{CHAPTER 1. INTRODUCTION}

The kidney functions as the filter of the body and is comprised of two principal regions: the renal cortex and the medulla (1). The cortex consists of the renal corpuscles, the proximal convoluted tubules, and distal convoluted tubules. The nephron starts in the cortex and are categorized into two groups, cortical and juxtamedullary nephrons, based on the distance they extend into the medulla. Cortical nephrons have short loops of Henle that do not infiltrate beyond the cortex while juxtamedullary nephrons have longer loops that extend deep into the tip of the medulla. The medulla contains columns of connective tissue that extend downward from the cortex through this region separating the renal pyramids and renal papillae. The renal papillae consist of collecting ducts grouped in bundles that transfer urine made by the nephron for excretion. The cortex has increased oxygen levels compared to the medulla, making these two regions both structurally and metabolically different. This phenomenon has further implications in AKI resulting in protection from the long-lasting damage from AKI. Meanwhile, the medulla remains sensitive to injury following a biological insult. A third region of the kidney is called the renal hilum which functions as the entry and exit site for the kidneys such as blood, lymphatic vessels, nerves, and ureters. The kidney functions as the filter of the body eliminating waste and working to maintain homeostasis of the body by interacting with multiple organ systems. These functions are primarily achieved through four mechanisms: 1) filtration, 2) reabsorption, 3) secretion and 4) hormone release.

Filtration begins at the glomerulus which is the transition point between the systemic blood flow and the primary functional unit of the kidney, the nephron. The delivery of blood to the kidney influences the rate of filtration with each of these branches being fundamental in the overall renal function. The nephron is perfused with blood entering the glomerulus from the afferent renal arterioles. Efferent arterioles allow for the blood to exit the glomerulus and combine with the afferent arterioles, which regulates the overall perfusion of filtrate into the nephron which is also called glomerular filtration rate or GFR. Through vascular constriction or vasodilation, the afferent and efferent arterioles can control the pressure within the glomerulus and thus regulate the overall GFR. GFR increases when the afferent arterioles are vasodilated, and the efferent arterioles are vaso-constricted. This control mechanism is vital for the normal function of the kidney as maintaining GFR is a necessary first step in all other renal functions. The filtrate perfuses across the glomerulus capillaries lined with specialized cells called podocytes which function to filter the blood through specialized filtration slits created by dedicated processes on these cells called pedicels. The resulting glomerular filtrate is determined by the structure of these cells and electrical charge of the collagen protein molecules that line the filtration barrier making glomerular filtration both size and charge selective. The filtrate is then carried through the proximal tubules to the loop of Henle and ultimately to the distal tubules and collecting ducts. During this transit, multiple substrates are exchanged between the nephron and surrounding microvasculature which function to control absorption and secretion of water, waste, and other nutrients. 
The proximal tubule acts as the primary site of absorption and secretion in the nephron. This includes the intake of salt, water, organic solutes (i.e., glucose and amino acids), potassium, urea, phosphate, and citrate. Secretion of most types of medications and ammonium formed through the breakdown of glutamine to alpha-ketoglutarate and ultimately bicarbonate anions occur in the proximal tubule. These processes are driven primarily by active transport and co-transport mechanisms that require ATP. Therefore, the proximal tubules have high metabolic needs. The loop of Henle is unique in its structure and functions to create a concentration gradient in the medulla of the kidney. This gradient is produced by electrolyte pumps and serves to control the concentration of urine through the regulation of water reabsorption. The nephron concludes with the collecting ducts which, as their name implies, collect and combine to carry the filtrate to the ureters where it continues to the bladder for excretion.

\section{Acute Kidney Injury}

A critical function of the kidney is its ability to filter and excrete nitrogenous waste products from the blood. In AKI there is a rapid decline in GFR resulting in increases in nitrogenous waste products, primarily blood urea nitrogen and creatinine (25). Currently, these values are used in the clinic to categorize AKI in patients; however, improved methods are needed due to the impreciseness of these surrogate markers for GFR. The causes of this decline in GFR are grouped into three primary categories: prerenal, renal, and postrenal, which will be discussed briefly here.

The kidneys receive $20-25 \%$ of total cardiac output which acts to maintain adequate renal perfusion and GFR (6). Prerenal conditions contributing to AKI are categorized by decreased renal perfusion without damage to the renal parenchyma, known as prerenal azotemia. Prerenal azotemia is commonly caused by hypovolemia resulting from several clinical conditions seen in hospital patients including diarrhea, excessive sweating, sepsis, burns, and impaired cardiac output (6). In response to prerenal conditions the kidney must act to concentrate the urine and reabsorb sodium to restore normal renal perfusion. Current therapies aimed at restoring renal perfusion have shown to promptly improve renal function, which further demonstrates the importance of renal hemodynamics in the recovery of AKI (7).

The kidney is particularly sensitive to a wide variety of insults, thus making renal causes of AKI challenging to describe. Therefore, it is often helpful to consider the damage to four distinct structures within the kidney separately when characterizing intrinsic renal failure: 1) tubules, 2) glomeruli, 3) the interstitium, and 4) the entry renal blood vessels. AKI resulting from tubular damage is also known as acute tubular necrosis (ATN) and is attributed to two significant clinical causes: 1) ischemic injury resulting from a loss of renal perfusion, and 2) nephrotoxic injury resulting from toxic genus compounds usually from pollutants or medicines. Glomerulonephritis occurs as part of other systemic diseases including lupus or Wagner's granulomatosis characterized by glomerular damage $(8,9)$. In severe cases of acute glomerulonephritis, AKI from 
glomerular injury can occur. Infections or allergic reactions to a variety of medications can cause acute interstitial nephritis, categorized by interstitial damage in the kidney, which in severe cases can develop into $\operatorname{AKI}(8,9)$. Furthermore, an intra-renal vascular injury leading to decreases in renal perfusion that diminish GFR can also cause AKI. Common causes of this type of vascular injury include preeclampsia, hypertension, and atherosclerosis $(8,9)$.

Postrenal causes of AKI are categorized by an obstruction of the output of the kidney usually in terms of urinary flow. The effect of any urinary tract obstruction increases the tubular pressure and thus decreases GFR independent of any compensatory mechanisms. Furthermore, inflammation due to this obstruction can further contribute to diminishing GFR (10-14). Causes of post-renal AKI include prostatic hyperplasia, prostate cancer in men, cervical cancer in women, and ureteral stones (15).

The critical component common to all three types of renal injury is the decrease in GFR caused by a reduction in renal perfusion and a loss of renal function. The mechanisms that underlie the recovery of nephron structures and the hemodynamic response of the kidney following AKI are paramount in the discovery of novel therapeutics aimed to aid in the recovery of AKI. The next few sections of this introduction to AKI will focus on the pathophysiology of acute to necrosis in the hemodynamic changes that occur during AKI, the cellular responses to injury, and the mechanisms of renal recovery following AKI.

\section{Acute Tubular Necrosis}

Clinically, ATN and the associated decrease in GFR is generally divided into four phases: initiation, extension, maintenance, and recovery phases (2). While ATN correctly identifies the site of injury this terminology is somewhat misleading because few renal epithelial cells undergo necrosis with most tubular epithelial cells facing some degrees of sublethal cellular damage. Although there is no simple explanation between tubular injury and the fall in GFR, there are three proposed mechanisms through which this effect could be mediated, which include vasoconstriction of afferent arterioles in response to tubuloglomerular feedback, back leak of glomerular filtrate, and tubular obstruction (6).

Initiation of ATN occurs when reductions in renal blood flow result in severe cellular ATP depletion which leads to acute cell injury and dysfunction. Inner sections of the kidney, namely the cells of the S3 segment of the outer medulla and TAL, have high rates of solute transport and abundant mitochondria. These segments also exist in a low oxygen environment under normal physiological conditions which further predisposes these areas to damage from any further localized decreases in oxygen. The proximal tubule cells located in these areas have unusually high metabolic needs and thus are injured in more significant numbers than other tubular cell types in the kidney during renal insult. Renal tubular cell damage is a critical feature characterized by a disruption of the standard framework within the cell $(8,16,17)$. The severity and duration of 
ischemic injury dictate the extent of these alterations, which usually are sublethal, lead to malfunctioning renal tubular appeal cells and renal vascular endothelial cells.

The activation phase consists of epithelial and endothelial cells initiating an upregulation of a variety of cytokines that activate an inflammatory cascade (18). The extent to which the immune system plays a role in AKI has not been fully described but there is indication of its role in the disease. Therapies aimed at decreasing oxidative stress and immune system response have shown some preclinical success. For our project, we focused on localized epithelial and endothelial cell changes within the kidney irrespective of immune cell infiltration.

Following the activation phase, there is continued hypoxia after the initial ischemic event and an inflammatory response brought on by the release of cytokines (6). These two events are more pronounced in the cortical medullary junction of the kidney and constitute the majority of the extension phase. During this phase there is a severe reduction in blood flow, accumulation of red and white blood cells, and vascular endothelial cell damage that can contribute to the continued ischemia in the kidney. The sustained ischemia leads to continued cell injury and death (i.e., necrosis and apoptosis) in the outer medulla (19). However, in the cortex where blood flow rapidly returns to normal levels, the tubular epithelial cells in this region can undergo cellular repair during this phase (6). Regardless of the recovery occurring in the cortex, medullary cells continue to respond to prolonged ischemic conditions resulting in an increased cell death through programmed cell death pathways, primarily apoptosis. Loss of the cells in this area contribute to further decreases in GFR and continued production of chemokines and cytokines that further enhance the immune response (20). These events happen within the first 24 hours following injury, and the messengers for the systems responsible for these effects appear in as little as two hours after the initial ischemic event (21-23). Dead tubular cells then start to collect in the tubular lumen causing loss of renal function and a further localized reduction in renal perfusion.

The maintenance phase of AKI occurs before the recovery phase and is where cells undergo repair, migration, proliferation, and apoptosis to reestablish tubular integrity (6). During this phase, the GFR remains stable; however, it is lowered proportional to the extent of the injury. These events contribute to improving cellular function through reorganization and repair of the structures and provide normalized blood flow to establish intra- and intercellular homeostasis. Following the maintenance phase, the recovery phase consists of further cellular differentiation, reestablishment of epithelial polarity, and the return to normal cellular and organ function $(8,24,25)$. These phases of AKI focus on the extent to which renal epithelial cells are damaged and respond to ischemic injury. Alongside these events, there are concurrent hemodynamic changes that occur to the vasculature and microvasculature of the kidney. 


\section{Hemodynamic Changes}

AKI was initially characterized as a vasomotor neuropathy defined by a sustained increase in renal vascular resistance that attributed to factors including sympathetic nervous system input, prostaglandin synthesis, and alterations in vascular function secondary to injury, the altered production response to vasoconstrictors or vasodilators (26). The underlying impairment of hemodynamic regulation in renal disease directly contributes to the reduction in GFR seen in AKI (26-28). Alterations in vascular function secondary to injury may occur with direct damage to the renal vasculature. The microvasculature is compromised with ischemic injury leading to further imbalances of oxygen supply. AKI effects on renal vascular include increased permeability, interstitial edema, vasoconstriction, and vascular occlusion causing an overall decrease in blood flow to the organ. Furthermore, oxidative stress and vasoconstrictive prostaglandin production from injured tubules negatively impact oxygen delivery, which leads to a local "no-reflow" phenomenon that can exacerbate the initial injury. The vasoconstrictive effect seen in this phenomenon is caused by changes in sympathetic nervous activity and prostaglandin production which increase the complications of AKI.

Sympathetic nervous activity induces increases in renal vascular resistance during AKI to mitigate the effects of hypotension or reductions in circulating plasma. There are elevated levels of norepinephrine, and renal venous blood following ischemic injury and studies demonstrate direct infusion of norepinephrine into the renal artery can lead to AKI through reductions of renal blood flow (29). Furthermore, denervation of the kidneys attenuates the effects of AKI through an improvement in renal blood flow (3032). While there is strong evidence for a direct consequence of norepinephrine and renal vascular resistance, increased norepinephrine levels lead to renin secretion and ultimately production of angiotensin II. However, angiotensin II activity may play a role in AKI following clinical evidence of increased risk of AKI in patients receiving ACE inhibitors following cardiac surgery $(33,34)$. While renin levels are increased in patients with AKI, there is still limited information about the role of renin in the disease $(35,36)$. Therapies aimed to decrease norepinephrine levels, and thus sympathetic nervous activity may prove advantageous clinically in the future.

Lipid-derived signaling molecules called Prostaglandins are produced locally and the generation of these molecules has implications in AKI. Prostaglandins are a group of arachidonic acid-derived lipid signaling molecules that are synthesized by the activity of the cyclooxygenase enzyme. The primary prostaglandins produced in the kidneys, include PGI2, PGE2, PGF2, PGD2, and TxA2. These prostaglandins play a pivotal role in maintaining renal perfusion during episodes of ischemia. Cyclooxygenase inhibitors, particularly for the inducible form (COX-2), represent a major cause of increased risk factor in hospitalized patients for AKI $(37,38)$. 


\section{Cell Death in AKI}

Tubular epithelial cells act to survive the insult and contribute to the early stages of renal function and recovery. Cells that are able to recover from the initial insult must work to provide some level of renal function following injury. Cells that are not able to recover from the initial injury or are damaged further in the later phases of recovery following AKI die through multiple cell death pathways including apoptosis, necrosis, ferropoptosis, pyroptosis, and in some incidences autophagy (6). Apoptosis is the primary mechanism of cell death in early stages of recovery from AKI particularly in the proximal tubular cells. Therefore, this section will highlight mechanisms predominantly mediating apoptosis and their involvement in AKI.

Apoptosis is a form of cell death that plays a role in normal cell turnover within the body distinguishing it from necrotic cell death in that processes involved in apoptosis are very ordered and mediated by pre-existing enzyme cascades (39). Apoptotic cell death occurs rapidly in response to ischemia in the kidney with evidence of occurrence in rats as early as 15 minutes following ischemic conditions. It is hard to determine the exact extent through which apoptosis occurs following AKI due to the differences in conditions between various models of the disease. However, several studies have shown that by blocking apoptosis as a beneficial effect on kidney function following injury. In this section, the initiation of apoptotic signaling in the pathways through which this is achieved will be discussed.

In terms of apoptotic cell death cysteine-aspartic proteases, or caspases, which are constitutively expressed are activated in response to a variety of apoptotic factors. These caspases act as either initiators or effectors of cell death cascades. Initiator caspases function to sense the apoptotic signal, self-activate, and activate effector caspases. Then effector caspases activate pathways resulting in an orderly destruction of the injured cell. Initiator caspases are activated by either extrinsic or intrinsic factors with either of these signal outputs converging on common effector caspases (40-42). Activation of the extrinsic factors occurs in AKI often as a secondary effect to the initial injury and can be activated by pro-inflammatory cytokines. The intrinsic pathway of apoptosis is responsive to self-stress and activated by oxidative stress commonly seen in ischemic injury among other forms of AKI (6). Features of this pathway include the release of mitochondrial apoptogenic substances, including cytochrome $\mathrm{C}$ and the interaction of the BCL-2 family of proteins, which function to stabilize the mitochondrial membrane preventing this release. Several studies have shown beneficial effects of activation and expression of members of the BCL-2 family of proteins in various models of AKI demonstrating that by preventing apoptosis there is a practical benefit for the kidney initially following injury (43).

\section{Tubular Repair and Regeneration}

Sub-lethally damaged tubular epithelial cells initiate a series of pathways in response to AKI to repair from damage induced during injury and regenerate to restore 
proper organ function. Classically, three groups of genes have been associated with the response to renal injury in tubular epithelial cells. These groups comprise what is known as the renal stress response and include heme oxygenase, heat shock proteins, and stressactivated protein kinases (6). In this section, these classical groups of proteins will be discussed.

Heme oxygenase has two isoforms that have been characterized (HO-1 and HO2). HO-1 is the inducible form of the enzyme and mediates the first step of heme catabolism (44). HO-1 is induced in the early stages of ischemia-reperfusion injury and is generally associated with cryoprotection (45-47). Impairment of HO-1 activity has been shown to worsen renal function following ischemia-reperfusion injury in multiple studies (46, 48-51). Additionally, induction of HO-1 a physiologic priming or viral delivery of HO-1 expressing gene protects tubular cells from damage $(52,53)$. Moreover, the production of carbon monoxide which is a byproduct of HO-1 activity has vasodilators were effects potentially on the renal vasculature that could lead to a restoration of blood flow (52).

Heat shock proteins are associated with the recovery of the cytoskeletal structure following injury (54). In fact, overexpression of either HSP-72 or HSP-27 preserves the changes that occur to the cytoskeleton following ATP depletion seen in AKI $(55,56)$. Additionally, this family of proteins is associated with the inhibition of cell signaling pathways leading towards cell death (57). In models of mitochondrial injury, HSP-27 provides a protective role through its interaction with the Bax protein (58). Heat shock protein family members may also have antioxidant and vasodilatory properties. HSP-70, for example, prevents increases in superoxide production, and HSP-90 preserves NO synthesis following injury $(59,60)$. These processes may contribute to decreases in antioxidant stress either directly or through increased blood flow to the region. While much is known about heat shock proteins, there is a lack of information about their role in AKI other than their overexpression following injury.

Stress-activated protein kinases make up another group of proteins expressed in tubular epithelial cells following AKI (61-63). These proteins called mitogen-activated protein kinases (MAPKs), traditionally respond to cellular stress due to DNA damaging agents and reactive oxygen species. This family of kinases includes both the extracellular related protein kinases (ERKs) and stress-activated protein kinase (SAPK). While both of these classes of kinases show clear function in the recovery of the kidney following AKI in multiple studies $(61,64)$, one of these proteins, ERKs, also play a role in induction of apoptotic cell death (65). In theory this should further worsen the effects of AKI creating a conflict in our understanding of this pathways role in the recovery from renal injury.

Following these initial regulations of protein families associated with the recovery of the kidney following AKI, there is a peak of proliferative activity of proximal tubules (2). Studies in cultured proximal tubular cells demonstrate proliferative activity in response to epidermal growth factor, hepatocyte growth factor, insulin-like growth factor, and fibroblast growth factors which are produced both locally and systemically (66-69). However, clinical trials aimed to promote renal recovery following AKI utilizing these 
growth factors have not proven lucrative (70). The dedifferentiation and proliferation of proximal tubular cells are imperative to the restoration of the kidney following AKI. It is through a concert of protein chaperones, cell cycle signaling transcription factors, and growth factors that this effect is achieved (2).

Because of the inability to integrate the information known about the signaling pathways to produce a therapeutic to treat AKI, further studies are essential to provide more information about AKI to move the field towards developing therapeutic targets. Some examples in the past several years are intrinsic proteins, such as accessory proteins (e.g. AGS3 (71), TRIP13 (72) etc.) and GPCRs (e.g. APJ (73), Rho (74), etc.), or extrinsic cells from the immune system (75).

\section{Cannabinoids and AKI}

GPCRs and other heterotrimeric G-proteins are continuing to emerge as new therapeutic targets for kidney diseases, including AKI. Increasingly the role of the cannabinoid system is being uncovered as research into the peripheral effects of cannabinoids grows. Currently, the laws regarding the use of cannabis, which contains significant concentrations of exogenous cannabinoids, are changing in the United States leading to increased access to these substances nationwide. This recent change in public policy has increased the urgency to uncover the effects of cannabinoid signaling across multiple models of disease including AKI. There are limited studies into the cannabinoid systems effect in renal injury, however, these studies demonstrate a potential role for the endocannabinoids and the cannabinoid system in the recovery from renal disease (76-82).

The role of the endocannabinoid system in the kidney after activation of its cognate $\mathrm{G}$ protein-coupled receptors, cannabinoid receptors 1 and 2 (CB1 and CB2, respectively), is continuing to emerge as a central response system after injury stimuli to the kidney (83). Recent studies demonstrate an emerging role of the CB2 activation in the kidney in CKD and AKI (83). Studies have determined a beneficial role for CB2 activation following renal injury with selective activation of the $\mathrm{CB} 2$ receptor protecting renal architecture and nephron function by mitigating the nephropathic effects associated with diabetes or diet-induced obesity in rodent models of CKD $(79,82,84)$. Diabetic nephropathy was attenuated after treatment with the natural product CB2 receptor agonist $\beta$-caryophyllene or a small molecule analog functioning as a CB2 agonist (79). Similarly, $\mathrm{CB} 2$ receptor activation in rodents with diet-induced obesity ameliorated their progression toward renal dysfunction. Conversely, CB2 receptor antagonists reduced renal function, as measured by creatinine clearance, which suggests that renal failure was exacerbated.

While some data is suggesting CB2 activation is beneficial in renal function in other models of kidney disease, specifically AKI $(78,79,82,84)$, little evidence has demonstrated a clear mechanism through which CB2 activation leads to decrease in renal damage following IRI. Currently, there is limited data into the $\mathrm{CB} 1$ and $\mathrm{CB} 2$ receptor expression in the kidney $(83,85,86)$. Previous studies demonstrate $\mathrm{CB} 1$ and $\mathrm{CB} 2$ 
expression in the kidney during normal and pathological conditions (87-92). It is known that the CB1 receptors are expressed in high abundance with a reasonably broad localization pattern, which includes all segments of the nephron and vasculature. The expression profile of $c n r 2 \mathrm{mRNA}$ is somewhat more limited, as it appears to be localized to the proximal tubular epithelial cells in the renal cortex (83). More importantly, however, there is differential expression profiling of the Cnrl and Cnr2 mRNA in the kidney and in rodent models of AKI. Interestingly, $C n r 2$ mRNA increases while Cnr1 mRNA remains unchanged indicating a role of $\mathrm{CB} 2$ and not $\mathrm{CB} 1$ in the recovery of the kidney following AKI $(83,85,86)$. Our findings (shown in Chapter 2) are consistent with this fact and demonstrate increased levels of Cnr2 mRNA that encodes for the CB2 receptor in whole kidney lysates following IRI suggesting a role of the CB2 receptor in the recovery from IRI (93).

The precise nature of the role of the cannabinoid receptors in the kidney during AKI remains to be fully understood. Few studies over the last decade have investigated the effects of CB2 activation following AKI. These studies demonstrate CB2 activation following both ischemic and nephrotoxic models of AKI provide beneficial therapeutic effects $(76,79-82)$. There is abundant evidence that CB2 activation leads to improved renal outcomes following nephrotoxic insult with cisplatin (79-82). These studies suggest that decreases in oxidative stress and immune cell infiltration are driving the effects seen in CB2 agonist treated animals. In IRI the evidence demonstrates a protective effect on renal architecture following IRI (76). These studies failed to address the exact mechanisms through which tubular epithelial cells are intrinsically protected from cell death. Furthermore, these studies did not investigate at an important component of AKI, the loss of renal perfusion and changes in renal hemodynamics. Cannabinoids have been implemented in systemic vascular changes and are gaining considerable interest as modulators of vascular resistance throughout the body and potentially in the kidney.

Cannabinoid activation has hemodynamic effects throughout the body with CB1/2 activation leading to systemic or localized changes in blood flow making these receptors prime targets for therapeutic intervention of hypoperfusion based diseases like renal IRI. To date, there is a lack of studies investigating a role of the cannabinoid receptors on the regulation of renal hemodynamics, and the activity of these receptors even under normal conditions remains poorly understood. What is evident through the following studies mentioned is that the effects of CB1 and CB2 activation generally contradict each other having opposing effects in rodents. Early rat studies implicated that anandamide (AEA) increased renal blood flow with a concomitant reduction in glomerular filtration rate by preferential vasodilation of the efferent arteriole via CB1 receptor activation (94). Other studies from Deutsch et al. demonstrate that segments of the renal and arcuate arteries were capable of dilating in the presence of AEA (90). CB1 receptor using a synthetic agonist either demonstrated renal vasoconstriction or was associated with increased blood flow changes and urine excretion, however, through a non-CB1 dependent mechanisms (95). The data suggests CB1 activation leads to localized renal vasoconstriction while selective $\mathrm{CB} 2$ receptor activation generally demonstrates opposite effects in the kidney seen by the $\mathrm{CB} 1$ receptor. Therefore, $\mathrm{CB} 2$ activation following renal injury may act to protect renal function in the glomerulus and integrity of the renal tubules. It is important 
to note this opposing effect of $\mathrm{CB} 1$ and $\mathrm{CB} 2$ activation on renal vascular resistance following AKI. It is known that CB1 activation can lead to modulation of sodium ion channels that would perturb function of the tubular epithelial function and prove deleterious for the kidney following injury (96). Therefore, it is paramount that therapeutic strategies aimed at the cannabinoid access have specificity between the two receptors through their various signaling outputs in the cell following activation.

\section{Cellular Mechanisms of CB2 Receptor Activation}

Extensive research efforts have gone into elucidating the molecular activation mechanisms of the cannabinoid receptors. Cannabinoid receptors, like other GPCR's, when activated facilitate the exchange of GDP for GTP associated with the Ga subunit enabling it to disassociate from the G $\beta \gamma$ subunit with each of these subunits able enact downstream changes in the cell. While these signal transduction pathways are not activated in isolation and are generally a constellation of activity, the next paragraph will describe the effects of CB2 receptor activation in the context of two well established GPCR transduction pathways: heterotrimeric G-protein signaling and $\beta$-arrestin cascades.

The CB1 receptor shows some promiscuity between $\mathrm{G} \alpha$ subtypes, however, the CB2 receptor preferentially couples to Gai (97-99). Gai activity leads to decreases in cAMP levels leading to further downstream changes including activation of kinases including PKA and various downstream mechanisms. Many signaling outputs of CB2 are sensitive to pertussis toxin indicating a role of $\mathrm{G} \alpha \mathrm{i}$ in these cascades $(83,100)$. Upon activation of CB2 Gai coupling adenylyl cyclase is inhibited and mitogen-activated protein kinase and extracellular kinase-1 and -2 are activated (101-103). Also, G $\beta \gamma$ and can activate inward rectifying $\mathrm{K}^{+}$channels and inhibit voltage-dependent calcium channels (104). CB2 activity is increasingly complicated by the biased signaling demonstrated by different agonists to the $\mathrm{CB} 2$ receptor. Active states of the $\mathrm{CB} 2$ receptor stabilized by different ligands exposes serines and threonines that can be phosphorylated by $\mathrm{G}$ protein-coupled receptor kinases leading to $\beta$-arrestin recruitment (100). Arrestins are a family of proteins involved in GPCR desensitization and internalization and there are two two isoforms that interact with CB2, $\beta$-arrestin 1 and $\beta$-arrestin $2(101,104,105)$. The $\mathrm{CB} 2$ receptor can interact with both $\beta$-arrestin isoforms. However, these isoforms are differentially expressed and show different levels specificity in various cell types and for specific GPCRs (106). Recently it has been demonstrated that CB2 internalization occurs through interaction with $\beta$-arrestin 2 resulting in rapid recruitment to endocytic pits where CB2 and colocalizes with $\beta$-arrestin 1 at endosomes resulting in $\beta$-arrestin 1 recruitment and signaling (107). The current knowledge regarding arrestin mediated signaling suggests GPCRs activated by different ligands produce different receptor confirmations depending on the type of ligand and where it binds resulting in differential downstream effects (108). These different ligand-dependent GPCR confirmations can act through either G-protein signaling or $\beta$-arrestin dependent signaling, a phenomenon known as functional selectivity or biased signaling opening a new avenue to utilize various CB2 functionally specific agonists therapeutically following future investigations into the effects of these compounds in multiple models of renal disease. For example, Hu-308 and 
JWH-133, two commonly used CB2 agonists, display very different bias toward different effector pathways. While both HU-308 and JWH-133 activate CB2 with a high level of specificity in the mouse, HU-308 has the ability to activate GIRK channels while JWH133 does not (100). This seemingly minor difference between the two compounds can cause vastly different physiological outcomes.

In conclusion the kidney is an organ of great importance in the maintenance of homeostasis and can be damaged by a variety of insults leading to AKI. To date there is no therapeutic available to ensure improved recovery from AKI. Recent studies have demonstrated the potential of CB2 as an emerging therapy in AKI. The following studies will highlight the progress by our group in uncovering the effects of CB2 activation in AKI by a novel selective CB2 agonist SMM-295.

\section{Specific Aims}

In the United States acute kidney injury (AKI) is responsible for more than $\$ 10$ billion in economic costs annually. The prevalence of AKI is increasing with an overall incidence of $22 \%$ globally in adult patients and is associated with further renal complications, including chronic kidney disease (CKD) and end stage renal disease, as well as cardiovascular disease and stroke.

A critical barrier is the lack of established therapeutics available to treat patients following AKI. Cannabinoid signaling has been implicated in renal disease and may provide a therapeutic target for the treatment of AKI. Recent studies have shown a protective effect of $\mathrm{CB} 2$ activation in chronic and acute models of kidney disease. To address the need for increased selective CB2 agonists our group has developed a novel CB2 agonist, SMM-295.

My goal in this proposal is to further categorize the effects of CB2 activation by SMM-295 in IRI and provide evidence for effective therapeutic strategies for the treatment of the disease which are currently lacking. This goal will function to uncover potential mechanisms through which $\mathrm{CB} 2$ activation contributes to renal tissue protection in response to IRI and build upon the current knowledge surrounding cannabinoid signaling in AKI which has direct implications for other chronic end of life diseases.

Therefore, my hypothesis for this proposal is that novel CB2 agonist SMM-295 has a favorable PK/PD profile and ameliorate acute kidney injury through both antiapoptotic effects on proximal tubule cells and vasodilatory effects on renal vascular cells leading to increased renal function and recovery from AKI. The following aims have been designed to test this hypothesis: 


\section{Aim 1: Determine the Effects of Novel Cannabinergic Drugs in a Mouse Model of IRI}

Recent studies have suggested a beneficial role of cannabinergic drugs regarding both acute and chronic kidney disease. While these studies have looked at specific agonists to $\mathrm{CB} 1$ and $\mathrm{CB} 2$ our study is the first to compare different types of $\mathrm{CB} 1$ and CB2 agonists and inverse agonists side-by-side to determine their effectiveness in treating IRI. It is our hypothesis that $\mathrm{CB} 2$ receptor agonists will cause decreases in renal damage and increases in renal function and CB1 agonists and CB2 inverse agonists resulting in the opposite effects in the immediate aftermath of IRI in mice.

\section{Aim 2: Categorize and Determine the Therapeutic Potential of SMM-295 in Treatment of IRI}

The hypothesis of this aim is that SMM-295 activation of CB2 receptors has a beneficial effect on recovery from IRI, in part due to protection of proximal tubule cells from cell death. Therefore, the function of this aim is to determine whether SMM-295 has therapeutic protentional when administered following IRI. Our data suggests mRNA levels of cnr2 increase following IRI in kidney lysates indicating a role of CB2 in recovery from the disease. This aim will describe the effects of CB2 activation on renal clearance, morphology, and tubular cell apoptosis levels following IRI.

\section{Aim 3: Determine the Renal Hemodynamic Effects of CB2 Receptor Agonist SMM- 295}

This aim will determine the mechanisms responsible for decreased vascular reactivity and increased renal blood flow seen with the administration of CB2 agonists. The hypothesis for this aim is that CB2 receptor activation will lead to increased blood flow to the kidney and aid in the recovery from IRI. To achieve this goal, we will employ a mixture of in vitro, ex vivo, and in vivo techniques to further describe the signaling cascades responsible for the decrease in vascular reactivity following CB2 activation in our preliminary studies.

My expected outcomes and impact will be: 1) outline the effects of cannabinergic drugs in IRI, 2) determine a beneficial effect of CB2 activation following IRI and 3) uncover the mechanisms surrounding CB2 activation and renal hemodynamics. These studies will provide fundamental pre-clinical information that is necessary in the development of novel therapeutic approaches to AKI, a debilitating disease with lacking therapeutic strategies. 


\section{CHAPTER 2. EFFECTS OF NOVEL CANNABINERGIC DRUGS IN A MOUSE MODEL OF IRI ${ }^{1}$}

\section{Introduction}

Over the last decade, the commercial availability of synthetic cannabinoid targeting compounds has increased rapidly, with varying degrees of specificity and efficacy (109). While a plethora of these compounds exists, each has its own set of pharmacokinetic and pharmacodynamic properties that make them individually distinct with regards to their modality (109). Due to the overlap of structural similarities between CB1 and CB2 structure, many drugs aimed at one of these receptors may have some activity at both (110). Initial studies determining the effects of drugs acting on the cannabinoid system following AKI demonstrate interesting results. Feizi et al. (76) showed a dose-dependent reduction in tubular damage following IRI with the administration of both selective $\mathrm{CB} 1$ and $\mathrm{CB} 2$ receptor agonists, arachidonylcyclopropylamide and JWH-133 respectively. These data highlight the early confusion surrounding the role of $\mathrm{CB} 1$ and $\mathrm{CB} 2$ in the kidney to treat AKI.

More recently, there is a trend showing that there is a beneficial role of cannabinergic compounds by either blocking CB1 or activating CB2 in animal models of both acute and chronic kidney disease (76-82). For example, new selective CB2 agonists results in reduced markers of renal injury following ischemia-reperfusion injury (76). This data coincided with other studies that showed a beneficial effect in the recovery from cisplatin-induced renal injury of CB2 agonists, LEI-101 and HU-308(80, 82). Confirming these effects is another study where $\beta$-caryophyllene, a natural CB2 agonist, also was protected the tubular epithelial cells from cisplatin-induced renal injury (79). While the cisplatin-induced renal injury is dependent on dose and is more likely to get consistent results across labs, IRI conditions can vary between research groups which are influenced by factors including surgical environment, duration of ischemic injury, and recovery conditions (111). Thus, data determining the effects of cannabinoids in the recovery from IRI between relatively few isolated groups that are performing these experiments are increasingly challenging to compare. Therefore, there is a need to perform a comprehensive screen including agonists and inverse agonists at CB1 and CB2 to systematically determine the therapeutic contribution in the context of AKI.

To understand the role of CB1 and CB2 activity following IRI, we performed a blinded screen of 4 distinct CB1/CB2 agonists and inverse agonists (Table 2-1),

\footnotetext{
${ }^{1}$ Except for the Introduction and Conclusion, reprinted with permission of the American Society for Pharmacology and Experimental Therapeutics. All rights reserved. Pressly, J. D., Mustafa, S. M., Adibi, A. H., Alghamdi, S., Pandey, P., Roy, K. K., \& Park, F. (2018). Selective cannabinoid 2 receptor stimulation reduces tubular epithelial cell damage after renal ischemia-reperfusion injury. Journal of Pharmacology and Experimental Therapeutics, 364(2), 287-299. https://doi.org/10.1124/jpet.117.245522 Final submission copy used. (93).
} 
Table 2-1. Cannabinergic compounds

\begin{tabular}{ccc}
\hline Drug Name & Mode of Action & Reference \\
\hline SMM-295 & CB2 agonist & $(93)$ \\
SMM-189 & CB2 inverse agonist & $(112)$ \\
KM-233 & CB1 agonist and CB2 & Relayed by personal \\
& neutral antagonist & communication with Dr. \\
& CB1 inverse agonist & Bob Moore \\
SR-141716A & CB2 agonist & $(114)$ \\
JWH-133 & & $(113)$ \\
\hline
\end{tabular}


SMM-295 (93), SMM-189 (112), KM-133,JWH-133 (113) and S141716A (114) using a mouse model of bilateral IRI. Bilateral IRI was our preferred mouse model of AKI rather than unilateral IRI, because unilateral IRI has a contralateral kidney that remains undamaged and can functionally compensate for the other injured kidney. Therefore, changes in AKI indicators, creatinine and NGAL, can be partially masked by the undamaged contralateral kidney. with regards to recovery of the kidney from IRI. We believe that this set of experiments will provide us new information on the direction of future studies using $\mathrm{CB}$ compounds to promote therapeutic responses in the kidney following AKI.

\section{Materials and Methods}

\section{Cannabinergic Compounds}

Table 2-1 lists the cannabinergic compounds used in this study.

\section{Renal Bilateral Ischemia-Reperfusion Injury}

C57B1/6 mice (6-7 weeks of age) were obtained from Jackson Laboratories and allowed to acclimate for at least three days before performing bilateral renal IRI surgeries. All protocols are approved by the Institutional Animal Care and Use Committee (IACUC) at the University of Tennessee Health Science Center, Memphis. All mice were provided ad libitum access to mouse chow and water before and after the surgical procedures. Mice were anesthetized with pentobarbital $(50-80 \mathrm{mg} / \mathrm{kg} \mathrm{IP})$, and renal flank incisions were made on each side of the mice to isolate the kidneys for clamping of the renal hilus using microisolator clamps. After clamping the organs, they were placed back into the abdominal area, and body temperature was maintained between $35-37^{\circ} \mathrm{C}$ as monitored by a rectal temperature probe. At the end of 24.5 minutes, the clamps were removed and immediately administered vehicle, SMM-189 (6 mg/kg IP), SMM-295 (6 mg/kg IP), SR141716A (6 mg/kg IP), or KM-133 (6 mg/kg IP) (Table 2-1). The kidneys were subsequently monitored for the restoration of blood perfusion by the kidneys before the closure of the wounds. All mice were administered analgesics and antibiotics following the surgery, and if needed during the remainder of the experimental period. After 24 hours, another dose of vehicle, SMM-189 (6 mg/kg IP), SMM-295, (6 $\mathrm{mg} / \mathrm{kg}$ IP), SR141716A (6 mg/kg IP), or KM-133 (6 mg/kg IP) was administered to each of the mice. Body weights were also obtained during the experimental period. The mice were euthanized after either 24 or 48 hours, and the kidneys were harvested for fixation in neutral buffer formalin to perform histology. 


\section{Serum Markers of Renal Injury}

Blood samples were collected in citrate-coated tubes after 24 and 48 hours following renal ischemia-reperfusion injury, and plasma was isolated by differential centrifugation. Creatinine levels were measured by LC-MS/MS (Department of Biochemistry, the University of Alabama at Birmingham, AL). NGAL was measured by ELISA (cat \#89189, Abcam).

\section{Histological Analysis of the Kidney}

Formalin-fixed, paraffin-embedded kidneys were sectioned ( $4 \mu \mathrm{m}$ thick), deparaffinized using xylene, dehydrated using increasing concentrations of ethanol, and stained with H\&E. Tubular damage was determined as a percent of the total tubules by using images at 40X magnification using previously published criteria $(115,116)$.

\section{Statistical Analysis}

All values are shown as mean +/- SEM using GraphPad Prism 6.0 software. Either unpaired t-test or one-way ANOVA was performed using Bonferroni's post-hoc test to confirm significant differences $(\mathrm{P}<0.05)$ between animal groups.

\section{Results}

\section{CB2 Receptor Activation Reduced Renal Injury Following Renal Bilateral Ischemia-Reperfusion Injury}

Following renal bilateral IRI, either SMM-295 (6 mg/kg IP; n=5), KM-133 (6 mg/kg IP; n=4), SR141716A (6 mg/kg IP; n=4), SMM-189 (6 mg/kg IP; $n=4)$, or vehicle solution $(n=6)$ was administered immediately upon removal of the renal clips, and blood was harvested to measure plasma creatinine levels, a functional marker of renal injury, after 24 hours. Creatinine levels were significantly lower $(\mathrm{P}=0.001)$ in mice treated with SMM-295 $(0.3 \pm 0.1 \mathrm{mg} / \mathrm{dL})$ compared to the vehicle solution control mice $(1.3 \pm 0.2$ $\mathrm{mg} / \mathrm{dL}$ ) (Figure 2-1). Mice treated with CB2 inverse agonist, SMM-189 (2.0 \pm 0.5 $\mathrm{mg} / \mathrm{dL}), \mathrm{CB} 1$ agonist, KM-233 (1.3 $\pm 0.2 \mathrm{mg} / \mathrm{dL})$, and CB1 inverse agonist, SR141716A $(1.7 \pm 0.2 \mathrm{mg} / \mathrm{dL})$ did not show a significant change $(\mathrm{P}>0.05)$ in creatinine levels compared to vehicle-treated mice (Figure 2-1).

After 48 hours of reperfusion following the ischemic period, treatment with SMM-295 caused significant $(\mathrm{P}=0.0002)$ reduction in outer medullary tubular epithelial cell damage by $\sim 33 \%$ (35.7 $\pm 2.2 \%$ damaged tubules; $n=4$; Figure $\mathbf{2 - 2 B}, \mathbf{F})$ compared to vehicle-treatment $(62.0 \pm 2.2 \%$ damaged tubules; $n=4$; Figure 2-2A, F). Mice treated 


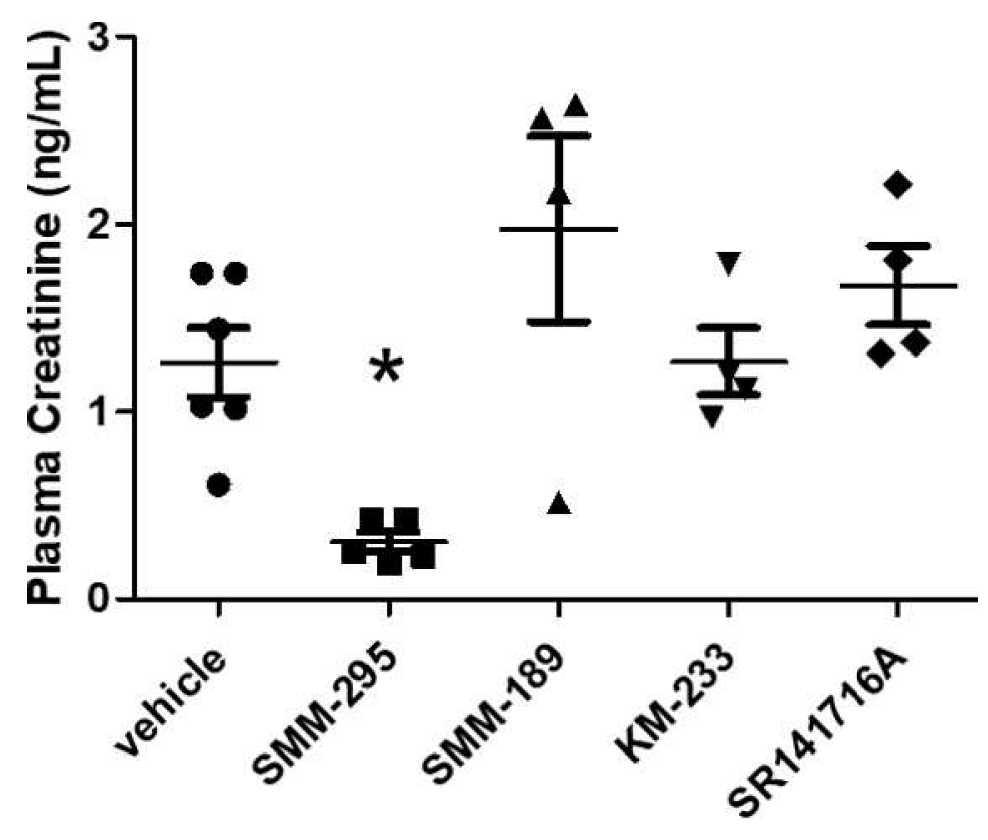

Figure 2-1. Serum analysis from mice following bilateral ischemia-reperfusion injury in the presence or absence of CB2 activation

Plasma measurements were obtained for $(\mathrm{A})$ creatinine in IRI-treated mice administered either SMM-295 (6 mg/kg IP; n=5), KM-133 (6 mg/kg IP; n=4), SR141716A (6 mg/kg IP; $n=4)$, SMM-189 (6 mg/kg IP; $n=4)$, or vehicle solution $(n=6)$ after 24 hours. * $\mathrm{P}<0.05$ significant difference between groups. 

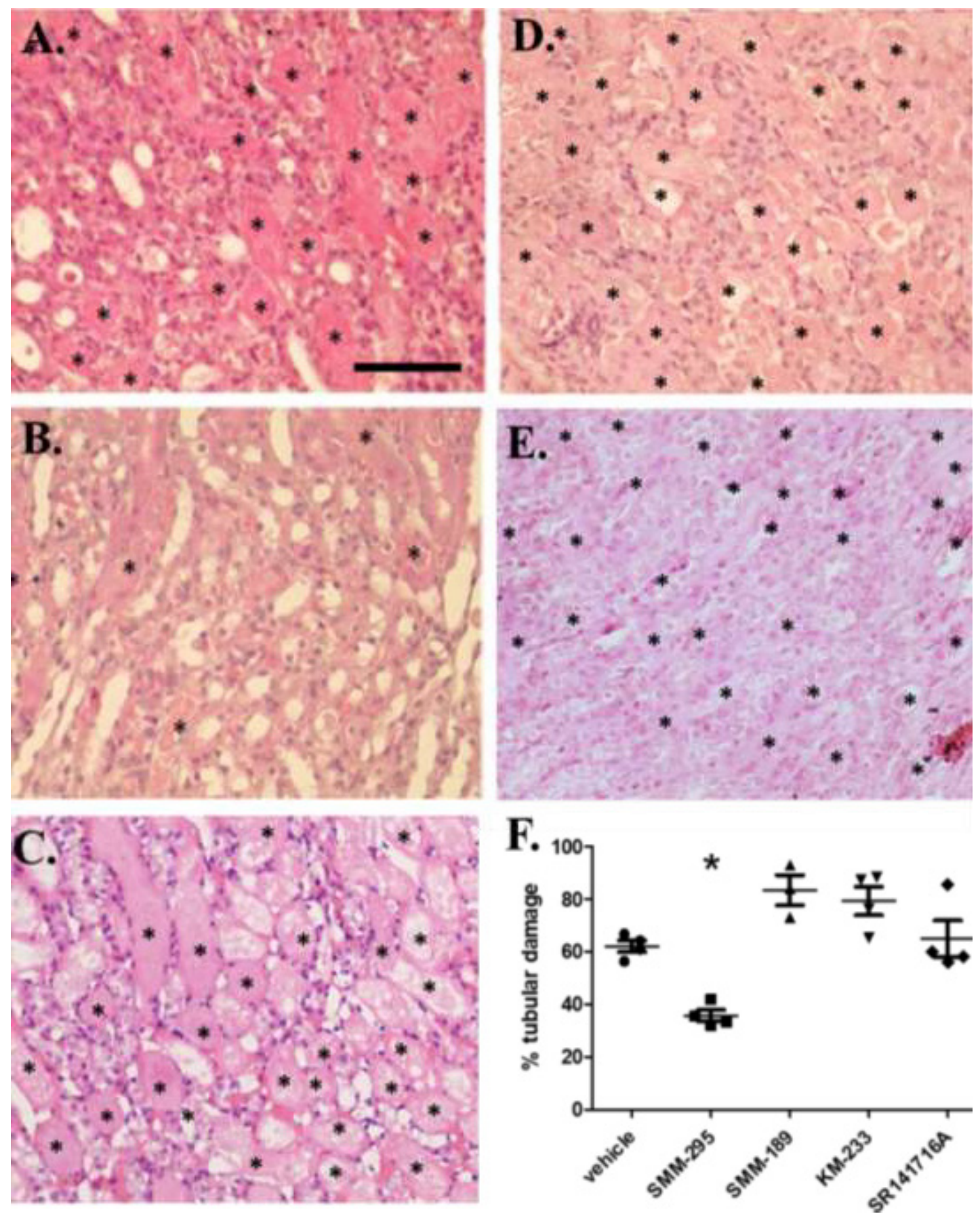

Figure 2-2. Tissue analysis from mice following bilateral ischemia-reperfusion injury in the presence or absence of $\mathrm{CB} 2$ activation

(A-E) displayed are representative images from IRI-treated mouse kidneys administered either with (A) vehicle solution ( $\mathrm{n}=6$ ), (B) SMM-295 (6 mg/kg IP; $\mathrm{n}=4)$, (C) SMM-189 (6 mg/kg IP; n=4), (D) KM-133 (6 mg/kg IP; n=4), or (E) SR141716A (6 mg/kg IP; n=4) after 48 hours. Scale bar $=100 \mu \mathrm{m}$. * indicate cast-containing tubules (F) Tubular damage is graphed as a percentage of the total number of tubules from the outer medullary. $* \mathrm{P}<0.05$ significant difference between groups. 
with CB2 inverse agonist, SMM-189 (83.4 \pm 5.7\% damaged tubules; $n=4$; Figure 2-2C), CB1 agonist, KM-233 (79.3 $\pm 5.4 \%$ damaged tubules; $n=4$; Figure 2-2D), and CB1 inverse agonist, SR141716A (65.0 $\pm 6.9 \%$ damaged tubules; $n=4$; Figure 2-2E) did not show a significant change $(\mathrm{P}>0.05)$ in tubular damage levels compared to vehicle-treated mice. Similarly, significantly lower NGAL levels $(\mathrm{P}=0.015)$ were measured in the blood from mice treated with SMM-295 $(4,489 \pm 680.5 \mathrm{ng} / \mathrm{mL})$ compared to vehicle $(11,252 \pm$ $1,867 \mathrm{ng} / \mathrm{mL}$ ) (Figure 2-3B).

\section{Effects of Novel CB2 Agonist, SMM-295, Compared to the "Gold Standard" Commercially Available CB2 Agonist, JWH-133}

Novel CB2 agonist, SMM-295, and commercially available CB2 agonist, JWH133, both provide protection from renal damage following IRI. Both SMM-295 and JWH-133 led to a statistically significant decrease in tubular damage, $26.39 \% \pm 12.81 \%$ $(\mathrm{P}=0.0002 ; \mathrm{n}=4)$ and $17.34 \% \pm 13.83 \%(\mathrm{P}=0.02 ; \mathrm{n}=3)$ respectively, compared to vehicletreated mice $(\mathrm{n}=4)$ (Figure 2-3C). However, SMM-295 $(\mathrm{n}=5)$ shows significantly decreased levels of creatinine $(\mathrm{P}=0.001)$ and NGAL $(\mathrm{P}=0.015)$ compared to vehicletreated mice, while JWH-133 $(\mathrm{n}=7)$ failed to significantly decrease $(\mathrm{P}>0.05)$ these levels compared to vehicle-treated mice $(n=6)$ (Figure 2-3A, B) suggesting a possible additional functional benefit of SMM-295 in the recovery from IRI.

\section{Discussion}

These results demonstrate that CB2 activation by SMM-295 can prevent renal injury following AKI while we also show that CB1 agonist, and inverse agonist, KM133, and CB1 inverse agonist, SR141716A respectively, failed to engender a statistically significant change in plasma creatine levels or tubular damage following IRI. These findings clarify the actions, particularly differences between CB1 and CB2 activation, of the cannabinoid system activation in IRI and provide additional measures of renal damage to confirm previously done studies in the literature. Recently, clinical cases are demonstrating that exogenous cannabinoids acting on CB1 receptor can also lead to a disruption in normal renal function resulting in AKI $(117,118)$. The mechanism by which renal function is impaired by cannabinoid signaling remains to be determined but may involve the differential activation of the $\mathrm{CB} 1$ and $\mathrm{CB} 2$ receptors $(83,85,86)$. While the contributions of $\mathrm{CB} 1$ versus $\mathrm{CB} 2$ activation in regard to AKI have not been fully established, data from the field of CKD may provide some insight as to the potential roles in $\mathrm{AKI}$. In CKD, CB1 receptor activation aggravates glomerular and tubular epithelial cell damage to exacerbate decrements in renal function (89), but in many cases, activation of the $\mathrm{CB} 2$ receptor can counteract the harmful effects mediated by the CB1 receptor $(84,119,120)$. 
A.
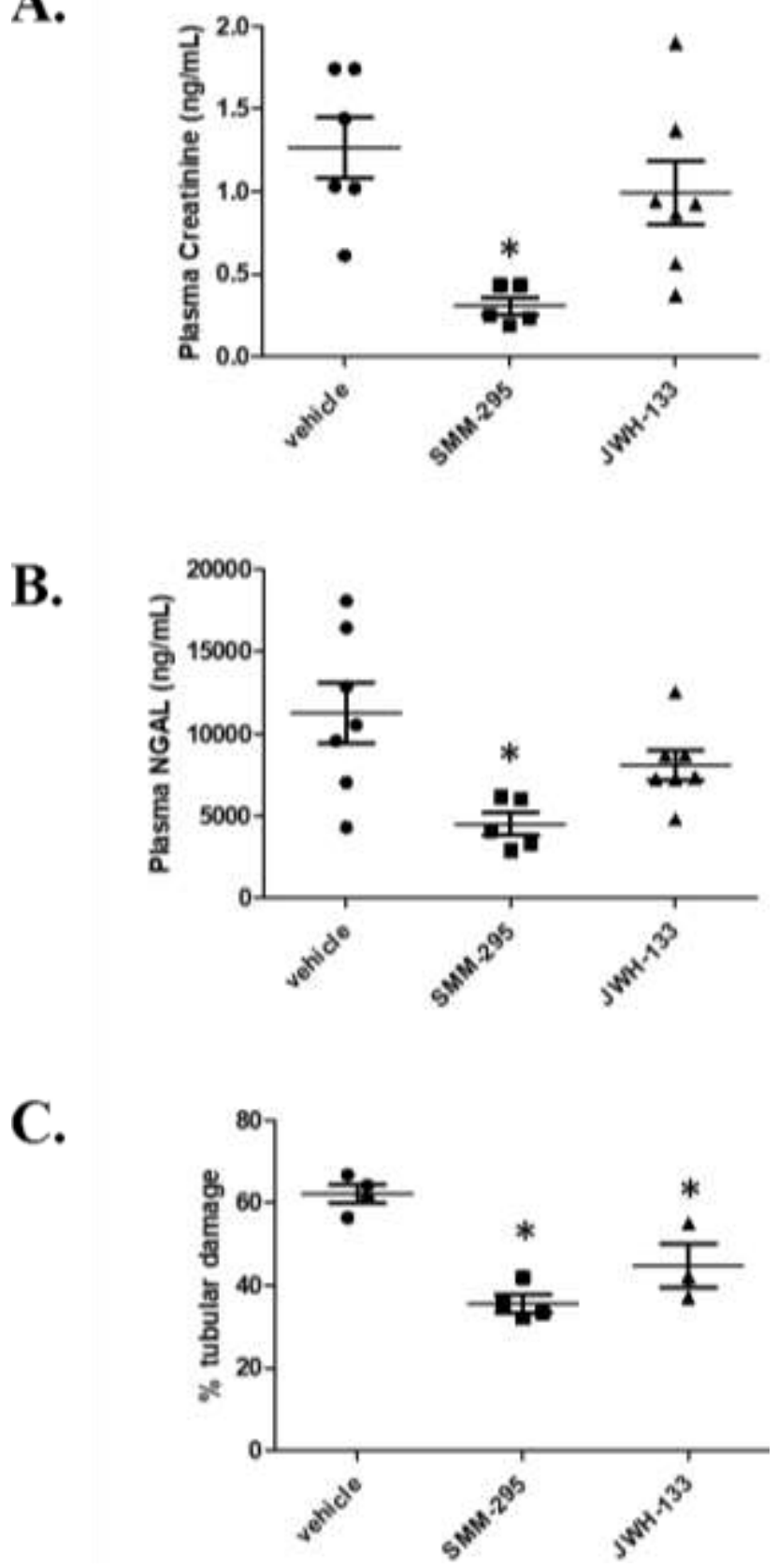

Figure 2-3. Comparison of novel CB2 agonist, SMM-295, compared to the "gold standard" CB2 agonist, JWH-133

Commercially available CB2 agonist, JWH-133, and novel CB2 agonist, SMM-295, leads to decreased tubular damage following IRI (A). However, SMM-295 leads to decreases in creatinine and NGAL levels $(B, C)$ whereas JWH-133 doesn't show this effect as creatinine and NGAL levels in JWH-133 treated mice are statistically similar as mice treated with vehicle. 
In obesity-related nephropathy, activation of the CB2 receptor with AM-1241 reduced urinary protein excretion and attenuated the appearance of fibrotic markers (120). This effect is confounded by the low specificity of AM-1241 between the CB1 and $\mathrm{CB} 2$, showing $71 \%$ activity at the $\mathrm{CB} 1$ receptors, along with off target effects at other receptors outside the cannabinoid system like 5HT (100).

Similarly, chronic renal function was improved in the presence of selective CB2 activation using either an experimental or genetic mouse model of diabetes $(84,121)$. Urinary albuminuria and podocytes protein loss were dramatically reduced in the AM1241 treated mice compared to the vehicle group (121). Consistent with these results, reduced glomerular damage was observed in the $\mathrm{BTBR}^{\mathrm{ob} / \mathrm{ob}}$ leptin-deficient mouse model of progressive diabetic nephropathy following administration of another CB2 agonist, HU-910 (84). Although the exact mechanism by which the renal architecture and function were preserved is not fully described, it may involve CB2 receptor-dependent inhibition of the immune system (120). Diabetic nephropathy is associated with increased chemokine production, inflammatory cell infiltration, and the consequent release of ROS and inflammatory mediators that activate tubular cell apoptosis (82). The CB2 receptor has been demonstrated to be highly produced in immune cells $(122,123)$, which is a necessary cell type that is recruited to the kidney upon the presentation of a damage response by injured tubular epithelial cells, especially during diabetic nephropathy (82). Glomerular damage was lessened by the decreased accumulation of monocytes and macrophages in the presence of HU-910, a CB2 agonist (84). Chronic treatment with CB2 receptor agonist, HU-308 limits inflammatory signaling by reducing oxidative stress, which can help to attenuate the nephropathic injury by possibly preventing tubular cell apoptosis $(82,121)$.

The precise nature of the role of the cannabinoid receptors in the kidney during AKI remains to be fully understood. Cannabidiol, a modest CB2 inverse agonist and weak CB1 antagonist (124), was shown to have a beneficial effect on renal function following IRI (77). In this study, the specific receptor activation was not evaluated, but the protection of the kidney was associated with reduced expression of pro-inflammatory factors (77). In another study using a rodent model of renal IRI, tubular epithelial cell damage was prevented following dose-dependent administration of either CB1 or CB2 receptor agonists (76).

This study provided us with some clarity regarding the role of cannabinoids in AKI by determining the effects on renal damage and function across a comprehensive profile of cannabinergic drugs. This pilot study suggests that CB2 activation has beneficial effects in the recovery of IRI creating possibilities for novel therapeutics clinically approved for the treatment of AKI. Furthermore, our novel CB2 agonist SMM295 led to a consistent improvement in all aspects of AKI from serum markers to histological damage compared to another commercially available "gold standard" CB2 agonist, JWH-133, which tended to show renal improvement in some, but not all parameters. JWH-133 is known in the mouse to favor GTPase activity over cAMP and $\beta$-Arresting signaling moieties and displays no GIRK activity (100). It is not clear as to the reason for the lack of consistency across all of the assays for JWH-133 compared to 
SMM-295, but it is most likely related to the ability of the ligand to differential stabilize distinct CB2 active states leading to functionally selective activation of downstream pathways, the need for higher doses for JWH-133, or activation of other non-CB2 receptors that helped to promote the beneficial effects. Regardless, both of these compounds provide us with the confidence that the $\mathrm{CB} 2$ can provide renal protection following exposure to AKI stimuli.

The mechanism by which CB2 activation leads to decreases in renal damage and increases in renal function early in the recovery from IRI has yet to be described. The pathways responsible for this protection could include a direct (or indirect) effects on the tubular epithelial cells, and possibly a change in the renal hemodynamics in response to CB2 agonism. Studies in the heart suggest that CB2 activation leads to activation of prosurvival pathways in ischemic injury (125). It has yet to be determined if this effect translates to the kidneys and more specifically tubular epithelial cells. If there is indeed activation of pro-survival pathways in tubular epithelial cells following CB2 activation this would explain the preservation of tubular structure in SMM-295 treated mice following IRI. Furthermore, CB2 activation leads to changes in systemic hemodynamics and has effects on blood pressure and vascular resistance (126-128). However, the implications of CB2 activation in regard to renal hemodynamics has not been studied in depth. In the following chapters, the mechanisms through which SMM-295 leads to decreases in renal injury and increases in renal function will be investigated in the early stages of recovery from IRI. 


\section{CHAPTER 3. CHARACTERIZATION OF CB2 AGONIST SMM-295 AND ITS EFFECTS IN IRI. ${ }^{2}$}

\section{Introduction}

Acute kidney injury (AKI) has clinically become an increasing problem for patients of all ages that has been linked with an elevated risk of mortality $(129,130)$. Most of the patients that develop AKI are in a pre-renal state, which typically includes organ hypoperfusion associated with sepsis, fluid depletion, pharmacological reductions in blood pressure, and vessel occlusion $(6,131)$. AKI is an important risk factor in the progression towards chronic kidney disease, which can also be a reciprocal risk factor in potentiating the onset of AKI $(132,133)$. At present, there remains a lack of adequate therapeutic approaches to diagnose and subsequently treat patients following an episode of AKI. Even though there is an increasing knowledge base regarding the mechanisms involved in the onset and recovery of damaged renal cells, particularly tubular epithelial cells $(2,6,134)$, further investigations are clearly in need to expand upon the current state of mechanistic understanding and have the possibility to increase our ability to develop new therapeutic targets.

The role of the cannabinoid system in the kidney following activation of its cognate G-protein coupled receptors, $\mathrm{CB} 1$ and $\mathrm{CB} 2$, is continuing to emerge as a crucial response system following injury stimuli to the kidney. CB1 and CB2 activation can exert a diverse array of biological functions, due to a combination of factors, which includes their ability to interact with several heterotrimeric G-protein $\alpha$ subunits, including Gai, Gas and $\mathrm{G} \alpha \mathrm{q} / 11$ (135), and their distribution within the distinct cell types in the kidney. The CB1 receptors are expressed in high abundance with a fairly broad localization pattern, which includes all segments of the nephron and vasculature (135). On the other hand, the CB2 receptor has been primarily detected in the renal cortex, specifically in mesangial cells and podocytes in the glomerulus $(92,119)$, and proximal tubular epithelial cells $(87,136,137)$. Selective activation of CB2 receptor has been shown to be protective of renal architecture and nephron function by mitigating the nephropathic effects associated with diabetes $(82,84)$ or diet-induced obesity $(137)$ in rodent models of chronic kidney injury. Diabetic nephropathy was attenuated following treatment with a natural $\mathrm{CB} 2$ agonist $\mathrm{BCP}(79)$, or a small molecule analog functioning as a CB2 agonist (82). Similarly, CB2 receptor activation in rodents with diet-induced obesity ameliorated their progression towards renal dysfunction as determined by urinary protein and sodium excretion rates (137). Conversely, CB2 receptor antagonists reduced renal function as measured by creatinine clearance, which suggests that renal failure was

\footnotetext{
${ }^{2}$ Except for the Introduction and Conclusion, reprinted with permission of the American Society for Pharmacology and Experimental Therapeutics. All rights reserved. Pressly, J. D., Mustafa, S. M., Adibi, A. H., Alghamdi, S., Pandey, P., Roy, K. K., \& Park, F. (2018). Selective cannabinoid 2 receptor stimulation reduces tubular epithelial cell damage after renal ischemia-reperfusion injury. Journal of Pharmacology and Experimental Therapeutics, 364(2), 287-299 https://doi.org/10.1124/jpet.117.245522 Final submission copy used. (93).
} 
exacerbated (137). These data demonstrate the potential clinical benefit of CB2 receptor agonists to treat chronic forms of kidney injury, but further investigations are needed to determine the utility of harnessing the CB2 receptor system following acute kidney injury.

Towards addressing this issue, Chapter 2 described our unbiased approach to identify modulators of the CB2 receptor of which a small molecule agonist, SMM-295, was identified to exert a therapeutic effect on reducing tubular epithelial cell damage following renal IRI. This chapter will describe new experiments that further categorize our novel CB2 agonist, SMM-295, in pharmacokinetic studies in vivo and in vivo as well as a more expansive study to determine its therapeutic potential to prevent tubular epithelial cell damage using a mouse model of renal bilateral IRI, which is a common type of AKI. The findings in our study will demonstrate that further investigation into selective activation of the CB2 receptor is merited to elucidate its potential as a therapy to treat AKI.

\section{Materials and Methods}

\section{Reagents}

G418 was purchased from KSE Scientific (Durham, NC). Puromycin, DMEM, penicillin/streptomycin, gentamicin, DPBS, Hank's Buffer, HEPES, EDTA, Tris base, sucrose, $\mathrm{MgCl}_{2}$, Millipore filter plates and punch kits, Eco-Lite scintillation cocktail, and Poly-D-lysine coated 96-well plates were purchased from Fisher Scientific (Waltham, MA). Ambisome and FBS were purchased from Atlanta Biologicals (Flowery Branch, GA). Ro 20-1724, acetonitrile, DMSO, lipopolysaccharide (LPS), polyethyleneamine, and fatty acid-free BSA were purchased from Sigma Aldrich (St. Louis, MO). Antibodies against proliferating cell nuclear antigen (PCNA) was purchased from Cell Signal. High bind plates (L15XB-3), anti-rat (R32AA-5), and anti-rabbit (R32AB-1) SULFO-TAG antibodies were purchased from Meso-Scale Discovery (Gaithersburg, MD). ACTOne Membrane Potential Dye was purchased from Codex BioSolutions (Gaithersburg, MD). Forskolin was purchased from Tocris (Bristol, UK).

\section{Receptor Binding}

Membrane proteins were isolated using binding buffer, as previously described (138). Prior to starting the assay, filter plates were prepared by incubating with $0.05 \%$ $(\mathrm{w} / \mathrm{v})$ polyethyleneamine mixed in deionized water for 60 minutes at room temperature. Afterwards, plates were filtered and washed 5 additional times with deionized water using a vacuum manifold. In each well, $10 \mu \mathrm{g}$ of membrane protein was added in the presence of $\left[{ }^{3} \mathrm{H}\right]$-CP 55,940 (final concentration $1 \mathrm{nM}$ ) with or without test ligands, such as SMM-295 (concentration range from $1 \mathrm{nM}$ to $10 \mu \mathrm{M}$ ). The samples were incubated at $30^{\circ} \mathrm{C}$ for 90 minutes, and then washed up to 9 times using binding buffer. At end of the 
final wash, the plate backing was removed, vacuum dried, and individual filters were collected using punch tips into scintillation vials containing Eco-Lite scintillation solution $(5 \mathrm{~mL})$. Vials were incubated overnight and analyzed the following day using the PerkinElmer Liquid Scintillation Analyzer Tri-Carb 2810TR with a dwell time of 3 minutes. All binding studies were performed with a minimum of 6 biological replicates, and the following parameters were measured: $\mathrm{CB} 1 \mathrm{~K}_{\mathrm{d}}$ was $1.98 \pm 0.6 \mathrm{nM}, \mathrm{B}_{\max } 8.47 \pm$ $2.35 \mathrm{pmol} / \mathrm{mg}$. CB2 $\mathrm{K}_{\mathrm{d}}$ was $1.65 \pm 0.5 \mathrm{nM}, \mathrm{B}_{\max } 3.18 \pm 0.1 \mathrm{pmol} / \mathrm{mg}$.

\section{ACTOne Functional Assay}

HEK-CNG, HEK-CNG+CB1, and HEK-CNG+CB2 cells were obtained from Codex BioSolutions (Gaithersburg, MD). The ACTOne functional assay was performed as described by Presley et al. (139). In brief, $5 \times 10^{4}$ cells were plated into clear poly-Dlysine coated 96-well plates using DMEM containing 10\% FBS and 1\% penicillin/streptomycin. The following day, SMM-295 or CP 55,940 was evaluated at final concentrations from $5 \times 10 \mu \mathrm{M}$ down to $500 \times 10 \mathrm{pM}$ in the presence of either or both Ro 20-1724 $(25 \mu \mathrm{M})$ and forskolin $(0.8 \mu \mathrm{M})$ in DPBS with 2.5\% (v/v) DMSO. At this point, the plates were read using a BioTek (Winooski, VT) plate reader (Ex $540 \mathrm{~nm}$, Em $590 \mathrm{~nm}$ ) at 50 mins. At least six biological replicates were performed for each data set.

\section{Drug Permeability Assay}

Bidirectional drug permeability for SMM-295 $(5 \mu \mathrm{M})$ was tested using the Caco-2 human epithelial cell line as previously described (140). As a positive control for Pglycoprotein (P-gp) efflux, loperamide $(5 \mu \mathrm{M})$ was used in the assay. Verapamil (100 $\mu \mathrm{M}$ ) was used as an inhibitor for P-gp transport activity. All data are shown as $10^{-6} \mathrm{~cm} / \mathrm{s}$.

\section{Plasma Protein Binding by SMM-295}

Rapid equilibrium dialysis (RED) was performed using a commercial plate-based RED device. SMM-295 was diluted to a final concentration of $5 \mu \mathrm{M}$ in triplicate using mouse and human plasma. As a control, warfarin was diluted to $5 \mu \mathrm{M}$ using mouse and human plasma, and PBS (pH 7.4) was added to the buffer chamber. After the RED device was sealed with an adhesive film, dialysis was performed in an incubator at $37^{\circ} \mathrm{C}$ with shaking at $100 \mathrm{rpm}$ for 4 hours. Aliquots of the buffer and the plasma were measured at specific times with a calibration curve by LC-MS/MS to determine the concentration of free and bound test compound by LC-MS/MS analysis. The calculation of the peak area ratios between the analyte versus the internal standard was used to determine the fraction of compound bound to plasma proteins. 


\section{Cytochrome P450 Metabolism Assay}

The in vivo stability of SMM-295 was assessed in duplicate using purified cytochrome P450 (P450) enzymes and measuring the disappearance of the native compound over an incubation period of 60 minutes. The various $\mathrm{P} 450$ proteins (50 $\mathrm{pmol} / \mathrm{ml}$ ) and their positive control drugs (in parentheses; $1 \mu \mathrm{M}$ ) tested in our assay are as follows: CYP1A2 (phenacetin), CYP3A4 (terfenadine), CYP2C9 (diclofenac), CYP2C19 (lansoprazole), and CYP2D6 (propranolol). SMM-295 $(1 \mu \mathrm{M})$ was added to each of the P450 enzymes, and the samples were placed in a 96-well plate that was preincubated at $37^{\circ} \mathrm{C}$. NADPH was added to a final concentration of $1 \mathrm{mM}$ to initiate the reaction, and all reactions were terminated using ice-cold acetonitrile containing an internal standard at 0 , $5,15,30$, and 60 minutes. The plates were centrifuged at $4000 \mathrm{rpm}$ for 15 minutes, and an aliquot from each sample was analyzed by LC-MS/MS to determine the percentage change in the native versus metabolized compounds and the calculation of the compound half-life.

\section{Human Ether-a-Go-Go-Related Gene Assay}

The potential inhibitory effect by SMM-295 (1 and $10 \mu \mathrm{M})$ on the human Ether-aGo-Go-related gene (hERG) channel was evaluated using the predictor hERG fluorescence polarization assay kit as per the manufacturer's instructions (Life Technologies, Carlsbad, CA).

\section{In Vivo Pharmacokinetic Studies}

Animal studies were performed by SAI Life Sciences Ltd. (Hyderabad, India) using an institutional animal ethics committee protocol (number FB-15-103). Twentyseven male C57BL/6J mice (aged 8-12 weeks; 25-35 g) were obtained from ACTREC (Maharashtra, India) and maintained in a temperature- and humidity-controlled environment under 12-hour light/dark cycles. All mice were allowed ad libitum access to food (Envigo Research Private Ltd., Hyderabad, India) and water.

The mice were administered SMM-295 (6 mg/kg i.p.), which was formulated in $5 \%(\mathrm{v} / \mathrm{v})$ 200-proof ethanol, 5\% (v/v) Cremophor ELP (BASF, Germany), and 90\% normal saline. At each time point $(0.08,0.25,0.5,1,2,4,8,12$, and 24 hours), three mice were euthanized to collect blood and kidney samples for measurement of SMM-295. Plasma was isolated from the collected blood by centrifugation, and the kidneys were immediately homogenized using ice-cold PBS ( $\mathrm{pH}$ 7.4). The plasma and kidney homogenates were stored at $-70^{\circ} \mathrm{C}$ until analysis by fit-for-purpose validation by LCMS/MS to obtain the concentration-time data for SMM-295. Subsequently, the plasma concentration-time data were used to calculate other pharmacokinetic variables using the noncompartmental analysis module in Phoenix WinNonlin software (version 6.3; Certara, Princeton, NJ). Maximum concentration $\left(C_{\max }\right)$ and time to reach the maximum concentration $\left(t_{\max }\right)$ were the observed values. The areas under the concentration-time 
curve $\left(\mathrm{AUC}_{\text {last }}\right.$ and $\left.\mathrm{AUC}_{\text {inf }}\right)$ were calculated using the linear trapezoidal rule. The terminal elimination rate constant $\left(k_{\mathrm{e}}\right)$ was determined by regression analysis of the linear terminal portion of the log plasma concentration-time curve.

\section{Renal Bilateral Ischemia-Reperfusion Injury}

C57Bl/6 mice (6-7 weeks of age) were obtained from Jackson Laboratories and allowed to acclimate for at least three days before performing bilateral renal IRI surgeries. All protocols are approved by the Institutional Animal Care and Use Committee (IACUC) at the University of Tennessee Health Science Center, Memphis. All mice were provided ad libitum access to mouse chow and water before and after the surgical procedures. Mice were anesthetized with pentobarbital $(50-80 \mathrm{mg} / \mathrm{kg}$ IP), and renal flank incisions were made on each side of the mice to isolate the kidneys for clamping of the renal hilus using microisolator clamps. After clamping the organs, they were placed back into the abdominal area, and body temperature was maintained between $35-37^{\circ} \mathrm{C}$ as monitored by a rectal temperature probe. At the end of 24.5 minutes, the clamps were removed and immediately administered vehicle, SMM-189 (6 mg/kg IP), SMM-295 (6 mg/kg IP), SR141716A (6 mg/kg IP), or KM-133 (6 mg/kg IP) (Table 2-1). The kidneys were subsequently monitored for the restoration of blood perfusion by the kidneys before the closure of the wounds. All mice were administered analgesics and antibiotics following the surgery, and if needed during the remainder of the experimental period. After 24 hours, another dose of vehicle or SMM-295 (6 mg/kg IP) was administered to each of the mice. Body weights were also obtained during the experimental period. The mice were euthanized after either 24 or 48 hours, and the kidneys were made into lysates for immunoblot analysis.

\section{LC-MS/MS Assay of SMM-295}

Plasma and kidney homogenates in ice-cold PBS ( $\mathrm{pH} 7.4)$ were isolated by centrifugation, and protein extraction was achieved using a 4:1 (acetonitrile/sample) ratio. As an internal control, glipizide $(500 \mathrm{ng} / \mathrm{ml})$ was added to each sample except for the blank control. Samples were vortexed and centrifuged for 10 minutes at $4000 \mathrm{rpm}$ at $4^{\circ} \mathrm{C}$. After centrifugation, $100 \mu \mathrm{l}$ clear supernatant was transferred in 96-well plates and analyzed using LC-MS/MS. Chromatographic separation was achieved using a Kinetex EVO C18 column $(3 \mu \mathrm{m}, 100 \times 4.6 \mathrm{~mm}$ i.d.; (Phenomenex, Torrance, CA). The system delivered a constant flow of $1 \mathrm{ml} / \mathrm{min}$, with the mobile phase consisting of $0.1 \%$ formic acid in acetonitrile and $10 \mathrm{mM}$ ammonium formate injected at a volume of $5 \mu \mathrm{l}$ at a temperature of $45^{\circ} \mathrm{C}$. Detection of SMM-295 and standards was performed with the QTRAP 4000 LC/triple-quadruple mass spectrometer (SCIEX, Concord, ON, Canada). A calibration curve was constructed and validated with spiked samples in either plasma or kidney homogenates. 


\section{Reverse Transcription Polymerase Chain Reaction Analysis for CB2 Receptor mRNA}

Total RNA was extracted from IRI-treated and contralateral kidneys using TRIzol reagent as previously described in our laboratory (141). DNAse treatment was performed on the total RNA, and the RNA was re-extracted with TRIzol reagent. Reverse transcription was performed using SuperScript III reverse transcription kit (Life Technologies). Upon completion of the reverse transcription step, polymerase chain reaction was performed using specific TaqMan primers targeted to the Cnr2 and 18s cDNA. Polymerase chain reaction product formation was calculated by the delta delta $\mathrm{Ct}$ $(\triangle \Delta \mathrm{CT})$ method, as previously performed by our laboratory (141). The resulting fold change of $C n r 2$ mRNA is the difference between the injured and uninjured kidneys normalized to $18 \mathrm{~s}$ mRNA to control for variation between samples.

\section{Hypoxia/Reoxygenation Injury in NRK-52E Cells}

Protein lysates were isolated from normal rat kidney NRK-52E cells treated with SMM-295 (1, 2, and $10 \mathrm{mM}$ ) for 15 minutes using established protocols in our laboratory $(115,116,142,143)$. In addition, NRK-52E cells were incubated for 12 hours in an incubator containing $4 \%$ oxygen and $5 \%$ carbon dioxide. After the hypoxic period, the cells were incubated in normal oxygen conditions in media containing either $2 \mu \mathrm{M}$ SMM295 or an equal volume of vehicle (DMSO) for 3 hours and lysates were collected for Western blot analysis.

\section{Immunoblot Analysis}

Protein samples were loaded onto a 4\%-20\% gradient SDS-PAGE gel for size fractionation, transferred onto a PVDF membrane, and incubated with primary antibodies (phospho- and total Akt; catalog numbers 9721 and 9272), extracellular signal-regulated kinase 1/2 (catalog numbers 8101 and 9102), p38 mitogen-activated protein kinase (MAPK) (catalog numbers 9211 and ab31828; Abcam), Bcl-xL (catalog number 2764), cleaved caspase 3 (CC3; catalog number 9665), and Bcl-2 (catalog number 2870) from Cell Signaling Technologies, unless otherwise mentioned, at a 1:1000 dilution overnight in $4^{\circ} \mathrm{C}$ conditions. Secondary goat anti-rabbit or anti-mouse horseradish peroxidaselinked IgG (1:1500 dilution; Cell Signaling Technologies; catalog numbers 7074 and 7076) secondary antibody was used for detection by chemiluminescence. Membranes were scanned using the Bio-Rad chemiluminescent detection system (Bio-Rad, Hercules, CA), and band intensities were calculated by ImageJ software (National Institutes of Health, Bethesda, MD). $\beta$-actin (1:8000, catalog number MA515739HRP; Thermo Fisher Scientific) was used as the loading control, and the relative expression of protein levels was calculated by normalizing band intensity values of the proteins of interest to either one of the loading controls. 


\section{Statistical Analysis}

The data and statistical analysis comply with the recommendations on experimental design and analysis in pharmacology (144). All values are shown as means \pm S.E.M. using GraphPad Prism software (version 6.0; GraphPad Inc., La Jolla, CA). Either an unpaired t test or one-way analysis of variance was performed using StudentNewman-Keuls post hoc analysis to confirm significant differences $(\mathrm{P}<0.05)$ between animal groups. Post hoc testing was only performed if $\mathrm{F}$ achieved $\mathrm{P}<0.05$ and there was no significant variance in homogeneity. For the ACTOne data, nonlinear analysis was performed.

\section{Results}

\section{Physicochemical and Pharmacokinetic Properties of SMM-295}

The chemical structure of SMM-295 is shown in Figure 1A Following intraperitoneal injection of SMM-295, the maximal plasma concentration $\left(\mathrm{C}_{\mathrm{max}}\right.$, plasma $)$ was $304.4 \pm 40.3 \mathrm{ng} / \mathrm{mL}$ after 0.25 hour ( $\mathrm{t}_{\max }$, plasma) (Figure 3-1B). In the kidney, there was high concentration of SMM-295 after 0.08 hour ( $\mathrm{t}_{\text {max }}$, kidney $)$ with an average peak value of 9,826 $\pm 5,461 \mathrm{ng} / \mathrm{g}$ kidney tissue $\left(\mathrm{C}_{\max }\right.$, kidney $)$ (Figure 3-1C). Using these values, the half-life $\left(\mathrm{t}_{1 / 2}\right)$ of SMM-295 was calculated at 0.25 hour and could be detected in the plasma between 4 to 8 hours. SMM-295 was highly bound to plasma proteins in both mouse and humans at $>99 \%$. The high plasma binding was similar to warfarin, which was used as a positive control since it binds to human $(98.8 \pm 0.2 \%)$ and mouse $(96.9 \pm 0.2 \%)$ proteins (Table 3-1).

Bidirectional permeability of SMM-295 using the standard Caco-2 cell system demonstrated that SMM-295 was moderately transported through the cell (efflux ratio = 1.4; Table 3-1) unlike loperamide (efflux ratio $=2.6$ ), which was a positive efflux drug for the activity of P-gp (data not shown). In addition, the permeability through the cell membranes was dependent upon P-gp activity as determined by the lack of any change in SMM-295 transport in the presence of verapamil (Table 3-1).

In vitro metabolism of SMM-295 was analyzed using a panel of biologically relevant drug metabolizing CYP450 enzymes, including 1A2, 2C9, 2C19, 3A4, and 2D6. To validate the metabolism of SMM-295 by each CYP450 enzyme used in the assay, positive control compounds were assayed in conjunction with SMM-295. Specifically, phenacetin (1A2), propranolol (2D6), diclofenac (2C9), lansoprazole (2C19) and terfenadine (3A4) were tested due to well established metabolism through each respective CYP450 enzyme. In summary, SMM-295 was metabolized by the CYP450 enzymes over the 60 minute period in the following order (from highest to lowest): 2C19>3A4 > 2D6 $>2$ C9 $>1$ A 2 (Table 3-2). The respective calculated half-lives for SMM-295 in the presence of each CYP450 enzyme is provided in Table 3-2. 
A. SMM-295
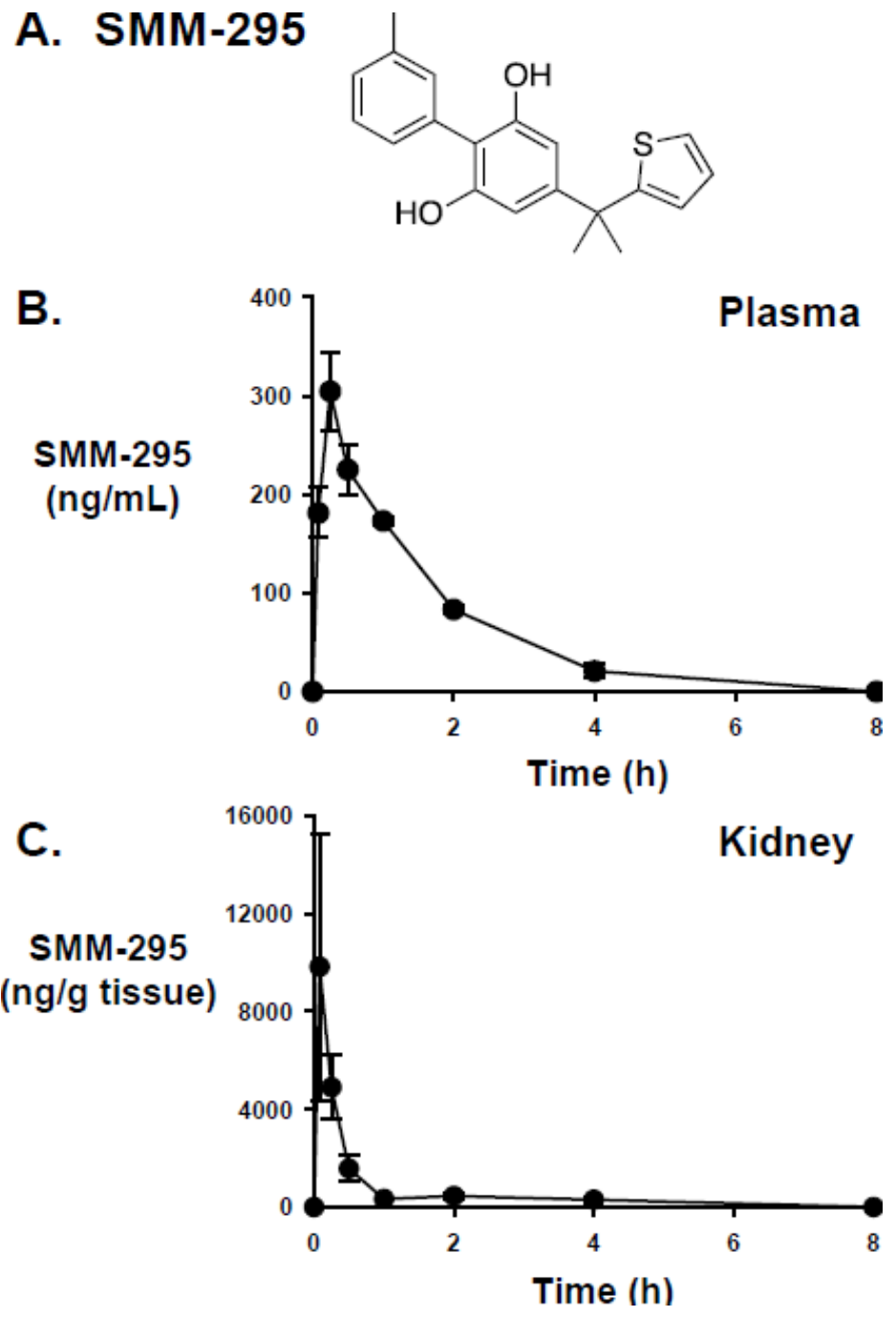

Figure 3-1. Chemical structure and in vivo pharmacokinetics of SMM-295

(A) Chemical structure of SMM-295 is shown. (B, C) C57BL/6J mice were administered $6 \mathrm{mg} / \mathrm{kg}$ into the intraperitoneal space and blood and kidneys were harvested at the appropriate time points shown in the graph. Plasma (B) and kidney tissue (C) levels of SMM-295 were measured by LC-MS/MS, and half-life was calculated and graphed. $n=3$ mice per time point. 
Table 3-1. Physiochemical and biochemical assays for SMM-295

\begin{tabular}{|c|c|c|c|c|c|c|}
\hline Assay & Species & Receptor & Parameter & Values & CB1/CB2 & $\begin{array}{c}\text { Efflux } \\
\text { Ratio } \\
\text { (B-A/A-B) }\end{array}$ \\
\hline \multirow[t]{2}{*}{ Binding } & Human & CB1 & $\mathrm{K}_{\mathrm{i}}$ & $\begin{array}{c}379 \pm 53 \\
\text { nM }\end{array}$ & 31 & \\
\hline & Human & CB2 & $\mathrm{K}_{\mathrm{i}}$ & $\begin{array}{c}12 \pm 2.26 \\
\mathrm{nM}\end{array}$ & & \\
\hline \multirow[t]{2}{*}{$\begin{array}{l}\text { cAMP } \\
\text { inhibition }\end{array}$} & Human & CB1 & $\mathrm{EC}_{50}$ & $\begin{array}{c}1,190 \pm \\
22.1 \mathrm{nM}\end{array}$ & 66 & \\
\hline & Human & CB2 & $\mathrm{EC}_{50}$ & $\begin{array}{c}18.1 \pm \\
1.45 \mathrm{nM}\end{array}$ & & \\
\hline \multirow[t]{2}{*}{$\begin{array}{l}\text { Protein } \\
\text { binding ( } \% \\
\text { bound) }\end{array}$} & Human & & & $>99.9$ & & \\
\hline & Mouse & & & $>99.9$ & & \\
\hline \multirow{2}{*}{$\begin{array}{l}\text { hERG (\% } \\
\text { inhibition) }\end{array}$} & Human & & $10 \mu \mathrm{M}$ & $4+/-3$ & & \\
\hline & Human & & $1 \mu \mathrm{M}$ & $<0.1 \%$ & & \\
\hline \multirow[t]{4}{*}{ Permeability } & Human & & $\mathrm{P}_{\text {app }} \mathrm{A} \rightarrow \mathrm{B}$ & $\begin{array}{c}5.2 \pm 0.4 \\
\times 10^{-6} \\
\mathrm{~cm} / \mathrm{sec}\end{array}$ & & 1.4 \\
\hline & Human & & $\begin{array}{c}\mathrm{P}_{\text {app }} \mathrm{B} \rightarrow \\
\mathrm{A}\end{array}$ & $\begin{array}{c}7.1 \pm 1.2 \\
\times 10^{-6} \\
\mathrm{~cm} / \mathrm{sec}\end{array}$ & & \\
\hline & Human & & $\begin{array}{c}\mathrm{P}_{\text {app }} \mathrm{A} \rightarrow \\
\mathrm{B} \\
(+ \\
\text { verapamil) }\end{array}$ & $\begin{array}{c}7.9 \pm 0.1 \\
\times 10^{-6} \\
\mathrm{~cm} / \mathrm{sec}\end{array}$ & & 0.9 \\
\hline & Human & & $\begin{array}{c}\mathrm{P}_{\text {app }} \mathrm{B} \rightarrow \\
\mathrm{A} \\
(+ \\
\text { verapamil })\end{array}$ & $\begin{array}{c}6.7 \pm 0.2 \\
\times 10^{-6} \\
\mathrm{~cm} / \mathrm{sec}\end{array}$ & & \\
\hline
\end{tabular}


Table 3-2. In vitro CYP450 enzyme metabolism

\begin{tabular}{|c|c|c|c|c|c|c|c|c|c|c|}
\hline \multirow{2}{*}{$\begin{array}{c}\text { Enzyme } \\
\text { Metabolism } \\
\text { Parameters }\end{array}$} & \multicolumn{2}{|c|}{ CYP1A2 } & \multicolumn{2}{|c|}{ CYP2D6 } & \multicolumn{2}{|c|}{ CYP2C9 } & \multicolumn{2}{|c|}{ CYP2C19 } & \multicolumn{2}{|c|}{ CYP3A4 } \\
\hline & $\begin{array}{l}\text { Phenc } \\
\text {-etin }\end{array}$ & $\begin{array}{c}\text { SMM- } \\
295\end{array}$ & $\begin{array}{l}\text { Propr- } \\
\text { anolol }\end{array}$ & $\begin{array}{l}\text { SMM- } \\
295\end{array}$ & $\begin{array}{l}\text { Diclof- } \\
\text { enac }\end{array}$ & $\begin{array}{l}\text { SMM- } \\
295\end{array}$ & $\begin{array}{l}\text { Lans- } \\
\text { razole }\end{array}$ & $\begin{array}{l}\text { SMM- } \\
295\end{array}$ & $\begin{array}{l}\text { Terfe- } \\
\text { nadie }\end{array}$ & $\begin{array}{l}\text { SMM- } \\
295\end{array}$ \\
\hline $\begin{array}{l}\text { Half-life } \\
\text { (minutes) }\end{array}$ & 49.3 & $>60$ & $<5.0$ & 28.4 & 9.0 & 55.3 & 7.4 & 6.8 & 19.0 & 12.2 \\
\hline $\begin{array}{c}\% \\
\text { Remaining } \\
\text { at } 60 \\
\text { minutes } \\
(+\mathrm{NADPH})\end{array}$ & 37 & 62 & 0 & 20 & 1 & 44 & 0 & 0 & 9 & 3 \\
\hline
\end{tabular}




\section{Receptor Binding and Functional Assays}

Measurement of CB1 and CB2 functional activities and receptor affinities of SMM-295 were carried out using the ACTOne functional assay cell lines and membrane preparations derived there from. The affinity of SMM-295 for CB2 was measured to be $12 \pm 2.26 \mathrm{nM}$ with 31 -fold selectivity over CB1 $(379 \pm 53 \mathrm{nM}$; Table 3-1). The potency of SMM-295 at CB2 was comparable to the affinity, with an $\mathrm{EC}_{50}$ of $18.1 \pm 1.45 \mathrm{nM}$ and efficacy of 54\% to prevent cAMP production (Figure 3-2). Compared to our internal standard, SMM-295 was 2-fold less potent than CP 55,940 $\left(\mathrm{EC}_{50}=8.74 \mathrm{nM}\right)$, which had a 77\% efficacy to inhibit cAMP production. At much higher doses, SMM-295 could act as a weak agonist of CB1 with an interpolated potency of $1,190 \pm 22 \mathrm{nM}$ and only $21 \%$ suppression of cAMP at $1 \mu \mathrm{M}$ (Figure 3-2A). In the parental cell line containing only the cyclic nucleotide gated $(\mathrm{CNG})$ ion channel, increasing concentrations of SMM-295 did not decrease the cAMP response, which confirmed that the observed cAMP response was not due to off-target effects. Moreover, in the hERG assay, higher doses of SMM$295(10 \mu \mathrm{M})$ exhibited only minimal inhibition of the channel $(4 \pm 3 \%$; Table 3-1). Using ADMET Predictor, the calculated $\log \mathrm{P}, \mathrm{S}+\log \mathrm{P}$, which has been a reliable predictor for the ratio of lipid solubility to water solubility and for membrane-crossing capability (Mannhold et al., 2009), for SMM-295 was 56 and the calculated water solubility $\mathrm{S}+\mathrm{Sw}$ was $0.0036 \mathrm{mg} / \mathrm{mL}$. By comparison, another common CB2 agonist, JWH-133, had considerably higher $\mathrm{S}+\log \mathrm{P}=7.78$ and lower $\mathrm{S}+\mathrm{Sw}=0.000019 \mathrm{mg} / \mathrm{mL}$ demonstrating that SMM-295 had improved biophysical properties that could potentially increase its ability to exert a biological response in vivo.

Rat NRK-52E proximal tubule cell line was incubated with increasing doses of SMM-295 $(0-10 \mu \mathrm{M})$ for 15 minutes and protein lysates were analyzed for changes in ERK1/2, p38 MAPK and Akt activation by immunoblot analysis. Figure 3-2B shows that there was a dose-dependent increase in the activation (phosphorylation) from 0 to 10 $\mu \mathrm{M}$ following exposure to SMM-295.

\section{CB2 Receptor Upregulation in the Kidney Following Ischemia-Reperfusion Injury}

Steady-state changes in the $C n r 2$ mRNA level were measured in a mouse model of unilateral IRI. In the IRI-treated kidneys, $C n r 2$ mRNA increased after 24 hours (1.3 \pm 0.2 -fold; $\mathrm{n}=5)$ and reached significance by 72 hours $(3.0 \pm 0.2$-fold; $\mathrm{P}<0.05 ; \mathrm{n}=5)$ compared to uninjured kidneys (Figure 3-3). The steady-state levels of CB2 mRNA trended back towards normal levels at 168 hours after IRI $(0.7 \pm 0.3$-fold; $\mathrm{n}=5)$.

\section{Upregulation of Anti-Apoptotic Pathways Following CB2 Receptor Activation in Kidney Lysates Obtained from Mice Following Renal Bilateral Ischemia- Reperfusion Injury}

In the SMM-295 treated kidneys, increased activation of Akt (Ser473) and total Akt was detected, which is associated with enhanced cell survival, compared to vehicle 
A.

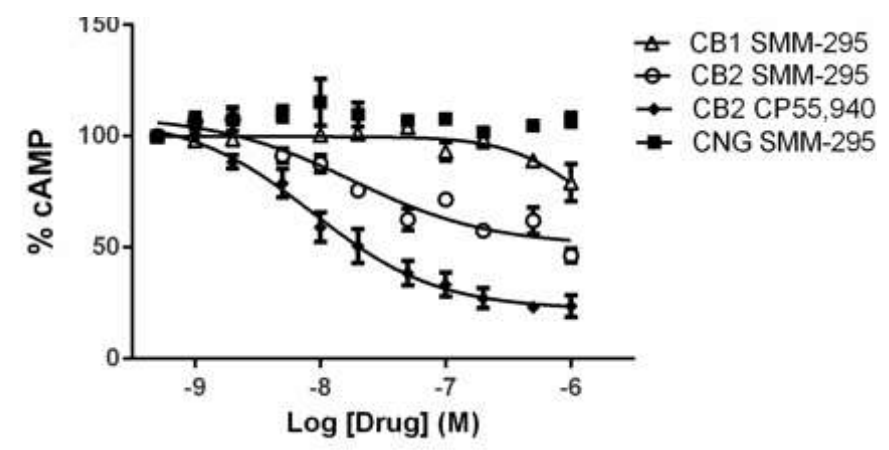

B.

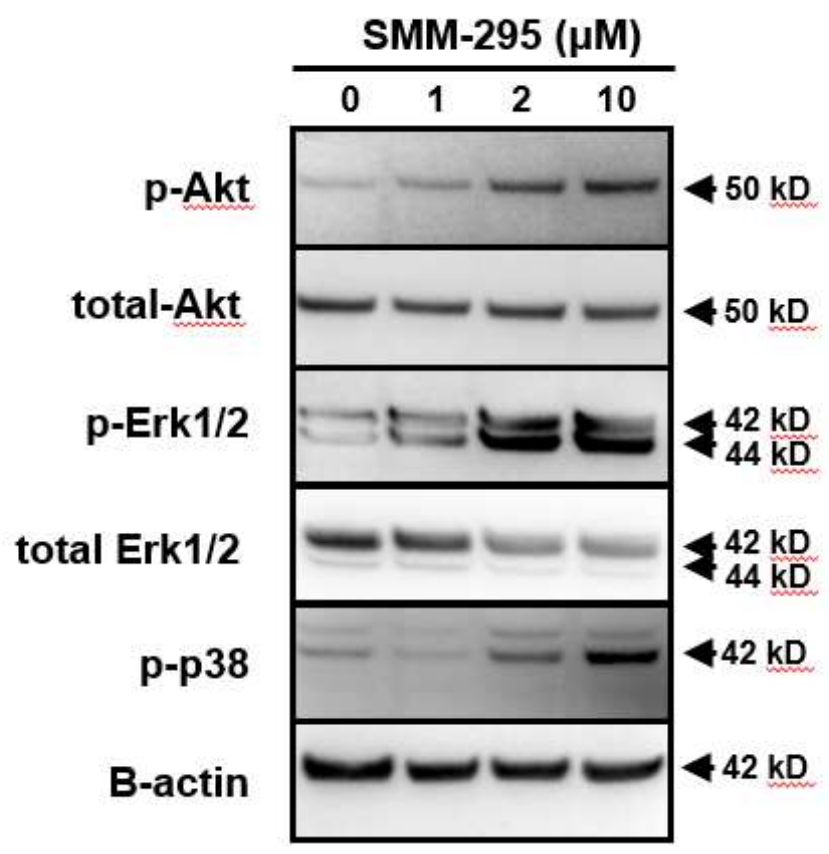

Figure 3-2. Functional activities of SMM-295

(A) Functional activities of SMM-295 in the CB2 ACTOne assay (open circles), CB1 ACTOne assay (open triangles), and parental ACTOne cells containing only the CNG ion channel (filled squares). The functional activation of CB2 by the internal control (CP 55,940; filled diamonds) is shown. (B) Western blot analysis of signaling proteins after brief exposure (15 minutes) to SMM-295 in rat NRK-52E proximal tubule epithelial cells. Activation of pro-survival Akt/PKB and MAPK (ERK1/2 and p38) was detected using specific antibodies. $\beta$-actin was used as a loading control. ERK1/2, extracellular signal-regulated kinase $1 / 2$. 


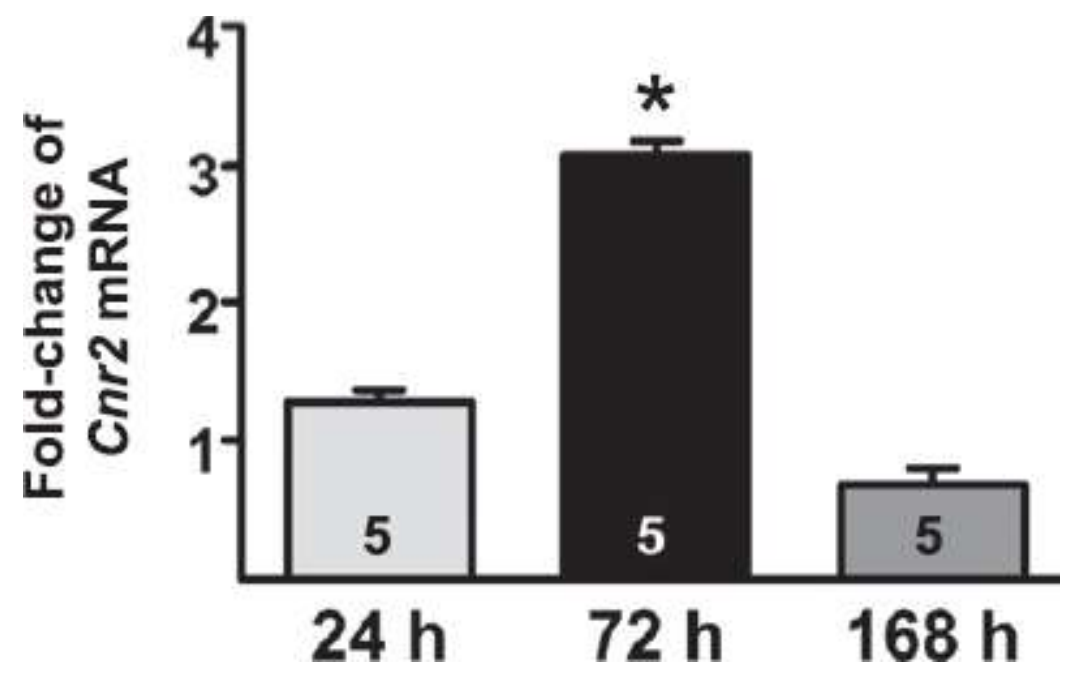

Figure 3-3. Increased steady-state levels of CB2 receptor mRNA in kidneys after ischemia-reperfusion injury

Fold change of mRNA levels for CB2 receptor between contralateral and injured kidneys from wild-type male C57BL/6J mice at various time points (24, 72, and 168 hours) after unilateral IRI. $\mathrm{n}=5$ mice/group per time point. A t-test was used to confirm significant differences $(* \mathrm{P}<0.05)$ between contralateral versus IRI kidneys at each time point. 
treatment (Figure 3-4A-C). In addition, Bcl-2 (Figure 3-4A, D) and Bcl-xL (Figure 3-4A, E) was also markedly elevated in the SMM-295 treated mouse kidneys, which provides evidence that SMM-295 would prevent apoptosis activation. This was supported by a significantly lower number of TUNEL positive nuclei in the outer medulla of were counted and graphed out of 1000 total nuclei counted in the sections. A t-test was used to confirm significant differences $(* \mathrm{P}<0.05)$ between groups. Scale bar, $100 \mu \mathrm{m}$ SMM-295 treated kidneys $(1.3 \pm 0.3 \% ; n=5)$ compared to vehicle-treated kidneys $(4.6 \pm$ $0.6 \%$; $=5$ ) (Figure 3-4F-H). The molecular evidence using the mouse kidneys from the in vivo studies would suggest that SMM-295 prevented tubular epithelial cell damage by enhancing cell survival, in part by decreasing the activation of apoptotic cell death. SMM-295 decreased the levels of CC3, a classic executioner of apoptosis, in NRK-52E cells following hypoxic conditions (Figure 3-5A). This data provides direct evidence of a decrease in apoptotic signaling molecules specifically on tubular epithelial cells using a common in-vitro model of IRI.

\section{Discussion}

Consistent with our study, Nettekoven et al. (78) showed that their newly synthesized CB2 receptor agonist could reduce circulating creatinine following renal IRI. Moreover, a partial CB2 agonist, LEI-101, was capable of attenuating cisplatin-induced tubular damage by reducing oxidative stress and inflammation in mice (80). Administration of LEI-101 in mice deficient in the full-length CB2 receptor confirmed that the $\mathrm{CB} 2$ receptor was responsible for the prevention of the cisplatin-dependent tubular injury (80). In addition, we showed that an inverse CB2 agonist, SMM-189, could exacerbate the tubular injury and promote renal damage. These studies provide strong evidence that exogenous administration of cannabinoid agonists to the CB2 receptor can protect the kidney during states of AKI. The mechanism by which the tubular epithelial cells were protected by CB2 receptor activation needs further investigation, but it may involve diverse signal transduction regulation of the various $\mathrm{G} \alpha \beta \gamma$ complexes in the tubular epithelial cells. The CB2 receptor is well established to activate Gai subunits to inhibit cAMP production, but other studies have also shown that the CB2 receptor can interact with Gaq to promote activation of phospholipase $\mathrm{C}$ (PLC), however this may be an artificial effect that is caused by the construct GFP-CB2- $\beta$ arrestin (145). PLC activation is known to activate Akt, which is involved in promoting cell survival and reducing the activation of pro-apoptotic pathways (146). Of these pathways, activation of Akt can lead to increases in the anti-apoptotic proteins Bcl-2 and Bcl-XL, which was observed in our study. Bcl-2 and Bcl-XL reside in the mitochondrial membrane and act to promote cellular survival through the inhibition of actions initiated by other proapoptotic proteins that would otherwise cause a release of mitochondrial contents like cytochrome c.(147). Cytochrome $\mathrm{c}$ from the mitochondria intrinsically activates caspase 3 leading to increased cleavage forms, which acts to degrade various cellular components during apoptosis (148). Our study demonstrated CB2 activation in vivo leads to increased phosphorylation of Akt with a concomitant increase in the Bcl-2 family proteins. This subsequently reduced apoptosis in sub-lethally injured tubular epithelial cells, and this 


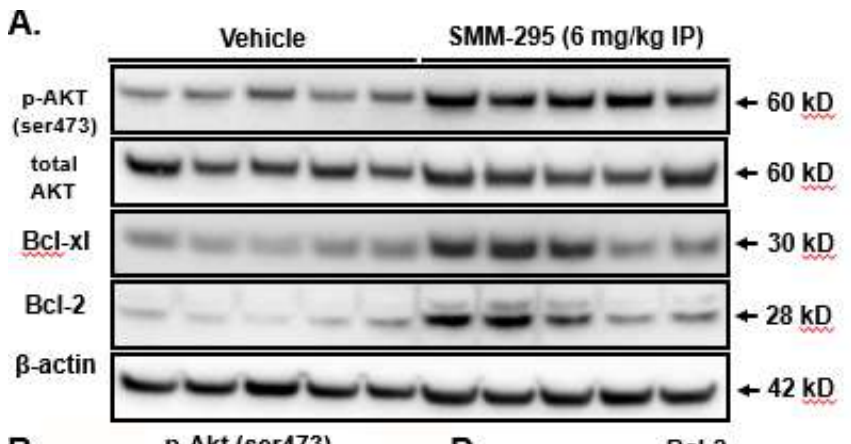

B.

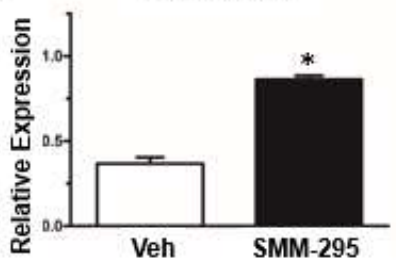

C.
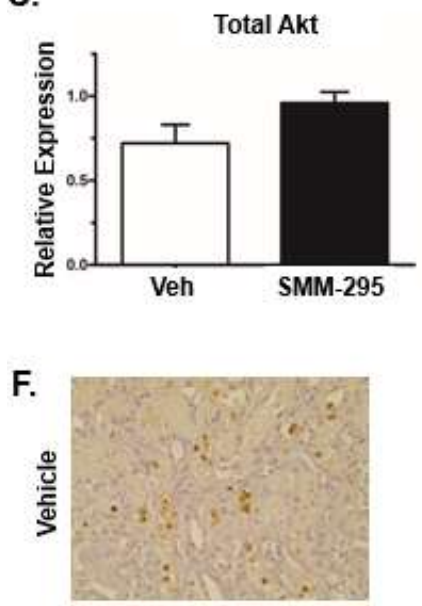

G.

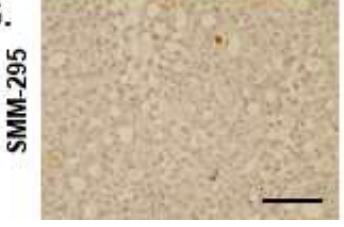

D.

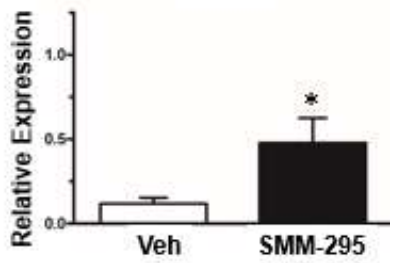

E.

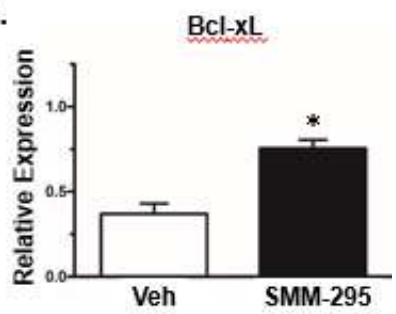

H.

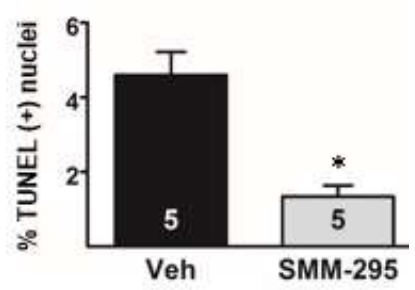

Figure 3-4. SMM-295 improved renal cell survival by reducing apoptotic signaling

A) Representative Western blot analyses of pro-survival Akt (phospho- and total) and anti-apoptotic Bcl-2 and Bcl-xL using protein lysates from mouse kidneys treated with vehicle $(n=5)$ or SMM-295 $(n=5)$. $\beta$-actin was used as a loading control. Arrows on the right indicate expected band size for the detected proteins. (B-E) Densitometric band intensities were determined by ImageJ analysis for p-Akt (Ser473) (B), total Akt (C), Bcl-2 (D), and Bcl-xL (E). (F and G) Representative images of TUNEL staining in vehicle-treated (F) or SMM-295-treated (G) mice after IRI. (H) TUNEL-positive nuclei. 
A.

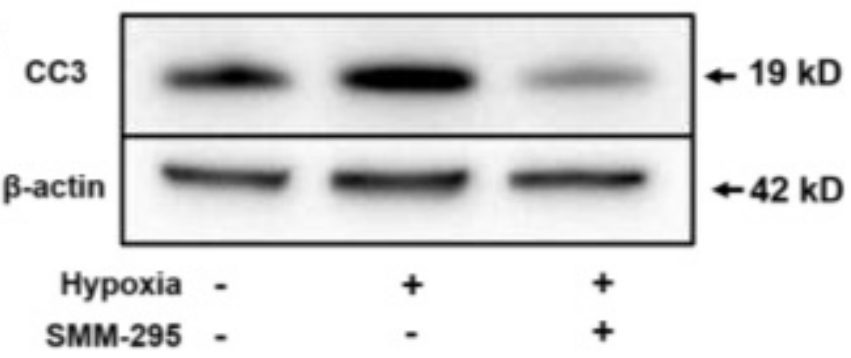

B.

Cleaved Caspase 3

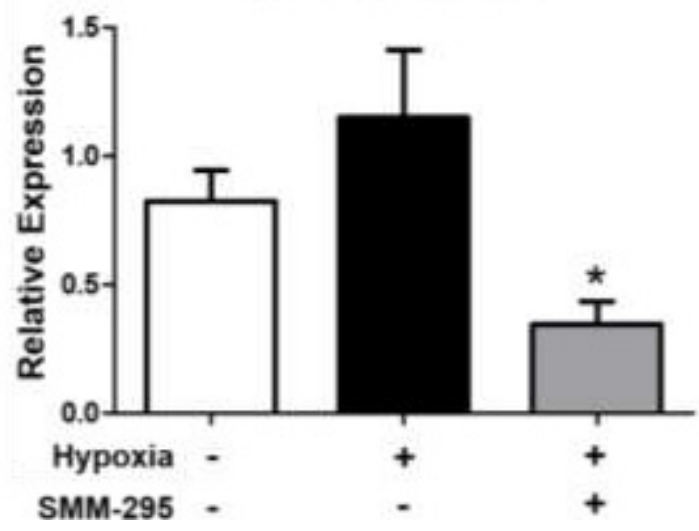

Figure 3-5. Analysis of cleaved caspase-3 levels in NRK-52E cells following hypoxic conditions in the presence of $\mathrm{CB} 2$ receptor activation

(A) Representative immunoblot images of cleaved caspase-3 levels in NRK-52E cells following either normal or hypoxic conditions and administration with either vehicle or SMM-295. ${ }^{*} \mathrm{P}<0.05$ significant different between groups. 
could have accounted for the increase in function and decrease in tubular damage seen in our study. Moreover, we confirmed that proximal tubular cells in vivo could suppress CC3 levels following hypoxia in the presence of SMM-295. Further in vivo studies are still needed to confirm that the signaling protein changes can be directly attributed to the activation of the CB2 receptor and are not due to compensation by the injured renal cells caused by activation or suppression of other pathways. Alternatively, the beneficial effects of selective $\mathrm{CB} 2$ receptor activation may be attributed to a systemic effect preventing immune cell recruitment to the sites of injury similar to the effects observed during chronic kidney disease. The endocannabinoid system through the stimulation of its cognate receptors, $\mathrm{CB} 1$ and $\mathrm{CB} 2$, has been shown to be involved in the regulation of inflammation and immune function $(149,150)$. In particular, brain microglia, which are proposed to be important in regulating the inflammatory response in the CNS, upregulate expression of the $\mathrm{CB} 2$ receptor in response to a biological insult. It has been demonstrated that CB2 ligands attenuate the adverse effects by reducing the release of pro-inflammatory cytokines and chemokines (151-153), and also regulating the activation state of microglia $(112,154)$. This biological effect is critical in the kidney, since the immune system has been shown to be an important component of the early pathogenic effects on renal cell damage, including vascular and tubular epithelial cells, which can be attributed to resident and infiltrating immune cell activity $(2,6)$. Although our findings are promising with regards to the potential therapeutic role of SMM-295 during the early phase of AKI, further studies are needed to characterize other long-term changes in renal architecture and function, such as urine concentrating mechanisms and vascular abnormalities, to fully understand the positive impact of the CB2 receptor system during kidney injury and recovery pathways. Therefore, future studies are necessary to elucidate the possible signaling pathways associated with the CB2 receptor to produce the prosurvival effects in the kidney.

In our study, we synthesized SMM-295, which demonstrated highly selective activation of the CB2 receptor that could provide beneficial protection of the renal tubular epithelial cell structure and function. SMM-295 inhibited cAMP production and also activated downstream MAPK signaling complexes consistent with the known actions of CB2 activation. Pharmacokinetic analyses showed that SMM-295 had a relatively short half-life. However, the short half-life for CB2 agonists remains a problem for most of the well characterized analogs in the literature (100). There was, however, accumulation of SMM-295 in the kidney, which could obviate the rapid decrement of circulating drug and provide more opportunity for renal cell signal activation, particularly during times of renal injury that would negatively impact clearance of exogenous drugs.

In conclusion, our group has demonstrated that SMM-295 is a selective agonist of CB2 with comparable affinity, potency, and efficacy to other CB2 ligands, e.g. AM-1241, HU-910, and LEI-101, which have previously been evaluated in kidney disease models. In the following chapters the effects of CB2 activation by SMM-295 administration will be determined in a commonly used pre-clinical mouse model of IRI. This study demonstrates for the first time a direct effect of CB2 agonist on renal epithelial cells. Although studies have shown an effect of cannabinoids on cell death in other organ systems and cancer $(155,156)$, the effects of cannabinoid signaling on cell death can be 
quite diverse for a number of factors, including distinct cell types, concentration of ligand used in the treatment, and disease models being evaluated. The complexity of the endocannabinoid system provides an opportunity to develop therapeutic strategies utilizing cannabinoid receptor ligands to treat a diverse array of diseases. We believe that this study provides novel evidence of anti-apoptotic signaling mediated by CB2 activation in renal ischemic injury, in which early onset of cell death signaling cascades and proliferation could play a large role in the pathophysiology of the disease. Moreover, administration of SMM-295 immediately upon reperfusion after a brief renal ischemic period reduced tubular epithelial cell damage in the outer medulla of the kidney. These data would suggest that there is considerable promise in the development of SMM-295 as a potential therapeutic, and that modifications to enhance its efficacy, potency and selectivity to the $\mathrm{CB} 2$ receptor could lead to $\mathrm{CB} 2$ receptor selective agonist analogs that will be clinically useful in the treatment of IRI and possibly other types of AKI. 


\section{CHAPTER 4. RENAL HEMODYNAMIC EFFECTS OF CB2 ACTIVATION ${ }^{3}$}

\section{Introduction}

Acute kidney injury (AKI) is defined by an immediate loss in renal function due to a number of factors, including the onset of sepsis, exposure to nephrotoxins, and organ hypoperfusion due to ischemia (6). Ischemia-reperfusion injury (IRI) is one of the most common forms of AKI and involves a complex series of cellular changes that can lead to lethal tubular damage and loss of renal function in the most severe cases. The regulation of renal blood flow dynamics to preserve glomerular filtration rate during AKI induced by IRI is critical in the recovery of the kidney. To date, our understanding regarding the mechanisms involved in regulating vascular function and hemodynamics in the kidney during AKI needs further investigation.

Natural and synthetic cannabinoids have emerged in the past few years as a topic of interest during normal and diseased states in the kidney, including AKI. Studies show that the complete endocannabinoid system can be identified in various cells within the kidney (158). The endocannabinoid system is comprised of endogenous molecules, $\mathrm{N}$ arachidonoylethanolamine (AEA) and 2-acylglycerol, both of its cognate G-protein coupled receptors, cannabinoid type 1 and 2 receptors, and the enzymes involved in their biosynthesis and catabolism (158). Moreover, there is impetus to understand the biological activity of the cannabinoid receptors due to increased acceptance in the medicinal purposes of cannabis and related compounds. The majority of studies to date have focused upon the role of the CB1 receptors in the central and peripheral organs, including the kidney, due in large part to its psychotropic and pain management effects. In the kidney, however, the $\mathrm{CB} 1$ receptors consistently demonstrate deleterious effects on glomerular and tubular function in various acute and chronic forms of injury. The role of the cannabinoid receptors on the regulation of renal hemodynamics, even under normal conditions remains poorly understand. Early rat studies implicated that anandamide (AEA) increased renal blood flow with a concomitant reduction in glomerular filtration rate by preferential vasodilation of the efferent arteriole via CB1 receptor activation (90). Consistent with this finding, Deutsch et al. (92) demonstrated that segments of the renal and arcuate arteries were capable of dilating in the presence of AEA through CB1 receptor stimulation. Conversely, a CB1 receptor using a synthetic agonist WIN 55212-2 demonstrated renal vasoconstriction (159). In addition, there is emerging new developments in selective $\mathrm{CB} 2$ receptor activation, whereby their role in the kidney generally opposes the effects by the $\mathrm{CB} 1$ receptor to protect renal function in the glomerulus and renal tubules (83). As part of these findings, our group demonstrated that the novel CB2 agonist, SMM-295, protects the renal tubular epithelial cells from severe damage following renal ischemia-reperfusion injury by reducing pro-apoptotic signaling

\footnotetext{
${ }^{3}$ Modified from final submission with permission. Pressly, J. D., Soni, H., Jiang, S., Wei, J., Liu, R., Moore, B. M., \& Park, F. (2019). Activation of the cannabinoid receptor 2 increases renal perfusion. Physiological genomics, 51(3), 90-96 (157).
} 
(93). However, the effects by CB2 receptor activation has not been studied using this compound on their potential to modulate renal vascular function.

While Chapter 3 focuses on direct effects of CB2 on tubular epithelial cell survival, this chapter will focus on the hemodynamic effects of CB2 activation, which may contribute to the survival of the tubular epithelial cells after injury. Additional blood flow could provide protection from tubular injury and increase renal function following IRI. For this reason, the present study was designed to evaluate the functional effects of a novel selective cannabinoid CB2 receptor agonist to control the renal vasculature through the use of laser Doppler flowmetry and changes in luminal diameters from isolated perfused afferent arterioles.

\section{Materials and Methods}

\section{Animals}

C57BL/6J and Cnr2 knockout (B6.129P2-Cnr2tm1Dgen/J; stock \#5786) mice aged 10-12 weeks were obtained from the Jackson Laboratory (Bar Harbor, Maine). Animal studies were approved by the Institutional Animal Care and Use Committee (IACUC) at the University of Tennessee Health Science Center prior to performing any procedures. All mice were provided ad libitum access to food and water prior to and after the surgical procedures and were kept on a $12 \mathrm{hr} / 12 \mathrm{hr}$ light/dark cycle during the course of their housing in the animal facilities.

\section{Chemicals and Assay Kits}

Indomethacin (cat \#I7378), capsaicin (cat \#M2028), and Nw-Nitro-L-arginine (LNNA; cat \#N5501) were obtained from Millipore Sigma (St. Louis, MO). Cremophor ELP was purchased from BASF. SMM-295 was synthesized by Dr. Bob Moore as previously described by our group (93). Mouse calcitonin gene related peptide (CGRP) ELISA (cat \#E0056Mo) was obtained from Bioassay Technology Laboratory (Shanghai, China) and performed according to the manufacturer's protocol.

\section{Isolated Perfused Afferent Arteriole Measurement of Luminal Diameter}

Measurements of the afferent arteriole luminal diameter were performed using isolated perfused mouse afferent arterioles as previously described (160-164). In brief, the afferent arterioles with attached glomeruli were isolated and transferred to a temperature regulated chamber mounted on an inverted microscope in media. A set of micropipettes held the glomerulus and cannulated the afferent arterioles holding the intraluminal pressure at $60 \mathrm{mmHg}$. The arteriole preparations were then incubated with 
Norepinephrine $(1 \mu \mathrm{M})$ and/or SMM-295 $(5 \mu \mathrm{M})$ for 15-minute periods during the measurement of the intraluminal diameter.

\section{Animal Surgeries}

A total of 72 mice were used in this study which utilizes both survival (bilateral ischemia-reperfusion injury) and non-survival surgical techniques (terminal anesthetized hemodynamic and CGRP analysis) using protocols that have been well established and published by our laboratories $(72,93,115,116,165)$

\section{Hemodynamic Analysis}

Renal cortical perfusion and mean arterial blood pressure measurements was conducted using techniques published by our group $(166,167)$. A total of 30 mice were anesthetized with a combination of ketamine $(100 \mathrm{mg} / \mathrm{kg}) / \mathrm{xylazine}(10 \mathrm{mg} / \mathrm{kg})$ mixture i.p. and re-administered as needed throughout the procedure to maintain a constant level of anesthesia. Catheters were placed into the jugular vein for infusion of drugs using an infusion pump, and carotid artery to measure arterial blood pressure (ADInstruments, Colorado Spring, CO). Laser Doppler probes were calibrated with a standard calibration device using a motility standard (Perimed, Jarfalla, Sweden) such that 1 Perfusion Unit (PU) corresponds to an analog output of $10 \mathrm{mV}$. The kidney was isolated, and a Doppler probe is placed on the surface of the kidney attached to a holder to measure cortical renal blood flow. Cortical renal blood flow was measured and analyzed using a PowerLab data acquisition system and LabChart software (ADInstruments) and allowed to come to a steady baseline level prior to any pharmacological manipulations. Indomethacin (1 $\mathrm{mg} / \mathrm{kg}$ ) and L-NG-Nitroarginine (LNNA; $10 \mathrm{mg} / \mathrm{kg}$ ) were administered i.p. 15 minutes before infusion of SMM-295 or vehicle [EtOH (5\%): Cremophor ELP (5\%):saline $(90 \%)]$. Capsaicin $(50 \mathrm{mM})$ was applied using a cotton tipped applicator for 15 minutes to the isolated renal vein and the animal rested for 90 minutes following capsaicin treatment. Subsequently, the vessels and surrounding tissues were washed with saline solution and allowed to rest for an additional 60 minutes prior to SMM-295 infusion as previously described by Peixoto-Neves et al. (167). SMM-295 or vehicle were administered via infusion pump with a volume of $1 \mathrm{~mL}$ over a 10 -minute period. At the end of the experiment, plasma was collected by cardiac puncture with a 23-gauge needle and $1 \mathrm{~mL}$ syringe, and the animal was euthanized by collecting the remainder of the tissues.

\section{Calcitonin Gene-Related Peptide (CGRP) ELISA}

A total of 12 mice were anesthetized with a mixture of ketamine (100 $\mathrm{mg} / \mathrm{kg}) / \mathrm{xylazine}(10 \mathrm{mg} / \mathrm{kg})$. An indwelling catheter was placed into the jugular vein for infusion with SMM-295 $(n=6)$ or the vehicle solution $(n=6)$ using an infusion pump at a rate of $0.1 \mathrm{~mL} / \mathrm{min}$ for 10 minutes. Blood was collected from the inferior vena cava after 
clamping with microisolator clips immediately above the renal veins. The detection for CGRP was performed using a commercially available mouse CGRP ELISA kit.

\section{Bilateral Ischemia-Reperfusion Injury (IRI)}

A total of 18 mice were anesthetized with pentobarbital (50-80 mg/kg i.p.) before IRI was performed. Flank incisions were made on both sides of the mice, the kidneys were isolated and the renal hilus was clamped. The renal ischemia was maintained for 24.5 minutes to and immediately upon removal of the microisolator clamps to initiate reperfusion either with CB2 receptor agonist, SMM-295 (6 mg/kg i.p.; $\mathrm{n}=6)$ or vehicle (Cremophor; $\mathrm{n}=6$ ) was administered. The kidneys were subsequently monitored for restoration of blood perfusion prior to closure of animal. All surgeries were conducted under aseptic conditions and all mice were administered buprenorphine for pain management and antibiotics, if needed, after the surgery and during the remainder of the experimental period. After 24 hours, another dose of vehicle or SMM-295 (6 mg/kg i.p.) was administered to each of the mice. Plasma was collected every 24 hours following IRI. The mice were euthanized after 48 hours following terminal anesthetized laser Doppler flow measurements.

\section{Statistics and Study Design}

The data and statistical analysis comply with the recommendations on experimental design and analysis in pharmacology (Curtis et al., 2015). All values are shown as means \pm S.E.M. using GraphPad Prism software (version 6.0; GraphPad Inc., La Jolla, CA). An unpaired t-test or one-way analysis of variance was performed using Bonferroni post hoc analysis to confirm significant differences $(\mathrm{P}<0.05)$ between animal groups. Post-hoc analysis was performed only in the groups where F achieved $\mathrm{P}<0.05$ and there was no significant variance in homogeneity. The ARRIVE guidelines were used to design animal experiments as a standardized approach to ensure validity and reproducibility of results.

\section{Results}

\section{SMM-295 Effect on Cortical Renal Perfusion}

Laser Doppler flowmetry was performed to detect changes in renal cortical perfusion in anesthetized C57B1/6J mice following the administration of a novel CB2 receptor agonist, SMM-295 (see chemical structure in Figure 4-1A). Administration of SMM-295 $(6 \mathrm{mg} / \mathrm{kg})$ or vehicle solution was infused into an indwelling jugular vein catheter over a 10 -minute period at a rate of $0.1 \mathrm{~mL} / \mathrm{min}$. Renal perfusion was monitored for a 30-minute period and vehicle treatment led to an insignificant increase in the renal 

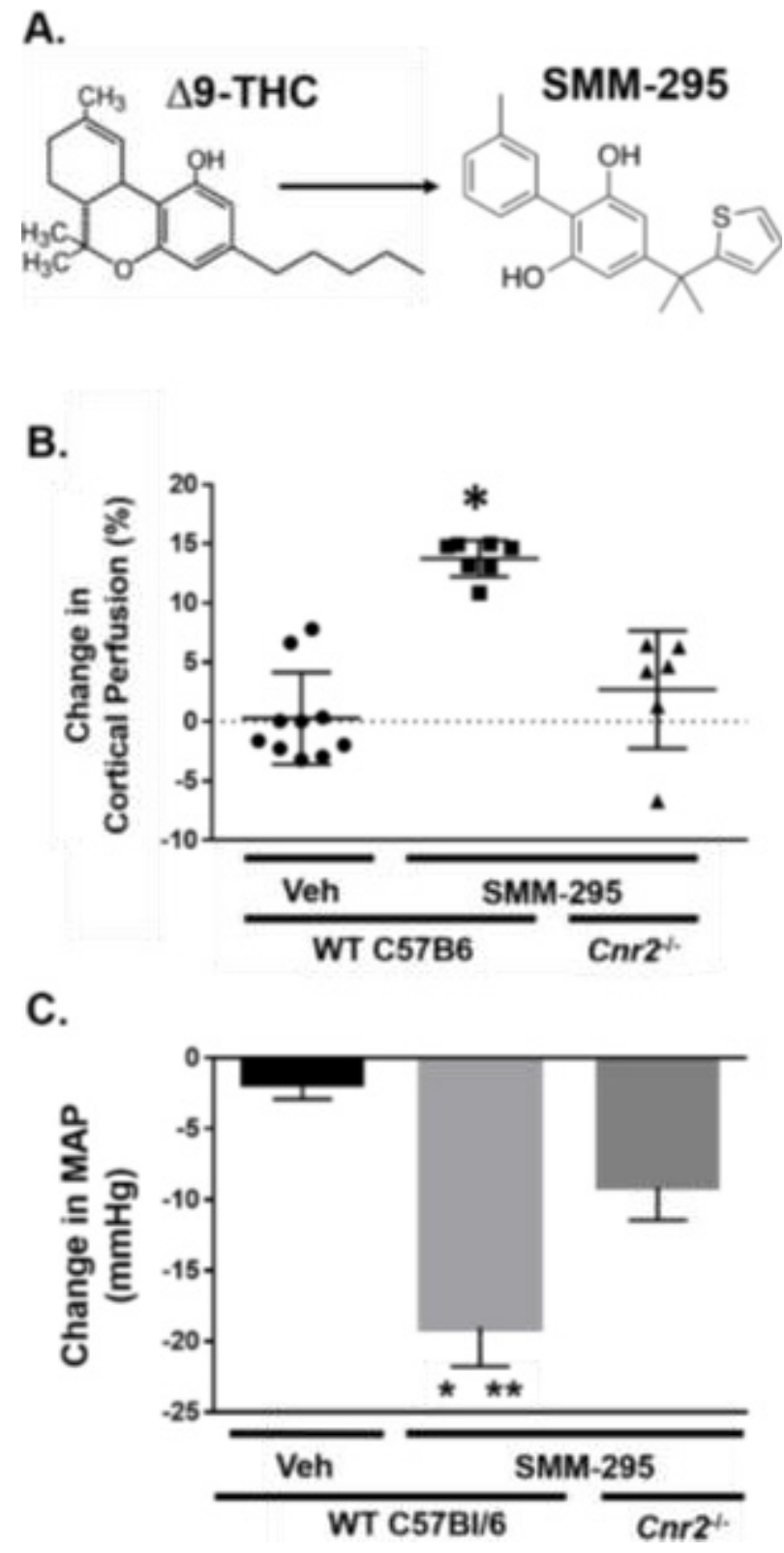

Figure 4-1. CB2 receptor agonist, SMM-295, promotes increased renal cortical perfusion

A) Chemical structure of D9-THC and SMM-295. (B) Measurement of renal cortical perfusion by laser Doppler flowmetry and (C) mean arterial pressure following intravenous infusion of vehicle (veh; $n=10)$ or SMM-295 $(6 \mathrm{mg} / \mathrm{kg} ; \mathrm{n}=7)$ in anesthetized C57BL/6J mice, and SMM-295 (6 mg/kg; $\mathrm{n}=6)$ in Cnr2 knockout mice. Data was graphed as a percent change from baseline levels in each mouse. $* \mathrm{P}<0.0001$ significant difference in cortical perfusion for both groups $(\mathrm{B}, \mathrm{C})$ and only vehicle group for MAP (C); ${ }^{* *} \mathrm{P}<0.05$ significant difference between WT and $\mathrm{Cnr} 2 \mathrm{KO}$ mouse. 
perfusion by $1.1 \pm 10.6$ units $(0.1 \pm 1.5 \%$ from baseline levels) (Figure 4-1B). Infusion of SMM-295 $(6 \mathrm{mg} / \mathrm{kg})$ resulted in a significant increase $(\mathrm{P}<0.0001)$ of $136.1 \pm 8.9$ perfusion units (or $13.8 \pm 0.6 \%$ ) from the baseline levels. Mean arterial pressure following administration of SMM-295 $(6 \mathrm{mg} / \mathrm{kg} \mathrm{IV})$ resulted in a significant reduction of $19.0 \pm 2.8 \mathrm{mmHg}(\mathrm{P}<0.0001 ; \mathrm{n}=7)$ compared to vehicle $(-1.3 \pm 1.1 \mathrm{mmHg} ; \mathrm{n}=10)$ (Fig. 1C). Cnr2 knockout mice only reduced blood pressure by $9.1 \pm 2.3 \mathrm{mmHg}(\mathrm{n}=6)$ similar to the changes measured with met-anandamide $(-7.3 \pm 2.6 ; n=6$; data not shown).

To exclude the possibility of the $\mathrm{CB} 1$ receptor, a highly selective $\mathrm{CB} 1$ receptor agonist, met-anandamide, was infused at the same dose $(6 \mathrm{mg} / \mathrm{kg})$ into a separate group of anesthetized mice (Figure 4-2). In these mice, there was nearly no change in the renal cortical perfusion following administration of met-anandamide ( $\Delta$ in perfusion units $=$ $3.6 \pm 12.0$ or $-0.7 \pm 1.9 \%$ from the baseline levels; $n=6$ mice) compared to the baseline levels. In addition, we examined the effect of SMM-295 using a genetic Cnr2 knockout mouse to confirm the selectivity of the CB2 receptor agonist (Figure 4-1B). Indeed, the change in cortical perfusion following intravascular administration of SMM-295 into the $\mathrm{Cnr} 2$ knockout mice resulted in an insignificant increase in perfusion units $(24.0 \pm 21.7)$ or $2.7 \pm 2.0 \%$ change from baseline levels ( $\mathrm{n}=6 \mathrm{mice})$. HU-308 $(6 \mathrm{mg} / \mathrm{kg})$, a selective CB2 agonist, was found to have a modest increase in renal cortical blood flow by $6.9 \pm$ $1.5 \%(\mathrm{P}<0.05 ; \mathrm{n}=6)$ demonstrating the role of the $\mathrm{CB} 2$ receptor in blood perfusion.

\section{CGRP Levels Following SMM-295 Infusion}

Plasma was isolated from blood collected from the renal vein to measure CGRP levels by ELISA (Figure 4-3A). In vehicle-treated mice, SMM-295 induced a significant increase $(\mathrm{P}=0.0068)$ in plasma CGRP by $44 \%$ to $64.5 \pm 3.9 \mathrm{ng} / \mathrm{L}(\mathrm{n}=6)$ from $44.7 \pm 2.2$ $\mathrm{ng} / \mathrm{L}(\mathrm{n}=6)$ in the vehicle treated mice.

To block the effects of CGRP release from afferent nerve terminals, capsaicin was applied to the renal nerves prior to the administration of SMM-295 into the anesthetized mice. Renal cortical perfusion was significantly lower $(\mathrm{P}<0.0001)$ at $38 \pm 9.7$ units (or $4.4 \pm 1.1 \%$ from baseline period; $n=6$ mice) following administration of SMM-295 (6 $\mathrm{mg} / \mathrm{kg}$ ) into the jugular vein compared to non-capsaicin treated mice (Figure 4-3B).

\section{Role of Cyclooxygenase and Nitric Oxide Synthase in CB2 Receptor Renal Perfusion}

To test whether cyclooxygenase products were involved in promoting the increase in cortical perfusion following stimulation of the $\mathrm{CB} 2$ receptor, we administered a single dose of indomethacin $(1 \mathrm{mg} / \mathrm{kg}$ IP) 20 minutes into the anesthetized mouse prior to injection of SMM-295 (6 mg/kg). The increase in cortical perfusion (131.5 +/- 8.6 units or $14.4+/-1.5 \%$ from baseline levels; $n=6$ ) by SMM-295 was not different in the presence of indomethacin compared to the SMM-295 group (Figure 4-4). As an alternate mode of action, we investigated whether nitric oxide could play a role in 


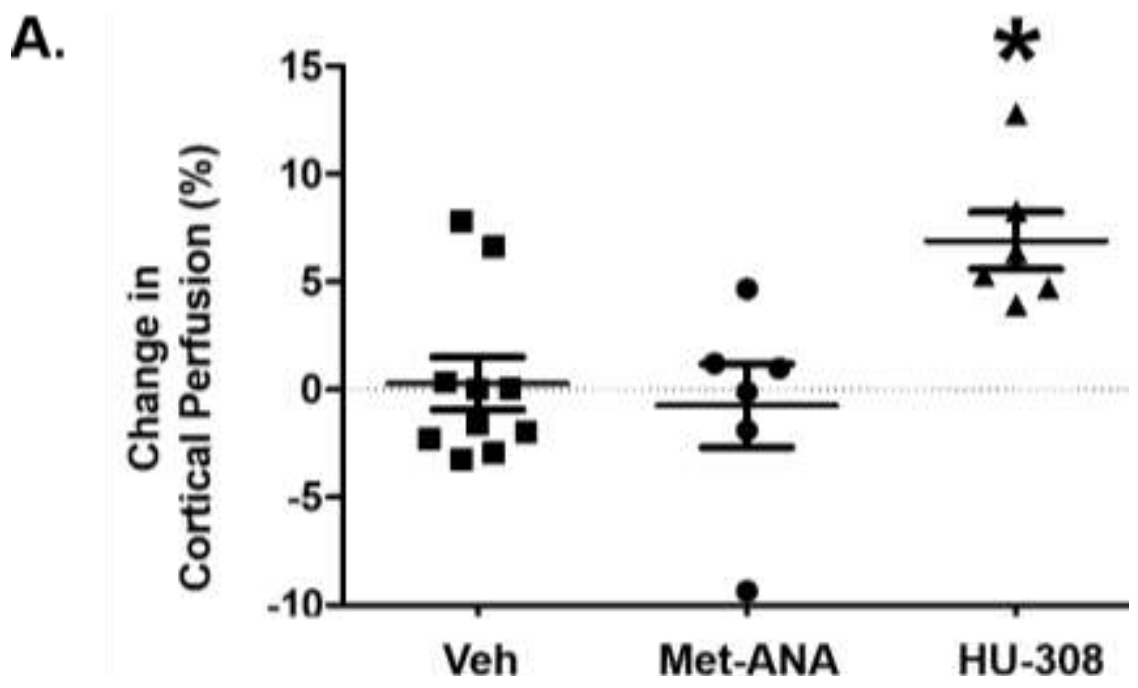

Figure 4-2. Increased cortical renal perfusion is not through the CB1 receptor Measurement of renal cortical perfusion by laser Doppler flowmetry following intravenous infusion of met-anandamide (Met-ANA; $6 \mathrm{mg} / \mathrm{kg}$; selective CB1 receptor agonist; $\mathrm{n}=6)$ and $\mathrm{HU}-308$ (6 mg/kg; selective $\mathrm{CB} 2$ receptor agonist; $\mathrm{n}=6)$ in anesthetized $\mathrm{C} 57 \mathrm{Bl} / 6 \mathrm{~J}$ mice. Data for the vehicle (control) was re-graphed from Figure 4-1 and was shown as a percent change from baseline levels in each mouse. ${ }^{*} \mathrm{P}<0.05$ significant different from control group.
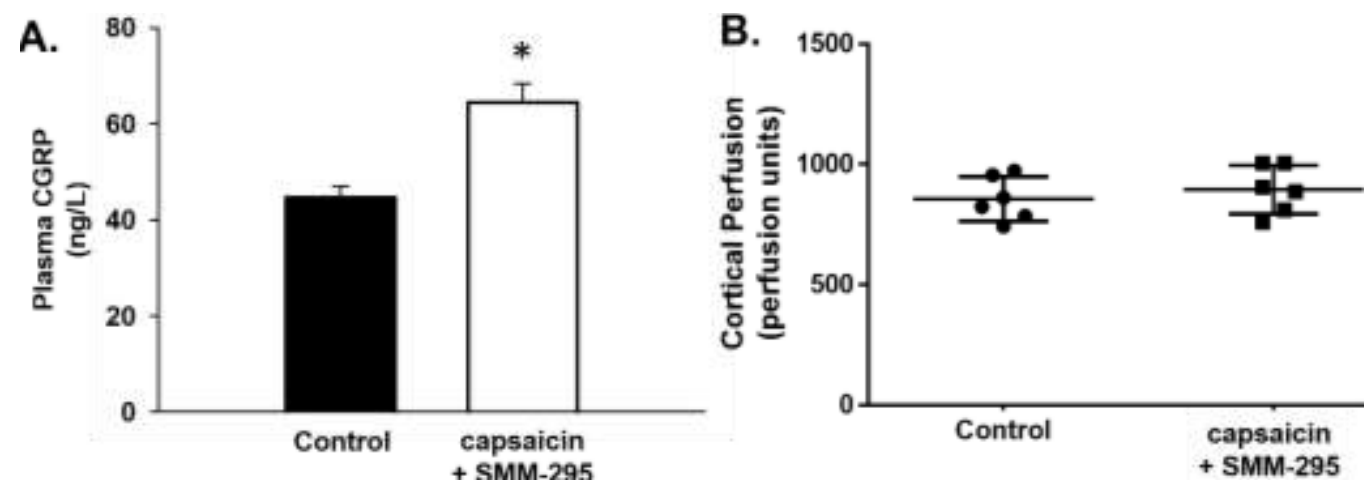

Figure 4-3. Renal afferent nerve activation is involved in CGRP release and increased cortical renal perfusion

(A)Plasma CGRP levels was measured by ELISA from C57BL/6J mice infused with either vehicle or SMM-295 (6 mg/kg). $\mathrm{n}=6$ mice per group. ${ }^{*} \mathrm{P}=0.0068$ significant difference between groups. (B) Measurement of renal cortical perfusion by laser Doppler flowmetry during control and SMM-295 $(6 \mathrm{mg} / \mathrm{kg})$ administration in mice treated with capsaicin to ablate renal afferent nerve activity. $\mathrm{N}=6$ mice per group. $\mathrm{P}<0.0001$ significant difference between groups. 


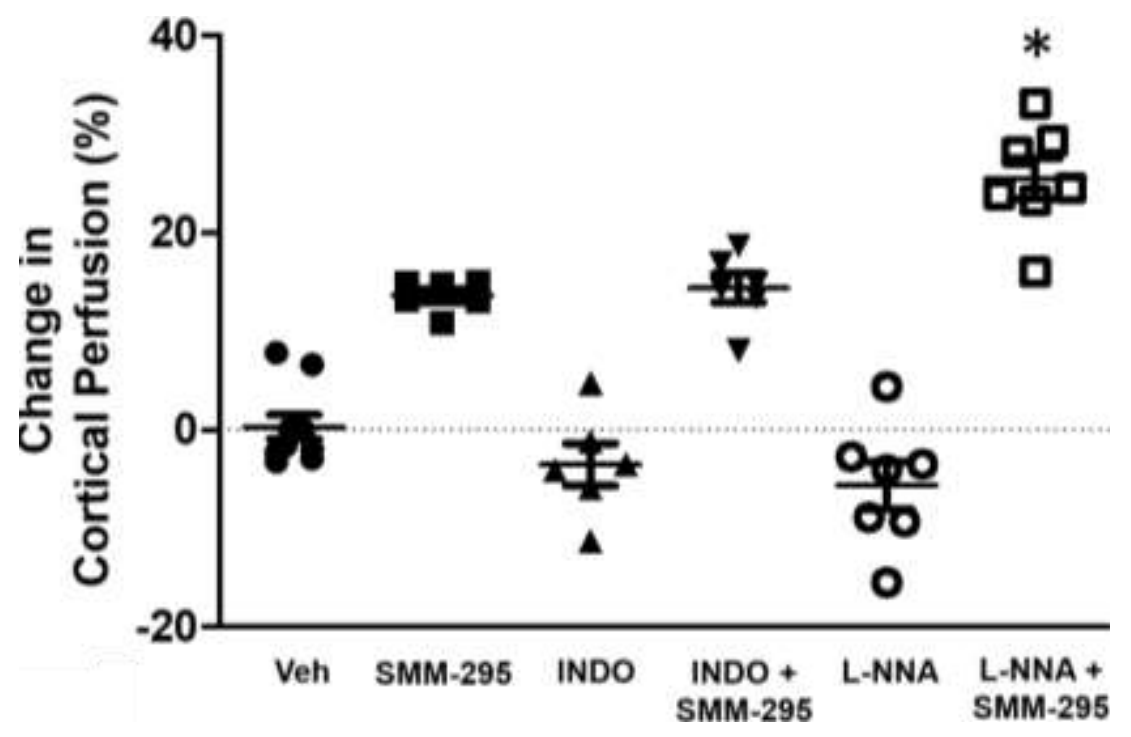

Figure 4-4. Endothelial derived factors COX and NOS are not involved with the increase in cortical renal perfusion following SMM-295 administration Change in cortical renal perfusion units using SMM-295 (6 mg/kg IV) as graphed by percent change from baseline levels following pre-treatment with indomethacin (INDO; 1 $\mathrm{mg} / \mathrm{kg} \mathrm{IP} ; \mathrm{n}=6)$ or L-NNA (10 mg/kg IP; $\mathrm{n}=7$ ) in $\mathrm{C} 57 \mathrm{Bl} / 6 \mathrm{~J}$ mice. $\mathrm{P}<0.01$ significant difference between LNNA and the other two groups. Data for the vehicle and SMM-295 was re-graphed from Figure 4-1 and was shown as a percent change from baseline levels in each mouse. 
controlling renal perfusion due to SMM-295. Similarly, blockade of nitric oxide synthase (NOS) was achieved using L-NNA pre-treatment 20 minutes prior to the administration of SMM-295 $(6 \mathrm{mg} / \mathrm{kg})$. The increase in the cortical perfusion promoted by SMM-295 was not reduced by the inhibition of NOS $(n=7)$, but it was significantly higher $(\mathrm{P}<0.01)$ than SMM-295 treated mice with either vehicle or indomethacin pre-treatment.

\section{SMM-295 Increases Luminal Diameter of Afferent Arterioles}

Afferent arterioles were isolated from the mouse and placed into a bath solution for perfusion to pressurize at $60 \mathrm{mmHg}$. Under these basal conditions, the luminal diameters were measured in the presence of the control solution at $12.9 \pm 0.41 \mu \mathrm{m}$ (Figure 4-5D). To determine whether SMM-295 promoted a vasoconstriction on the isolated afferent arterioles, SMM-295 $(5 \mu \mathrm{M})$ was applied to the bath solution and did not result in any changes in the luminal diameters during the two separate, but consecutive 15 -minute incubation periods. Both of the luminal diameters remained similar to the control period ( $13.19 \pm 0.42$ and $13.22 \pm 0.36 \mu \mathrm{m}$, respectively; $\mathrm{n}=4)$.

To test whether SMM-295 could dilate afferent arterioles, the vessels were preconstricted with norepinephrine (NE; $1 \mu \mathrm{M}$ ) for 15 minutes, followed by addition of either SMM-295 $(5 \mu \mathrm{M})$ in the bath solution (Figure 4-5F) or vehicle (Figure 4-5E) in the presence of NE $(1 \mu \mathrm{M})$. As shown in Fig. 4-5B, E, the luminal diameters of the afferent arterioles were significantly decreased $(\mathrm{P}=0.0019)$ from $12.71 \pm 0.83 \mu \mathrm{m}$ to 7.94 $\pm 0.73 \mu \mathrm{m}$ following application of $\mathrm{NE}(\mathrm{n}=4)$. The afferent arteriole remained constricted $8.06 \pm 0.64 \mu \mathrm{m}$ in a subsequent 15 -minute period with the vehicle. In the presence of SMM-295 $(5 \mu \mathrm{M})$, afferent arteriolar diameter significantly increased by $37 \pm 7 \%$ $(\mathrm{P}<0.0001)$ to $10.41 \pm 0.55 \mu \mathrm{m}$ from the NE pre-constricted state of $7.62 \pm 0.37 \mu \mathrm{m}$ (Figure 4-5E). All of the changes in the luminal diameter occurred within 5 min after the addition of each individual drug or combination of drugs.

\section{SMM-295 Effect on Cortical Renal Perfusion Following IRI}

In a separate group of $\mathrm{C} 57 \mathrm{Bl} / 6$ mice, bilateral ischemia-reperfusion injury was initiated and either vehicle or SMM-295 (6 mg/kg IP) was administered immediately after removal of the clamps to allow for reperfusion of the ischemic kidneys (Figure 4-6). Daily injections were made with either vehicle or SMM-295 for a period of 48 hours at which point the mice were anesthetized to measure the cortical perfusion. As shown in Figure 4-6, the sham-operated (no IRI) mice for a period of 48 hours exhibited cortical perfusion of $979.6 \pm 73.3$ units $(\mathrm{n}=6)$, which was considerably higher $(\mathrm{P}=0.0002)$ than the IRI-treated mice administered vehicle $(604.8 \pm 31.1$ units; $n=6)$. Administration of SMM-295 (6 mg/kg IP once a day) was measured to have cortical perfusion similar to the sham-operated mouse kidneys measurements (1005.9 \pm 62 units; $\mathrm{n}=6)$. 
A.

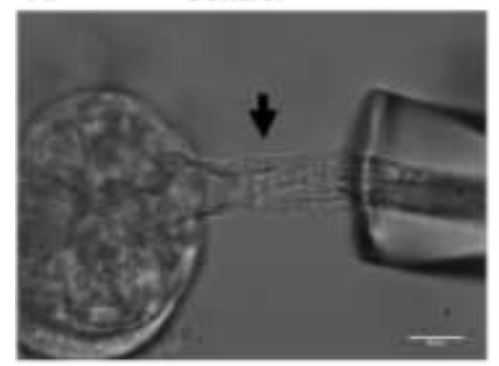

D.

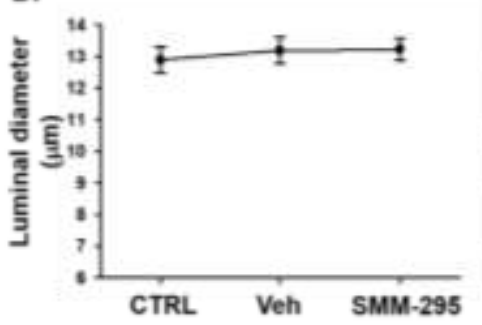

B.

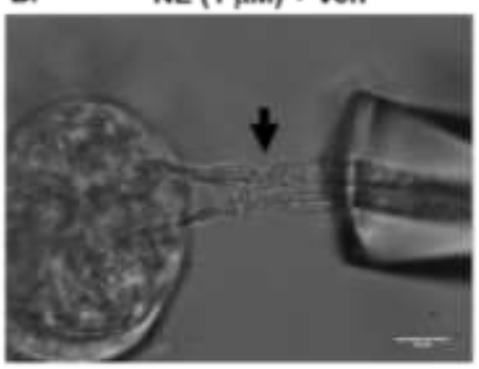

E.

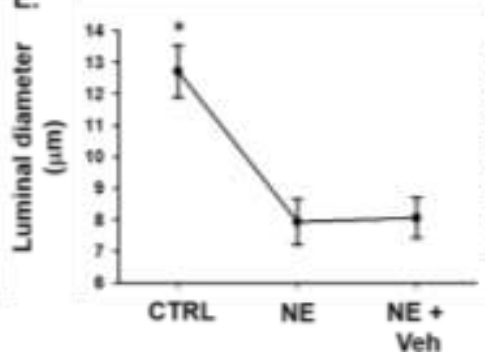

C. $N E(1 \mu M)+S M M-295(5 \mu M)$

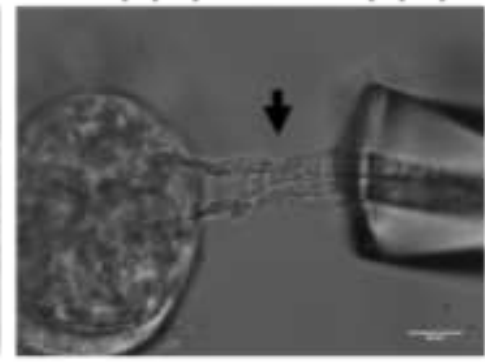

F.

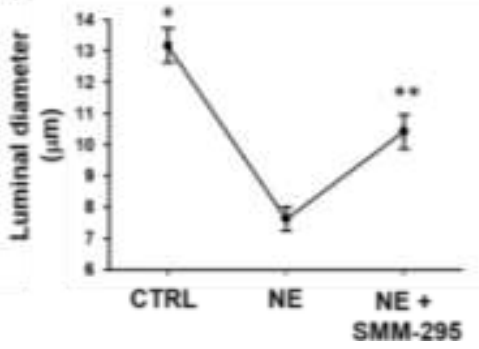

Figure 4-5. SMM-295 increases luminal diameter of pre-constricted isolated perfused afferent arterioles

Afferent arterioles were isolated from $\mathrm{C} 57 \mathrm{Bl} / 6$ mice and perfused to measure luminal diameter changes during basal, norepinephrine (NE; $1 \mu \mathrm{M})$ and SMM-295 (5 $\mu \mathrm{M})(\mathrm{A}-\mathrm{C})$ Representative images of the isolated afferent arterioles during (A) basal (control), (B) $\mathrm{NE}$, and (C) NE + SMM-295. (D-F) Graphical analyses of the luminal diameter changes, if any, during the following conditions: (D) SMM-295 incubation during 2 consecutive periods (15 minutes each period); (E) NE incubation during 2 consecutive periods (15 minutes each period); (F) NE incubation during the first period, and NE + SMM-295 during the second period. $\mathrm{N}=4$ arterioles per group. $* \mathrm{P}=0.0019$ significant difference between NE treatment with or without vehicle; $* * \mathrm{P}<0.001$ significant difference between $\mathrm{NE}$ alone and NE + SMM-295 groups. 


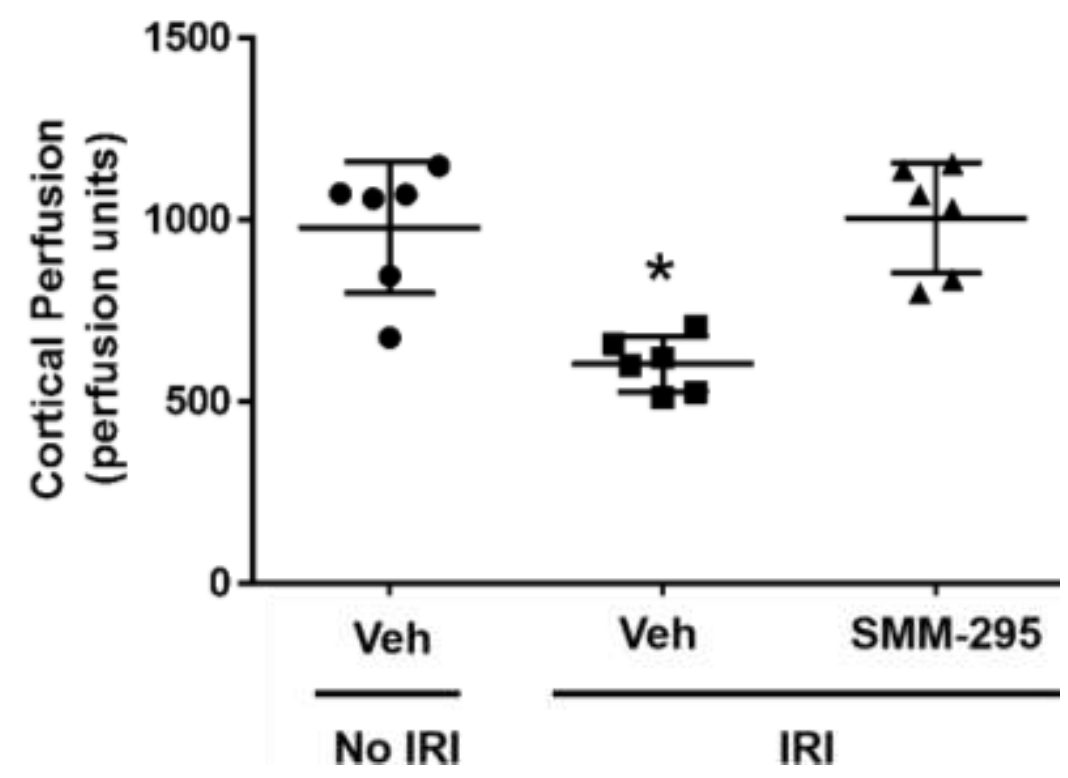

Figure 4-6. Daily administration of SMM-295 prevented the reduction in renal cortical perfusion following bilateral renal IRI

Renal cortical perfusion was measured using laser Doppler flowmetry in normal and IRItreated C57B1/6J mice ( $\mathrm{n}=6$ mice/group) administered vehicle or SMM-295 (6 mg/kg IP) every 24 hours for 2 days. $\mathrm{N}=6$ mice per group. $* \mathrm{P}=0.0002$ significant difference between the other two groups. 


\section{Discussion}

This is the first study to demonstrate that SMM-295, a novel selective cannabinoid CB2 receptor agonist, has the capability to increase renal cortical blood floand also promote direct vasodilation of isolated perfused afferent arterioles. Due to the absence of an effective and selective neutral CB2 receptor antagonist, our pharmacological findings were confirmed by evaluating our CB2 agonist in a genetic Cnr2 knockout mouse model on the C57B1/6J background. Previous studies have primarily investigated the effects of synthetic and endocannabinoids to control renal tubular and excretory function, but little was investigated regarding vascular effects (83). Early studies evaluating the biological function of the endocannabinoid, AEA, which has activity at both $\mathrm{CB} 1$ and $\mathrm{CB} 2$, show a putative vasodilator effect in the kidney leading to reduced renal vascular resistance $(90,92)$. These studies demonstrate that the primary receptor responsible for this effect was CB1 $(90,92)$, which is similar to other published studies using similar endogenous and synthetic cannabinoid receptor analogs to evaluate central and peripheral vascular bed regulation through the CB1 receptor (168).

Alternatively, there is evidence that AEA increased renal blood flow changes and urine excretion through a non-CB1 dependent mechanism (95). Conversely, there are conflicting studies that provide evidence that $\mathrm{CB} 1$ can have an opposite effect to produce vasoconstriction in the kidney (159) or no effect on renal hemodynamics (94). Similar to our results, Li and Wang (94) showed that renal cortical and medullary blood flow was non-responsive to direct intramedullary administration of a highly selective CB1 agonist, met-anandamide. Moreover, Koura et al. (90) could not fully explain the increased vasodilation of the afferent arteriole solely to the CB1 receptor but may have involved a non-CB1 receptor. This would be consistent with our findings where $\mathrm{CB} 2$ receptor stimulation with SMM-295 increased luminal diameter of the norepinephrine preconstricted isolated perfused afferent arterioles. The direct vasodilator effects by CB2 receptors has also been reported in other vascular beds, including the mesenteric arteries (169) and cerebral vasculature (170). It may be possible that other cannabinoid binding proteins, such as TRPV1, GPR18 or GPR55, could also indirectly be activated to increase their function to promote changes in the systemic and regional vasculature either alone or in concert with the non-CB1 receptors (171-173). However, there is evidence that GPR55 may have no effect on the anandamide-dependent vasodilation, at least in mesenteric arteries (172).

Using the intact kidney in the anesthetized mouse, we confirmed that there is increased renal cortical blood flow mediated by SMM-295 through the activation of the $\mathrm{CB} 2$, but not the $\mathrm{CB} 1$ receptor. This effect may be attributed to dilation of peripheral blood vessels on $\mathrm{CB} 2$ receptors, including those in the kidney, since a marked reduction in mean arterial pressure was associated with the increased renal perfusion mediated by SMM-295. Moreover, there was a lesser increase in renal perfusion by SMM-295 in Cnr2 knockout mice with reduced change in blood pressure. In previous studies and in our present study, the $\mathrm{CB} 1$ receptor stimulation reduces blood pressure using specific agonists either by direct vascular effect or vagal stimulation $(94,174)$, but there is no change in renal cortical perfusion (94). 
Moreover, the effect of SMM-295 to mediate this effect may not be solely due to its effects within the kidney but contributed by sensory nerve activation outside of the kidney. Prior studies showed that drugs non-selective at CB1/CB2, such as $\triangle 9-T H C$ and WIN 55,212-2, can augment release of CGRP $(175,176)$, which can promote rat mesenteric arterial bed dilation (176). Other studies showed that CB2 receptors can mediate the release CGRP for attenuation of osteoarthritic knee joint pain and in the rat spinal cord $(177,178)$, but these effects may not be universally confirmed (179). In our study, SMM-295 produces an increase in calcitonin gene-related peptide (CGRP) levels from blood collected immediately flowing out of the renal vein. CGRP is known to be a potent vasodilator and released at the nerve terminals of sensory nerves to regulate blood vessel tone $(180,181)$. The mechanisms by which CGRP can promote vasorelaxation remains to be fully understood, but it has been suggested that the primary mode of action is through a cAMP-dependent activation of protein kinase A (PKA) to open potassium $(\mathrm{K}+)$ ion channels $(180,181)$. The subsequent hyperpolarization of the cell membrane leads to dilation of the smooth muscle cells surrounding the blood vessels. This may be the mode of action in the kidney, since we were unable to determine any reduction in blood flow by pre-treating the mice with either indomethacin or L-NNA to prevent the production of vasodilator prostaglandins and nitric oxide, respectively. Previous studies have documented that CGRP may activate other second messenger systems to increase the production and release of nitric oxide $(180,181)$. Further studies will be needed to ascertain the mechanism by which CB2 receptor activation of the sensory nerves leading to the kidneys regulate cortical hemodynamics.

\section{Perspectives and Conclusion}

With the increasing societal acceptance in drugs that activate cannabinoid receptors for medicinal use, it is essential to better understand the biological function of these receptors, particularly the $\mathrm{CB} 2$ receptor in the control of renal function. In the kidney, there is increasing data to demonstrate that activation of the CB2, and not CB1 receptor, can play a crucial role in protecting renal tubular and vascular cells during acute injury or chronic disease states (83). Moreover, the negative psychotropic effects of cannabinoid receptor activation is exclusive to the $\mathrm{CB} 1$ receptor. For this reason, the development of $\mathrm{CB} 2$ receptor agonists remains an area of intense research. A recent review of the commercially available $\mathrm{CB} 2$ agonists re-validated for their selectivity and efficacy to identify only a handful of CB2 agonists as "gold standard" (182). Even the most optimal CB2 receptor agonists have their limitations in terms of their selectivity, high metabolism in vivo, and lack of testing for their efficacy in animal models in vivo. Our recent work using our newly synthesized CB2 receptor agonist, SMM-295, demonstrated a protective effect to reduce renal tubular epithelial cells damage following AKI by decreasing apoptotic signaling (93). The current study builds upon our knowledge about SMM-295 by showing its ability to increase renal cortical perfusion and promote afferent arteriolar dilation. Further studies are needed, however, to better understand the role of $\mathrm{CB} 2$ receptors in the regulation of blood flow distribution in the 
kidney between the renal cortex and medulla, and also whether there are direct effects to control GFR.

In conclusion, our study has provided the first evidence for CB2 receptor activation to promote increased renal perfusion, and this receptor should be further evaluated in pre-clinical studies for its beneficial effects in other acute and chronic disease models of the kidney. 


\section{CHAPTER 5. DISCUSSION}

Researchers have been studying the cannabinoid system for decades to understand their role in homeostatic and disease mechanisms throughout the body. To optimize the use of cannabinoid receptor binding compounds to promote beneficial effects in the kidney, a plethora of synthetic cannabinoids have been designed and synthesized for testing in the kidney and other organs. These compounds have various selectivity and activity at both the $\mathrm{CB} 1$ and $\mathrm{CB} 2$ receptors having different effects depending on the compound structure. Our studies focus on a novel CB2 selective agonist SMM-295 which displays unique properties compared to conventional synthetic CB2 agonists, JWH-133, and HU-308. Our study functions to contribute to the increasing volume of knowledge into how the cannabinoid system plays a role in renal function and repair from injury and categorizes the effects of the novel compound SMM-295 administered following IRI.

SMM-295 demonstrated an ability to decrease injury and increase renal function following IRI by decreasing the apoptosis levels in tubular epithelial cells through activation of $\mathrm{CB} 2$. Our initial investigation into the effects of $\mathrm{CB} 2$ activation was justified by several studies demonstrating a protective effect of CB2 agonists in AKI (7683). Our results proved consistent with these studies using a novel CB2 agonist, SMM295. The CB2 receptor can activate PLC which activate AKT leading to increased cell survival though activation of anti-apoptotic cascades $(145,146)$. In our studies, apoptosis was decreased by an associated increase in AKT signaling of BCL-2 family of proteins, which are known to stabilize the mitochondrial membrane preventing the release of cytochrome c, which initiates apoptotic pathways. $(147,148)$. Apoptosis is a primary mechanism of cell death in tubular epithelial cells in response to ischemic injury as well as other types of AKI $(183,184)$, including nephrotoxic insults that can be detected by measuring indicators, such as caspases and p53 levels at various early time points upon exposure to the injury stimuli (2). Our data demonstrate that SMM-295 is a moderately selective agonist of CB2 with comparable affinity, potency, and efficacy to other CB2 ligands (e.g., AM-1241, HU-910, and LEI-101) which have previously been evaluated in kidney disease models (76-82). Future studies aimed at determining the full cascade leading to a reduction in apoptosis could uncover novel potential targets for future studies and therapeutic applications. Additionally, consequent studies should also investigate the effectiveness of SMM-295 in other models of renal injury, including cisplatin and sepsisinduced AKI.

While this effect can explain the decrease in tubular damage following ischemic injury in SMM-295 treated mice, we recognized that there also could be a hemodynamic effect driving the increases in renal function seen in these mice. Increases in renal perfusion and subsequently, GFR provides an additional mechanism to protect tubular epithelial cells from injury. Restoration of renal blood flow and increased oxygen through increased blood supply provides relief to injured cells that are acting to survive and contribute to renal function following the insult. Increases in renal perfusion lead to increases in medullary oxygen levels (185). This region is particularly susceptible to hypoxia and damage in this region can lead to increasing and persistent hypoxic 
conditions following injury (2). Our novel compound provides protection from apoptosis by a direct effect on proximal tubule cells and indirectly through increased renal perfusion. These effects could potentially provide a synergistic role in preventing renal damage and maintaining renal function following injury. There are other clinical studies being developed to target either the blockade of apoptosis or increase renal perfusion, but not concurrently, to determine their effectiveness as a treatment modality for AKI (186).

Our data confirmed that there is increased renal cortical blood flow mediated by SMM-295 through the selective activation of CB2. Mean arterial pressure also reduced with SMM-295 administration indicating the effect of increased renal perfusion by SMM-295. Other studies have demonstrated cardiovascular effects of both CB1 and CB2 agonists, which can lead to dilation of peripheral blood vessels in the kidney as well as other organs in the body $(90,92,94,95,159,169,170,187)$. These studies, however, showed this effect was caused by CB1 and non-CB1/2 mechanisms. Our study also demonstrates that SMM-295 produces an increase in CGRP consistent with other studies that demonstrate nonselective $\mathrm{CB} 1 / \mathrm{CB} 2$ agonists can cause changes to CGRP release promoting vasodilation $(175,176)$. Vasodilation of renal arterioles led to an increase in renal perfusion in our study which could prove beneficial in treating AKI by possibly increasing GFR. AKI is defined by a sudden decrease in GFR and thus increasing GFR should be the goal for treatment of AKI in the clinical setting. The increase in renal perfusion demonstrated in our study could alter GFR, however, this was not a parameter that was directly measured. It is possible that SMM-295 does not affect GFR, but only blood flow dynamics, due to regulatory mechanisms that underlie the control of GFR, such as concurrent vasodilation of efferent arterioles (2).

While multiple CB2 agonists have demonstrated beneficial effects in AKI, SMM295 is the first compound that also demonstrates beneficial effects on renal hemodynamics. This unique property of SMM-295 may be attributed to the differential ability of different CB2 agonists to bind to various active states of the CB2 receptor. This concept is known as biased signaling or functional selectivity and is an emerging area of interest being incorporated into drug design (108). The idea is that GPCRs have various active and inactive confirmations that they are cycling through randomly even if just by Brownian motion (188). Each of these active or inactive confirmations have specific binding pockets that can preferentially bind to different molecules (i.e., antagonists, agonists, and inverse agonists) leading to stabilization of the confirmation. These different active confirmations also have different signaling outputs, whether it be through mechanisms like cyclic AMP, GIRK activation, GTPase activity or receptor internalization through $\beta$-arrestin recruitment (189). Therefore, different therapeutics aimed at a particular receptor can be investigated for their ability to interact with specific active or inactive states stabilizing these confirmations in leading to particular downstream effectors of interest. In unpublished data our lab demonstrated that HU-308 had no effect on renal perfusion or blood pressure. This could be because HU-308 is known to have preference for GIRK channels while other CB2 agonists like SMM-295 and JWH-133 have not been established to show GIRK activity (100). Therefore, the effect seen by SMM-295 is established through other mechanisms outside of a potassium channel opening. Furthermore, the mechanism through which SMM-295 could impact 
renal hemodynamics may be even more complicated than first assumed. Cannabinoid receptors are known to dimerize with other receptors, notably dopamine receptors, and this dimerization could be the effector stimulus on the sensory nerves that could drive the changes seen in renal hemodynamics (190). Future studies should act to employ multiple methods including western bot analysis, ELISA, and FRET analysis will identify the ability of novel CB2 agonists to respond through different signaling outputs including cAMP accumulation, ERK phosphorylation, GIRK activation, GTP $\gamma \mathrm{S}$ binding, and $\beta$ arrestin recruitment $(191,192)$. Future studies investigating the functional selectivity of SMM-295 compared to other CB2 agonists will enhance our understanding of the behavior of these compounds at CB2 and enable the development of novel agonists designed to address multiple disease state pathologies.

Interestingly, during our studies monitoring renal perfusion, we notice that blood pressure also decreases in response SMM-295. Administration of SMM-295 to Cnr2 $2^{-/-}$ mice resulted in a decrease in blood pressure, but this decrease was only half of the magnitude seen in WT mice. There may be in fact multiple mechanisms governing systemic hemodynamics mediated by CB2 activation that could include off target effects and possibly activation of other cannabinoid targets, such as the hypothesized endothelial cannabinoid receptor, $\mathrm{CBe}$, that could be implicated in systemic blood pressure regulation (193-195). Additionally, while SMM-295 has increased selectivity for CB2 over CB1, SMM-295 still has some activity at CB1. It is known that THC which has activity at both $\mathrm{CB} 1$ and $\mathrm{CB} 2$ can decrease blood pressure (187). In animals that lack the CB2, SMM-295 may still retain activity at CB1 which is known to have hemodynamic effects in the body that could explain the effect seen in the $\mathrm{Cnr}^{-/-}$mice (187). Therefore, the hypotensive effects of THC may in fact be due to both CB1 and CB2 activity instead of CB1 activity alone based on the data in our studies. Further studies should be aimed at uncovering the full mechanism of the effect of SMM-295 on systemic blood pressure. More interestingly, while the effect on renal blood flow can be blocked by ablation of the renal nerve, the blood pressure decreasing effect of SMM-295 remains intact. This may be due to differences in CB2 receptor expression between cells of different tissues (196, 197). At present, there is limited data pertaining to the expression patterns of CB2 receptors due to inadequate tools to detect the receptor. However, a recent paper described the invention of a novel transgenic mouse model which expresses eGFP under the same promoter as Cnr2 (198). This mouse model is novel in that it enables scientists to determine in real time the expression of CB2 within different cell types by simply detecting fluorescent levels corresponding to eGFP expression. Therefore, we can better answer what cell types express CB2 and how this expression pattern changes in models of disease. Further understanding of these alternate modes of action may provide greater insight into the systemic effects of SMM-295 on blood pressure through the effects of CB2 activation.

In conclusion, this body of work demonstrates a beneficial effect of CB2 activation following IRI. Additionally, the novel CB2 selective agonist, SMM-295, provides additional benefits over current commercially available CB2 agonists. The employment of various CB2 agonists with various functional properties in AKI may be required in the clinic due to different properties of the drugs to mitigate the effects of 
AKI. For example, patients who experience AKI that have compromised cardiac function would benefit from a CB2 agonist that does not decrease blood pressure like SMM-295.

Therefore, we need more data about different and novel CB2 agonists to treat AKI using exogenous cannabinoid system activation effectively. Our studies along with future investigation of the localized effects of CB2 agonists throughout the body will continue to provide the crucial foundation for the use of therapeutics targeting the cannabinoid system which is becoming a rapidly evolving area of interest in various renal pathologies including AKI. 


\section{LIST OF REFERENCES}

1. Kriz, W., and Elger, M. (2014) Renal anatomy. SPEC-Comprehensive Clinical Nephrology, 12-Month Access, eBook, 1

2. Bonventre, J. V., and Yang, L. (2011) Cellular pathophysiology of ischemic acute kidney injury. The Journal of clinical investigation 121, 4210-4221

3. Edelstein, C. L. (2016) Biomarkers of kidney disease, Academic press

4. Mehta, R. L., and Chertow, G. M. (2003) Acute renal failure definitions and classification: time for change? Journal of the American Society of Nephrology 14, 2178-2187

5. Coca, S., Yalavarthy, R., Concato, J., and Parikh, C. (2008) Biomarkers for the diagnosis and risk stratification of acute kidney injury: a systematic review. Kidney international 73, 1008-1016

6. Basile, D. P., Anderson, M. D., and Sutton, T. A. (2012) Pathophysiology of acute kidney injury. Comprehensive Physiology 2, 1303-1353

7. Matejovic, M., Ince, C., Chawla, L. S., Blantz, R., Molitoris, B. A., Rosner, M. H., Okusa, M. D., Kellum, J. A., and Ronco, C. (2016) Renal hemodynamics in AKI: in search of new treatment targets. Journal of the American Society of Nephrology 27, 49-58

8. Thadhani, R. (1996) pascual M, Bonventre Jv. Acute renal failure. N Engl J Med 334, 1448-1460

9. Molitoris, B. A., and Finn, F. (2001) Acute renal failure: a companion to Brenner and Rector's The kidney, WB Saunders Company

10. Hegarty, N. J., Young, L. S., Kirwan, C. N., O'Neill, A. J., Bouchier-Hayes, D. M., Sweeney, P., Watson, R. W. G., and Fitzpatrick, J. M. (2001) Nitric oxide in unilateral ureteral obstruction: effect on regional renal blood flow. Kidney international 59, 1059-1065

11. Ichikawa, I., Kiyama, S., and Yoshioka, T. (1994) Renal antioxidant enzymes: their regulation and function. Kidney international 45, 1-9

12. Jensen, A. M., Nørregaard, R., Topcu, S. O., Frøkiær, J., and Pedersen, M. (2009) Oxygen tension correlates with regional blood flow in obstructed rat kidney. Journal of experimental biology 212, 3156-3163

13. Siegel, N. J., Feldman, R. A., Lytton, B., Hayslett, J. P., and Kashgarian, M. (1977) Renal cortical blood flow distribution in obstructive nephropathy in rats. Circulation research 40, 379-384

14. Wahlberg, J., KARLBERG, L., and PERSSON, A. E. G. (1984) Total and regional renal blood flow during complete unilateral ureteral obstruction. Acta physiologica scandinavica 121, 111-118

15. Choudhury, D., and Ahmed, Z. (2006) Drug-associated renal dysfunction and injury. Nature Reviews Nephrology 2, 80

16. Sutton, T. A., Fisher, C. J., and Molitoris, B. A. (2002) Microvascular endothelial injury and dysfunction during ischemic acute renal failure. Kidney international 62, 1539-1549

17. Siegel, N. J., Devarajan, P., and Van Why, S. (1994) Renal cell injury: metabolic and structural alterations. Pediatric research 36, 129 
18. Lee, S. A., Noel, S., Sadasivam, M., Hamad, A. R. A., and Rabb, H. (2017) Role of Immune Cells in Acute Kidney Injury and Repair. Nephron 137, 282-286

19. Kaushal, G. P., Kaushal, V., Hong, X., and Shah, S. V. (2001) Role and regulation of activation of caspases in cisplatin-induced injury to renal tubular epithelial cells. Kidney international 60, 1726-1736

20. Donnahoo, K. K., Meng, X., Ayala, A., Cain, M. P., Harken, A. H., and Meldrum, D. R. (1999) Early kidney TNF- $\alpha$ expression mediates neutrophil infiltration and injury after renal ischemia-reperfusion. American Journal of PhysiologyRegulatory, Integrative and Comparative Physiology 277, R922-R929

21. Kelly, K., Williams, W. W., Colvin, R. B., and Bonventre, J. V. (1994) Antibody to intercellular adhesion molecule 1 protects the kidney against ischemic injury.

Proceedings of the National Academy of Sciences 91, 812-816

22. Rabb, H., Mendiola, C. C., Saba, S. R., Dietz, J. R., Smith, C. W., Bonventre, J. V., and Ramirez, G. (1995) Antibodies to ICAM-1 protect kidneys in severe ischemic reperfusion injury. Biochemical and biophysical research communications 211, 67-73

23. Ysebaert, D. K., De Greef, K. E., Vercauteren, S. R., Ghielli, M., Verpooten, G. A., Eyskens, E. J., and De Broe, M. E. (2000) Identification and kinetics of leukocytes after severe ischaemia/reperfusion renal injury. Nephrology Dialysis Transplantation 15, 1562-1574

24. Nony, P. A., and Schnellmann, R. G. (2003) Mechanisms of renal cell repair and regeneration after acute renal failure. Journal of Pharmacology and Experimental Therapeutics 304, 905-912

25. Harris, R. C. (1997) Growth factors and cytokines in acute renal failure. Advances in renal replacement therapy 4, 43-53

26. Hollenberg, N., Epstein, M., Rosen, S., Basch, R., Oken, D., and Merrill, J. (1968) Acute oliguric renal failure in man: evidence for preferential renal cortical ischemia. Medicine 47, 455-474

27. Hellberg, P., Kallskog, O. T., Ojteg, G., and Wolgast, M. (1990) Peritubular capillary permeability and intravascular RBC aggregation after ischemia: effects of neutrophils. American Journal of Physiology-Renal Physiology 258, F1018F1025

28. Dagher, P. C. (2004) Apoptosis in ischemic renal injury: roles of GTP depletion and p53. Kidney international 66, 506-509

29. Conger, J. D., Robinette, J. B., and Guggenheim, S. J. (1981) Effect of acetylcholine on the early phase of reversible norepinephrine-induced acute renal failure. Kidney international 19, 399-409

30. Fujii, T., Kurata, H., Takaoka, M., Muraoka, T., Fujisawa, Y., Shokoji, T., Nishiyama, A., Abe, Y., and Matsumura, Y. (2003) The role of renal sympathetic nervous system in the pathogenesis of ischemic acute renal failure. European journal of pharmacology 481, 241-248

31. Salman, I. M., Ameer, O. Z., Sattar, M. A., Abdullah, N. A., Yam, M. F., Najim, H. S., Khan, M. A. H., and Johns, E. J. (2010) Role of the renal sympathetic nervous system in mediating renal ischaemic injury-induced reductions in renal haemodynamic and excretory functions. Pathology 42, 259-266 
32. Wang, W., Falk, S. A., Jittikanont, S., Gengaro, P. E., Edelstein, C. L., and Schrier, R. W. (2002) Protective effect of renal denervation on normotensive endotoxemia-induced acute renal failure (ARF) in mice. American Journal of Physiology-Renal Physiology

33. Arora, P., Rajagopalam, S., Ranjan, R., Kolli, H., Singh, M., Venuto, R., and Lohr, J. (2008) Preoperative use of angiotensin-converting enzyme inhibitors/angiotensin receptor blockers is associated with increased risk for acute kidney injury after cardiovascular surgery. Clinical Journal of the American Society of Nephrology 3, 1266-1273

34. Chaumont, M., Pourcelet, A., van Nuffelen, M., Racapé, J., Leeman, M., and Hougardy, J. M. (2016) Acute Kidney Injury in Elderly Patients With Chronic Kidney Disease: Do Angiotensin-Converting Enzyme Inhibitors Carry a Risk? The Journal of Clinical Hypertension 18, 514-521

35. Sreedharan, R., Devarajan, P., and Van Why, S. K. (2009) Pathogenesis of acute renal failure. Pediatric Nephrology: Sixth Completely Revised, Updated and Enlarged Edition, 1579-1602

36. Sharma, N., Anders, H.-J., and Gaikwad, A. B. (2019) Fiend and friend in the renin angiotensin system: An insight on acute kidney injury. Biomedicine \& Pharmacotherapy 110, 764-774

37. Borthwick, E., and Ferguson, A. (2010) Perioperative acute kidney injury: risk factors, recognition, management, and outcomes. Bmj 341, c3365

38. Brezis, M., and Rosen, S. (1995) Hypoxia of the renal medulla - its implications for disease. New England Journal of Medicine 332, 647-655

39. Kerr, J. F., Wyllie, A. H., and Currie, A. R. (1972) Apoptosis: a basic biological phenomenon with wide-ranging implications in tissue kinetics. British journal of cancer 26, 239-257

40. Ortiz, A., Lorz, C., and Egido, J. (1999) The Fas ligand/Fas system in renal injury. Nephrology, dialysis, transplantation : official publication of the European Dialysis and Transplant Association - European Renal Association 14, 1831-1834

41. Padanilam, B. J. (2003) Cell death induced by acute renal injury: a perspective on the contributions of apoptosis and necrosis. American journal of physiology. Renal physiology 284, F608-627

42. Ueda, N., Kaushal, G. P., and Shah, S. V. (2000) Apoptotic mechanisms in acute renal failure. The American journal of medicine 108, 403-415

43. Chiang-Ting, C., Tzu-Ching, C., Ching-Yi, T., Song-Kuen, S., and Ming-Kuen, L. (2005) Adenovirus-mediated bcl-2 gene transfer inhibits renal ischemia/reperfusion induced tubular oxidative stress and apoptosis. American journal of transplantation 5, 1194-1203

44. Sikorski, E. M., Hock, T., Hill-Kapturczak, N., and Agarwal, A. (2004) The story so far: molecular regulation of the heme oxygenase-1 gene in renal injury. American Journal of Physiology-Renal Physiology 286, F425-F441

45. Agarwal, A., Balla, J., Alam, J., Croatt, A. J., and Nath, K. A. (1995) Induction of heme oxygenase in toxic renal injury: a protective role in cisplatin nephrotoxicity in the rat. Kidney international 48, 1298-1307

46. Nath, K. A., Haggard, J. J., Croatt, A. J., Grande, J. P., Poss, K. D., and Alam, J. (2000) The indispensability of heme oxygenase-1 in protecting against acute 
heme protein-induced toxicity in vivo. The American journal of pathology 156, 1527-1535

47. Maines, M., Mayer, R., Ewing, J., and McCoubrey, W. (1993) Induction of kidney heme oxygenase-1 (HSP32) mRNA and protein by ischemia/reperfusion: possible role of heme as both promotor of tissue damage and regulator of HSP32. Journal of Pharmacology and Experimental Therapeutics 264, 457-462

48. Tracz, M. J., Juncos, J. P., Grande, J. P., Croatt, A. J., Ackerman, A. W., Rajagopalan, G., Knutson, K. L., Badley, A. D., Griffin, M. D., and Alam, J. (2007) Renal hemodynamic, inflammatory, and apoptotic responses to lipopolysaccharide in HO-1-/- mice. The American journal of pathology $\mathbf{1 7 0}$, $1820-1830$

49. Liu, M., Grigoryev, D. N., Crow, M. T., Haas, M., Yamamoto, M., Reddy, S. P., and Rabb, H. (2009) Transcription factor Nrf2 is protective during ischemic and nephrotoxic acute kidney injury in mice. Kidney international 76, 277-285

50. López-Novoa, J. M. (1999) Potential role of platelet activating factor in acute renal failure. Kidney international 55, 1672-1682

51. Shimizu, H., Takahashi, T., Suzuki, T., Yamasaki, A., Fujiwara, T., Odaka, Y., Hirakawa, M., Fujita, H., and Akagi, R. (2000) Protective effect of heme oxygenase induction in ischemic acute renal failure. Critical care medicine $\mathbf{2 8}$, 809-817

52. Nath, K. A. (2006) Heme oxygenase-1: a provenance for cytoprotective pathways in the kidney and other tissues. Kidney international 70, 432-443

53. Nath, K. A., and Norby, S. M. (2000) Reactive oxygen species and acute renal failure. The American journal of medicine 109, 665-678

54. Bidmon, B., Endemann, M., Müller, T., Arbeiter, K., Herkner, K., and Aufricht, C. (2000) Heat shock protein-70 repairs proximal tubule structure after renal ischemia. Kidney international 58, 2400-2407

55. Du, C., Guan, Q., Yin, Z., Zhong, R., and Jevnikar, A. M. (2005) IL-2-mediated apoptosis of kidney tubular epithelial cells is regulated by the caspase- 8 inhibitor c-FLIP. Kidney international 67, 1397-1409

56. Gopalakrishnan, S., Hallett, M. A., Atkinson, S. J., and Marrs, J. A. (2003) Differential regulation of junctional complex assembly in renal epithelial cell lines. American Journal of Physiology-Cell Physiology 285, C102-C111

57. Ruchalski, K., Mao, H., Singh, S. K., Wang, Y. D., Mosser, D., Li, F. H., Schwartz, J. H., and Borkan, S. C. (2003) HSP72 inhibits apoptosis-inducing factor release in ATP depleted renal epithelial cells. American Journal of Physiology-Cell Physiology

58. Havasi, A., Li, Z., Wang, Z., Martin, J. L., Botla, V., Ruchalski, K., Schwartz, J. H., and Borkan, S. C. (2008) Hsp27 inhibits Bax activation and apoptosis via a phosphatidylinositol 3-kinase-dependent mechanism. Journal of Biological Chemistry 283, 12305-12313

59. Guo, S., Wharton, W., Moseley, P., and Shi, H. (2007) Heat shock protein 70 regulates cellular redox status by modulating glutathione-related enzyme activities. Cell stress \& chaperones 12, 245

60. Pritchard, K. A., Ackerman, A. W., Gross, E. R., Stepp, D. W., Shi, Y., Fontana, J. T., Baker, J. E., and Sessa, W. C. (2001) Heat shock protein 90 mediates the 
balance of nitric oxide and superoxide anion from endothelial nitric-oxide synthase. Journal of Biological Chemistry 276, 17621-17624

61. Safirstein, R. (1997) Renal stress response and acute renal failure. Advances in renal replacement therapy $4,38-42$

62. di Mari, J. F., Davis, R., and Safirstein, R. L. (1999) MAPK activation determines renal epithelial cell survival during oxidative injury. American Journal of Physiology-Renal Physiology 277, F195-F203

63. Arany, I., Megyesi, J. K., Kaneto, H., Tanaka, S., and Safirstein, R. L. (2004) Activation of ERK or inhibition of JNK ameliorates H2O2 cytotoxicity in mouse renal proximal tubule cells. Kidney international 65, 1231-1239

64. Ishizuka, S., Yano, T., Hagiwara, K., Sone, M., Nihei, H., Ozasa, H., and Horikawa, S. (1999) Extracellular signal-regulated kinase mediates renal regeneration in rats with myoglobinuric acute renal injury. Biochemical and biophysical research communications 254, 88-92

65. Zhuang, S., and Schnellmann, R. G. (2006) A death-promoting role for extracellular signal-regulated kinase. Journal of Pharmacology and Experimental Therapeutics 319, 991-997

66. Norman, J., Badie-Dezfooly, B., Nord, E. P., Kurtz, I., Schlosser, J., Chaudhari, A., and Fine, L. G. (1987) EGF-induced mitogenesis in proximal tubular cells: potentiation by angiotensin II. American Journal of Physiology-Renal Physiology 253, F299-F309

67. Stracke, S., Ernst, F., Jehle, D. R., Grunewald, R. W., Haller, H., Keller, F., and Jehle, P. M. (1998) Differentiating and proliferative effects of HGF in renal proximal tubular cells are mediated via different signalling pathways. Nephrology, dialysis, transplantation: official publication of the European Dialysis and Transplant Association-European Renal Association 13, 1398-1405

68. Zhang, G., Ichimura, T., Wallin, A., Kan, M., and Stevens, J. L. (1991) Regulation of rat proximal tubule epithelial cell growth by fibroblast growth factors, insulin-like growth factor- 1 and transforming growth factor- $\beta$, and analysis of fibroblast growth factors in rat kidney. Journal of cellular physiology 148, 295-305

69. Blazer-Yost, B. L., Watanabe, M., Haverty, T. P., and Ziyadeh, F. N. (1992) Role of insulin and IGF1 receptors in proliferation of cultured renal proximal tubule cells. Biochimica et Biophysica Acta (BBA)-Molecular Cell Research 1133, 329335

70. Hirschberg, R., Kopple, J., Lipsett, P., Benjamin, E., Minei, J., Albertson, T., Munger, M., Metzler, M., Zaloga, G., and Murray, M. (1999) Multicenter clinical trial of recombinant human insulin-like growth factor I in patients with acute renal failure. Kidney international 55, 2423-2432

71. Park, F. (2015) Activators of G protein signaling in the kidney. The Journal of pharmacology and experimental therapeutics 353, 235-245

72. Pressly, J. D., Hama, T., Brien, S. O., Regner, K. R., and Park, F. (2017) TRIP13deficient tubular epithelial cells are susceptible to apoptosis following acute kidney injury. Scientific reports 7, 43196

73. Huang, Z., Wu, L., and Chen, L. (2018) Apelin/APJ system: A novel potential therapy target for kidney disease. J Cell Physiol 233, 3892-3900 
74. Wakino, S., Kanda, T., and Hayashi, K. (2005) Rho/Rho kinase as a potential target for the treatment of renal disease. Drug news \& perspectives 18, 639-643

75. Singbartl, K., Formeck, C. L., and Kellum, J. A. (2019) Kidney-Immune System Crosstalk in AKI. Seminars in nephrology 39, 96-106

76. Feizi, A., Jafari, M. R., Hamedivafa, F., Tabrizian, P., and Djahanguiri, B. (2008) The preventive effect of cannabinoids on reperfusion-induced ischemia of mouse kidney. Experimental and toxicologic pathology : official journal of the Gesellschaft fur Toxikologische Pathologie 60, 405-410

77. Fouad, A. A., Al-Mulhim, A. S., and Jresat, I. (2012) Cannabidiol treatment ameliorates ischemia/reperfusion renal injury in rats. Life sciences 91, 284-292

78. Nettekoven, M., Adam, J. M., Bendels, S., Bissantz, C., Fingerle, J., Grether, U., Gruner, S., Guba, W., Kimbara, A., Ottaviani, G., Pullmann, B., Rogers-Evans, M., Rover, S., Rothenhausler, B., Schmitt, S., Schuler, F., Schulz-Gasch, T., and Ullmer, C. (2016) Novel Triazolopyrimidine-Derived Cannabinoid Receptor 2 Agonists as Potential Treatment for Inflammatory Kidney Diseases. ChemMedChem 11, 179-189

79. Horvath, B., Mukhopadhyay, P., Kechrid, M., Patel, V., Tanchian, G., Wink, D. A., Gertsch, J., and Pacher, P. (2012) beta-Caryophyllene ameliorates cisplatininduced nephrotoxicity in a cannabinoid 2 receptor-dependent manner. Free radical biology \& medicine 52, 1325-1333

80. Mukhopadhyay, P., Baggelaar, M., Erdelyi, K., Cao, Z., Cinar, R., Fezza, F., Ignatowska-Janlowska, B., Wilkerson, J., van Gils, N., Hansen, T., Ruben, M., Soethoudt, M., Heitman, L., Kunos, G., Maccarrone, M., Lichtman, A., Pacher, P., and Van der Stelt, M. (2016) The novel, orally available and peripherally restricted selective cannabinoid CB2 receptor agonist LEI-101 prevents cisplatininduced nephrotoxicity. British journal of pharmacology 173, 446-458

81. Mukhopadhyay, P., Pan, H., Rajesh, M., Batkai, S., Patel, V., Harvey-White, J., Mukhopadhyay, B., Hasko, G., Gao, B., Mackie, K., and Pacher, P. (2010) CB1 cannabinoid receptors promote oxidative/nitrosative stress, inflammation and cell death in a murine nephropathy model. British journal of pharmacology 160, 657668

82. Mukhopadhyay, P., Rajesh, M., Pan, H., Patel, V., Mukhopadhyay, B., Batkai, S., Gao, B., Hasko, G., and Pacher, P. (2010) Cannabinoid-2 receptor limits inflammation, oxidative/nitrosative stress, and cell death in nephropathy. Free radical biology \& medicine $\mathbf{4 8}, 457-467$

83. Park, F., Potukuchi, P. K., Moradi, H., and Kovesdy, C. P. (2017) Cannabinoids and the kidney: effects in health and disease. American journal of physiology. Renal physiology 313, F1124-f1132

84. Zoja, C., Locatelli, M., Corna, D., Villa, S., Rottoli, D., Nava, V., Verde, R., Piscitelli, F., Di Marzo, V., Fingerle, J., Adam, J. M., Rothenhaeusler, B., Ottaviani, G., Benardeau, A., Abbate, M., Remuzzi, G., and Benigni, A. (2016) Therapy with a Selective Cannabinoid Receptor Type 2 Agonist Limits Albuminuria and Renal Injury in Mice with Type 2 Diabetic Nephropathy. Nephron 132, 59-69 
85. Barutta, F., Bruno, G., Mastrocola, R., Bellini, S., and Gruden, G. (2018) The role of cannabinoid signaling in acute and chronic kidney diseases. Kidney Int 94, 252258

86. Chua, J. T., Argueta, D. A., DiPatrizio, N. V., Kovesdy, C. P., Vaziri, N. D., Kalantar-Zadeh, K., and Moradi, H. Endocannabinoid System and the Kidneys: From Renal Physiology to Injury and Disease. Cannabis and Cannabinoid Research 4, 10-20

87. Jenkin, K. A., McAinch, A. J., Grinfeld, E., and Hryciw, D. H. (2010) Role for cannabinoid receptors in human proximal tubular hypertrophy. Cellular physiology and biochemistry : international journal of experimental cellular physiology, biochemistry, and pharmacology 26, 879-886

88. Lin, C. L., Hsu, Y. C., Lee, P. H., Lei, C. C., Wang, J. Y., Huang, Y. T., Wang, S. Y., and Wang, F. S. (2014) Cannabinoid receptor 1 disturbance of PPARgamma2 augments hyperglycemia induction of mesangial inflammation and fibrosis in renal glomeruli. Journal of molecular medicine (Berlin, Germany) 92, 779-792

89. Jourdan, T., Szanda, G., Rosenberg, A. Z., Tam, J., Earley, B. J., Godlewski, G., Cinar, R., Liu, Z., Liu, J., Ju, C., Pacher, P., and Kunos, G. (2014) Overactive cannabinoid 1 receptor in podocytes drives type 2 diabetic nephropathy. Proceedings of the National Academy of Sciences 111, E5420-E5428

90. Koura, Y., Ichihara, A., Tada, Y., Kaneshiro, Y., Okada, H., Temm, C. J., Hayashi, M., and Saruta, T. (2004) Anandamide decreases glomerular filtration rate through predominant vasodilation of efferent arterioles in rat kidneys. Journal of the American Society of Nephrology : JASN 15, 1488-1494

91. Hsu, Y. C., Lei, C. C., Shih, Y. H., Ho, C., and Lin, C. L. (2015) Induction of proteinuria by cannabinoid receptors 1 signaling activation in $\mathrm{CB} 1$ transgenic mice. The American journal of the medical sciences 349, 162-168

92. Deutsch, D. G., Goligorsky, M. S., Schmid, P. C., Krebsbach, R. J., Schmid, H. H., Das, S. K., Dey, S. K., Arreaza, G., Thorup, C., Stefano, G., and Moore, L. C. (1997) Production and physiological actions of anandamide in the vasculature of the rat kidney. The Journal of clinical investigation 100, 1538-1546

93. Pressly, J. D., Mustafa, S. M., Adibi, A. H., Alghamdi, S., Pandey, P., Roy, K. K., Doerksen, R. J., Moore, B. M., Jr., and Park, F. (2018) Selective Cannabinoid 2 Receptor Stimulation Reduces Tubular Epithelial Cell Damage after Renal Ischemia-Reperfusion Injury. The Journal of pharmacology and experimental therapeutics 364, 287-299 https://doi.org/10.1124/jpet.117.245522

94. Li, J., and Wang, D. H. (2006) Differential mechanisms mediating depressor and diuretic effects of anandamide. Journal of hypertension 24, 2271-2276

95. Ritter, J. K., Li, C., Xia, M., Poklis, J. L., Lichtman, A. H., Abdullah, R. A., Dewey, W. L., and Li, P. L. (2012) Production and actions of the anandamide metabolite prostamide E2 in the renal medulla. The Journal of pharmacology and experimental therapeutics 342, 770-779

96. Sampaio, L. S., Taveira Da Silva, R., Lima, D., Sampaio, C. L., Iannotti, F. A., Mazzarella, E., Di Marzo, V., Vieyra, A., Reis, R. A., and Einicker-Lamas, M. (2015) The endocannabinoid system in renal cells: regulation of $\mathrm{Na}(+)$ transport by $\mathrm{CB} 1$ receptors through distinct cell signalling pathways. British journal of pharmacology 172, 4615-4625 
97. Garzón, J., de la Torre-Madrid, E., Rodríguez-Muñoz, M., Vicente-Sánchez, A., and Sánchez-Blázquez, P. (2009) Gz mediates the long-lasting desensitization of brain CB1 receptors and is essential for cross-tolerance with morphine. Molecular pain 5, 11

98. Bash, R., Rubovitch, V., Gafni, M., and Sarne, Y. (2003) The stimulatory effect of cannabinoids on calcium uptake is mediated by Gs GTP-binding proteins and cAMP formation. Neurosignals 12, 39-44

99. Glass, M., and Northup, J. K. (1999) Agonist selective regulation of G proteins by cannabinoid CB1 and CB2 receptors. Molecular pharmacology 56, 1362-1369

100. Soethoudt, M., Grether, U., Fingerle, J., Grim, T. W., Fezza, F., de Petrocellis, L., Ullmer, C., Rothenhäusler, B., Perret, C., van Gils, N., Finlay, D., MacDonald, C., Chicca, A., Gens, M. D., Stuart, J., de Vries, H., Mastrangelo, N., Xia, L., Alachouzos, G., Baggelaar, M. P., Martella, A., Mock, E. D., Deng, H., Heitman, L. H., Connor, M., Di Marzo, V., Gertsch, J., Lichtman, A. H., Maccarrone, M., Pacher, P., Glass, M., and van der Stelt, M. (2017) Cannabinoid CB(2) receptor ligand profiling reveals biased signalling and off-target activity. Nature Communications $\mathbf{8}$

101. Howlett, A., Barth, F., Bonner, T., Cabral, G., Casellas, P., Devane, W., Felder, C., Herkenham, M., Mackie, K., and Martin, B. (2002) International Union of Pharmacology. XXVII. Classification of cannabinoid receptors. Pharmacological reviews 54, 161-202

102. Dhopeshwarkar, A., and Mackie, K. (2014) CB2 Cannabinoid receptors as a therapeutic target — what does the future hold? Molecular pharmacology 86, 430437

103. Felder, C. C., Joyce, K. E., Briley, E. M., Mansouri, J., Mackie, K., Blond, O., Lai, Y., Ma, A. L., and Mitchell, R. L. (1995) Comparison of the pharmacology and signal transduction of the human cannabinoid $\mathrm{CB} 1$ and $\mathrm{CB} 2$ receptors. Molecular pharmacology 48, 443-450

104. Khan, S. M., Sung, J. Y., and Hebert, T. E. (2016) G $\beta \gamma$ subunits-Different spaces, different faces. Pharmacological research 111, 434-441

105. Ferguson, S. S. (2001) Evolving concepts in G protein-coupled receptor endocytosis: the role in receptor desensitization and signaling. Pharmacological reviews 53, 1-24

106. Smith, J. S., and Rajagopal, S. (2016) The $\beta$-arrestins: multifunctional regulators of $\mathrm{G}$ protein-coupled receptors. Journal of Biological Chemistry 291, 8969-8977

107. Nogueras-Ortiz, C., Roman-Vendrell, C., Mateo-Semidey, G. E., Liao, Y.-H., Kendall, D. A., and Yudowski, G. A. (2017) Retromer stops beta-arrestin 1mediated signaling from internalized cannabinoid 2 receptors. Molecular biology of the cell 28, 3554-3561

108. Wootten, D., Christopoulos, A., Marti-Solano, M., Babu, M. M., and Sexton, P. M. (2018) Mechanisms of signalling and biased agonism in G protein-coupled receptors. Nature reviews. Molecular cell biology 19, 638-653

109. Aamann, M. D., Norregaard, R., Kristensen, M. L., Stevnsner, T., and Frokiaer, J. (2015) Unilateral ureteral obstruction induces DNA repair by APE1. American journal of physiology. Renal physiology, ajprenal.00613.02014 
110. Ashton, J. C., Wright, J. L., McPartland, J. M., and Tyndall, J. D. (2008)

Cannabinoid CB1 and CB2 receptor ligand specificity and the development of CB2-selective agonists. Current medicinal chemistry 15, 1428-1443

111. Fu, Y., Tang, C., Cai, J., Chen, G., Zhang, D., and Dong, Z. (2018) Rodent models of AKI-CKD transition. American journal of physiology. Renal physiology 315, F1098-f1106

112. Presley, C., Abidi, A., Suryawanshi, S., Mustafa, S., Meibohm, B., and Moore, B. M. (2015) Preclinical evaluation of SMM-189, a cannabinoid receptor 2-specific inverse agonist. Pharmacology research \& perspectives 3, e00159

113. Pertwee, R. G. (1993) Cannabinoid Receptor Ligands. Tocris Cookson Rev 44

114. Aceto, M. D., Scates, S. M., Lowe, J. A., and Martin, B. R. (1995) Cannabinoid precipitated withdrawal by the selective cannabinoid receptor antagonist, SR 141716A. European journal of pharmacology 282, R1-R2

115. Regner, K. R., Nozu, K., Lanier, S. M., Blumer, J. B., Avner, E. D., Sweeney, W. E., Jr., and Park, F. (2011) Loss of activator of G-protein signaling 3 impairs renal tubular regeneration following acute kidney injury in rodents. FASEB journal : official publication of the Federation of American Societies for Experimental Biology 25, 1844-1855

116. White, S. M., North, L. M., Haines, E., Goldberg, M., Sullivan, L. M., Pressly, J. D., Weber, D. S., Park, F., and Regner, K. R. (2014) G-protein betagamma subunit dimers modulate kidney repair after ischemia-reperfusion injury in rats. Mol Pharmacol 86, 369-377

117. Kazory, A., and Aiyer, R. (2013) Synthetic marijuana and acute kidney injury: an unforeseen association. Clinical kidney journal 6, 330-333

118. Srisung, W., Jamal, F., and Prabhakar, S. (2015) Synthetic cannabinoids and acute kidney injury. In Baylor University Medical Center Proceedings Vol. 28 pp. 475477, Taylor \& Francis

119. Barutta, F., Piscitelli, F., Pinach, S., Bruno, G., Gambino, R., Rastaldi, M. P., Salvidio, G., Di Marzo, V., Cavallo Perin, P., and Gruden, G. (2011) Protective role of cannabinoid receptor type 2 in a mouse model of diabetic nephropathy. Diabetes 60, 2386-2396

120. Jenkin, K., O'keefe, L., Simcocks, A., Briffa, J., Mathai, M., McAinch, A., and Hryciw, D. H. (2016) Renal effects of chronic pharmacological manipulation of CB2 receptors in rats with diet-induced obesity. British journal of pharmacology 173, 1128-1142

121. Barutta, F., Piscitelli, F., Pinach, S., Bruno, G., Gambino, R., Rastaldi, M. P., Salvidio, G., Di Marzo, V., Perin, P. C., and Gruden, G. (2011) Protective role of cannabinoid receptor type 2 in a mouse model of diabetic nephropathy. Diabetes 60, 2386-2396

122. Klein, T. W., Newton, C., Larsen, K., Lu, L., Perkins, I., Nong, L., and Friedman, H. (2003) The cannabinoid system and immune modulation. Journal of leukocyte biology 74, 486-496

123. Cabral, G. A., and Griffin-Thomas, L. (2009) Emerging role of the cannabinoid receptor $\mathrm{CB} 2$ in immune regulation: therapeutic prospects for neuroinflammation. Expert reviews in molecular medicine 11, e3 
124. Thomas, A., Baillie, G. L., Phillips, A. M., Razdan, R. K., Ross, R. A., and Pertwee, R. G. (2007) Cannabidiol displays unexpectedly high potency as an antagonist of $\mathrm{CB} 1$ and $\mathrm{CB} 2$ receptor agonists in vitro. British journal of pharmacology 150, 613-623

125. Fulmer, M. L., and Thewke, D. P. (2018) The Endocannabinoid System and Heart Disease: The Role of Cannabinoid Receptor Type 2. Cardiovascular \& hematological disorders drug targets 18, 34-51

126. Lipez-Miranda, V., Herradon, E., and Martin, M. I. (2008) Vasorelaxation caused by cannabinoids: mechanisms in different vascular beds. Current vascular pharmacology 6, 335-346

127. Randall, M. D., and Kendall, D. A. (1998) Endocannabinoids: a new class of vasoactive substances. Trends in pharmacological sciences 19, 55-58

128. Sarzani, R. (2008) Endocannabinoids, blood pressure and the human heart. Journal of neuroendocrinology 20 Suppl 1, 58-62

129. Chertow, G. M., Burdick, E., Honour, M., Bonventre, J. V., and Bates, D. W. (2005) Acute kidney injury, mortality, length of stay, and costs in hospitalized patients. Journal of the American Society of Nephrology: JASN 16, 3365-3370

130. Wang, H. E., Muntner, P., Chertow, G. M., and Warnock, D. G. (2012) Acute kidney injury and mortality in hospitalized patients. American journal of nephrology 35, 349-355

131. Macedo, E., and Mehta, R. L. (2009) Prerenal failure: from old concepts to new paradigms. Current opinion in critical care 15, 467-473

132. Chawla, L. S., Eggers, P. W., Star, R. A., and Kimmel, P. L. (2014) Acute kidney injury and chronic kidney disease as interconnected syndromes. The New England journal of medicine 371, 58-66

133. Heung, M., and Chawla, L. S. (2014) Acute kidney injury: gateway to chronic kidney disease. Nephron. Clinical practice 127, 30-34

134. Yang, L., Humphreys, B. D., and Bonventre, J. V. (2011) Pathophysiology of acute kidney injury to chronic kidney disease: maladaptive repair. Contributions to nephrology 174, 149-155

135. Hryciw, D. H., and McAinch, A. J. (2016) Cannabinoid receptors in the kidney. Current opinion in nephrology and hypertension 25, 459-464

136. Jenkin, K. A., McAinch, A. J., Briffa, J. F., Zhang, Y., Kelly, D. J., Pollock, C. A., Poronnik, P., and Hryciw, D. H. (2013) Cannabinoid receptor 2 expression in human proximal tubule cells is regulated by albumin independent of ERK1/2 signaling. Cellular physiology and biochemistry : international journal of experimental cellular physiology, biochemistry, and pharmacology 32, 1309-1319

137. Jenkin, K. A., O'Keefe, L., Simcocks, A. C., Briffa, J. F., Mathai, M. L., McAinch, A. J., and Hryciw, D. H. (2016) Renal effects of chronic pharmacological manipulation of CB2 receptors in rats with diet-induced obesity. British journal of pharmacology 173, 1128-1142

138. Presley, C. S., Abidi, A. H., Suryawanshi, S., Mustafa, S., Meibohm, B., and Moore, B. M., 2nd. (2015) Pre-clinical evaluation of SMM-189, a CB2 specific inverse agonist. Pharmacology Research and Perspectives

139. Presley, C. S., Mustafa, S. M., Abidi, A. H., and Moore, B. M., 2nd. (2015) Synthesis and biological evaluation of (3',5'-dichloro-2,6-dihydroxy-biphenyl-4- 
yl)-aryl/alkyl-methanone selective CB2 inverse agonist. Bioorganic \& medicinal chemistry 23, 5390-5401

140. Rastogi, H., Pinjari, J., Honrao, P., Praband, S., and Somani, R. (2013) The impact of permeability enhancers on assessment for monolayer of colon adenocarcinoma cell line (CaCo-2) used in in vitro permeability assay. Journal of Drug Delivery and Therapeutics 3, 20-29

141. Lenarczyk, M., Pressly, J. D., Arnett, J., Regner, K. R., and Park, F. (2015) Localization and expression profile of Group I and II Activators of G-protein Signaling in the kidney. Journal of molecular histology 46, 123-136

142. Park, F., Sweeney, W. E., Jia, G., Roman, R. J., and Avner, E. D. (2008) 20HETE mediates proliferation of renal epithelial cells in polycystic kidney disease. Journal of the American Society of Nephrology : JASN 19, 1929-1939

143. Kwon, M., Pavlov, T. S., Nozu, K., Rasmussen, S. A., Ilatovskaya, D. V., LerchGaggl, A., North, L. M., Kim, H., Qian, F., Sweeney, W. E., Jr., Avner, E. D., Blumer, J. B., Staruschenko, A., and Park, F. (2012) G-protein signaling modulator 1 deficiency accelerates cystic disease in an orthologous mouse model of autosomal dominant polycystic kidney disease. Proceedings of the National Academy of Sciences of the United States of America 109, 21462-21467

144. Curtis, M. J., Bond, R. A., Spina, D., Ahluwalia, A., Alexander, S. P., Giembycz, M. A., Gilchrist, A., Hoyer, D., Insel, P. A., Izzo, A. A., Lawrence, A. J., MacEwan, D. J., Moon, L. D., Wonnacott, S., Weston, A. H., and McGrath, J. C. (2015) Experimental design and analysis and their reporting: new guidance for publication in BJP. British journal of pharmacology 172, 3461-3471

145. Howlett, A. (2005) Cannabinoid receptor signaling. In Cannabinoids pp. 53-79, Springer

146. Datta, S. R., Brunet, A., and Greenberg, M. E. (1999) Cellular survival: a play in three Akts. Genes \& development 13, 2905-2927

147. Chao, D. T., and Korsmeyer, S. J. (1998) BCL-2 family: regulators of cell death. Annual review of immunology $\mathbf{1 6}$

148. Porter, A. G., and Jänicke, R. U. (1999) Emerging roles of caspase-3 in apoptosis. Cell death and differentiation 6, 99

149. Shohami, E., Cohen-Yeshurun, A., Magid, L., Algali, M., and Mechoulam, R. (2011) Endocannabinoids and traumatic brain injury. British journal of pharmacology 163, 1402-1410

150. Witkamp, R., and Meijerink, J. (2014) The endocannabinoid system: an emerging key player in inflammation. Current Opinion in Clinical Nutrition \& Metabolic Care 17, 130-138

151. Walter, L., and Stella, N. (2003) Endothelin-1 increases 2-arachidonoyl glycerol (2-AG) production in astrocytes. Glia 44, 85-90

152. Ortega-Gutiérrez, S., Molina-Holgado, E., and Guaza, C. (2005) Effect of anandamide uptake inhibition in the production of nitric oxide and in the release of cytokines in astrocyte cultures. Glia 52, 163-168

153. Zarruk, J. G., Fernández-López, D., García-Yébenes, I., García-Gutiérrez, M. S., Vivancos, J., Nombela, F., Torres, M., Burguete, M. C., Manzanares, J., and Lizasoain, I. (2012) Cannabinoid type 2 receptor activation downregulates stroke- 
induced classic and alternative brain macrophage/microglial activation concomitant to neuroprotection. Stroke 43, 211-219

154. Bu, W., Ren, H., Deng, Y., Del Mar, N., Guley, N. M., Moore, B. M., Honig, M. G., and Reiner, A. (2016) Mild traumatic brain injury produces neuron loss that can be rescued by modulating microglial activation using a CB2 receptor inverse agonist. Frontiers in neuroscience 10, 449

155. Galve-Roperh, I., Rueda, D., del Pulgar, T. G., Velasco, G., and Guzmán, M. (2002) Mechanism of extracellular signal-regulated kinase activation by the CB1 cannabinoid receptor. Molecular pharmacology 62, 1385-1392

156. Calvaruso, G., Pellerito, O., Notaro, A., and Giuliano, M. (2012) Cannabinoidassociated cell death mechanisms in tumor models. International journal of oncology 41, 407-413

157. Pressly, J. D., Soni, H., Jiang, S., Wei, J., Liu, R., Moore, B. M., Adebiyi, A., and Park, F. (2019) Activation of the cannabinoid receptor 2 increases renal perfusion. Physiological genomics 51, 90-96

158. Tam, J. (2016) The emerging role of the endocannabinoid system in the pathogenesis and treatment of kidney diseases. Journal of basic and clinical physiology and pharmacology 27, 267-276

159. Gardiner, S. M., March, J. E., Kemp, P. A., and Bennett, T. (2001) Regional haemodynamic responses to the cannabinoid agonist, WIN 55212-2, in conscious, normotensive rats, and in hypertensive, transgenic rats. British journal of pharmacology 133, 445-453

160. Fu, Y., Hall, J. E., Lu, D., Lin, L., Manning, R. D., Jr., Cheng, L., GomezSanchez, C. E., Juncos, L. A., and Liu, R. (2012) Aldosterone blunts tubuloglomerular feedback by activating macula densa mineralocorticoid receptors. Hypertension 59, 599-606

161. Lai, E. Y., Wang, Y., Persson, A. E., Manning, R. D., Jr., and Liu, R. (2011) Pressure induces intracellular calcium changes in juxtaglomerular cells in perfused afferent arterioles. Hypertension research : official journal of the Japanese Society of Hypertension 34, 942-948

162. Wang, L., Shen, C., Liu, H., Wang, S., Chen, X., Roman, R. J., Juncos, L. A., Lu, Y., Wei, J., Zhang, J., Yip, K. P., and Liu, R. (2015) Shear stress blunts tubuloglomerular feedback partially mediated by primary cilia and nitric oxide at the macula densa. American journal of physiology. Regulatory, integrative and comparative physiology 309, R757-766

163. Yip, K. P., Balasubramanian, L., Kan, C., Wang, L., Liu, R., Ribeiro-Silva, L., and Sham, J. S. K. (2018) Intraluminal Pressure Triggers Myogenic Response via Activation of Calcium Spark and Calcium-Activated Chloride Channel in Rat Renal Afferent Arteriole. American journal of physiology. Renal physiology

164. Zhang, Q., Lin, L., Lu, Y., Liu, H., Duan, Y., Zhu, X., Zou, C., Manning, R. D., Jr., and Liu, R. (2013) Interaction between nitric oxide and superoxide in the macula densa in aldosterone-induced alterations of tubuloglomerular feedback. American journal of physiology. Renal physiology 304, F326-332

165. Soni, H., Kaminski, D., Gangaraju, R., and Adebiyi, A. (2018) Cisplatin-induced oxidative stress stimulates renal Fas ligand shedding. Renal failure 40, 314-322 
166. Park, F., Zou, A. P., and Cowley, A. W., Jr. (1998) Arginine vasopressinmediated stimulation of nitric oxide within the rat renal medulla. Hypertension 32, 896-901

167. Peixoto-Neves, D., Soni, H., and Adebiyi, A. (2018) CGRPergic Nerve TRPA1 Channels Contribute to Epigallocatechin Gallate-Induced Neurogenic Vasodilation. ACS chemical neuroscience

168. Stanley, C. P., Hind, W. H., Tufarelli, C., and O'Sullivan, S. E. (2015) Cannabidiol causes endothelium-dependent vasorelaxation of human mesenteric arteries via CB1 activation. Cardiovascular research 107, 568-578

169. Lopez-Dyck, E., Andrade-Urzua, F., Elizalde, A., Ferrer-Villada, T., DagninoAcosta, A., Huerta, M., Osuna-Calleros, Z., Rangel-Sandoval, C., and SanchezPastor, E. (2017) ACPA and JWH-133 modulate the vascular tone of superior mesenteric arteries through cannabinoid receptors, BKCa channels, and nitric oxide dependent mechanisms. Pharmacological reports : PR 69, 1131-1139

170. Benyo, Z., Ruisanchez, E., Leszl-Ishiguro, M., Sandor, P., and Pacher, P. (2016) Endocannabinoids in cerebrovascular regulation. American journal of physiology. Heart and circulatory physiology 310, H785-801

171. Akerman, S., Kaube, H., and Goadsby, P. J. (2004) Anandamide acts as a vasodilator of dural blood vessels in vivo by activating TRPV1 receptors. British journal of pharmacology 142, 1354-1360

172. Johns, D. G., Behm, D. J., Walker, D. J., Ao, Z., Shapland, E. M., Daniels, D. A., Riddick, M., Dowell, S., Staton, P. C., Green, P., Shabon, U., Bao, W., Aiyar, N., Yue, T. L., Brown, A. J., Morrison, A. D., and Douglas, S. A. (2007) The novel endocannabinoid receptor GPR55 is activated by atypical cannabinoids but does not mediate their vasodilator effects. British journal of pharmacology 152, 825831

173. Penumarti, A., and Abdel-Rahman, A. A. (2014) The novel endocannabinoid receptor GPR18 is expressed in the rostral ventrolateral medulla and exerts tonic restraining influence on blood pressure. The Journal of pharmacology and experimental therapeutics 349, 29-38

174. Pacher, P., Nagayama, T., Mukhopadhyay, P., Batkai, S., and Kass, D. A. (2008) Measurement of cardiac function using pressure-volume conductance catheter technique in mice and rats. Nature protocols 3, 1422-1434

175. Tumati, S., Yamamura, H. I., St John, P. A., Vanderah, T. W., Roeske, W. R., and Varga, E. V. (2009) Sustained cannabinoid agonist treatment augments CGRP release in a PKA-dependent manner. Neuroreport 20, 815-819

176. Wilkinson, J. D., Kendall, D. A., and Ralevic, V. (2007) Delta 9tetrahydrocannabinol inhibits electrically-evoked CGRP release and capsaicinsensitive sensory neurogenic vasodilatation in the rat mesenteric arterial bed. British journal of pharmacology 152, 709-716

177. Beltramo, M., Bernardini, N., Bertorelli, R., Campanella, M., Nicolussi, E., Fredduzzi, S., and Reggiani, A. (2006) CB2 receptor-mediated antihyperalgesia: possible direct involvement of neural mechanisms. The European journal of neuroscience 23, 1530-1538

178. Schuelert, N., Zhang, C., Mogg, A. J., Broad, L. M., Hepburn, D. L., Nisenbaum, E. S., Johnson, M. P., and McDougall, J. J. (2010) Paradoxical effects of the 
cannabinoid CB2 receptor agonist GW405833 on rat osteoarthritic knee joint pain. Osteoarthritis and cartilage 18, 1536-1543

179. Milne, M., and Ashton, J. C. (2016) Effect of cannabinoids on CGRP release in the isolated rat lumbar spinal cord. Neuroscience letters 614, 39-42

180. Brain, S. D., and Grant, A. D. (2004) Vascular actions of calcitonin gene-related peptide and adrenomedullin. Physiological reviews 84, 903-934

181. Russell, F. A., King, R., Smillie, S. J., Kodji, X., and Brain, S. D. (2014) Calcitonin gene-related peptide: physiology and pathophysiology. Physiological reviews 94, 1099-1142

182. Soethoudt, M., Grether, U., Fingerle, J., Grim, T. W., Fezza, F., de Petrocellis, L., Ullmer, C., Rothenhausler, B., Perret, C., van Gils, N., Finlay, D., MacDonald, C., Chicca, A., Gens, M. D., Stuart, J., de Vries, H., Mastrangelo, N., Xia, L., Alachouzos, G., Baggelaar, M. P., Martella, A., Mock, E. D., Deng, H., Heitman, L. H., Connor, M., Di Marzo, V., Gertsch, J., Lichtman, A. H., Maccarrone, M., Pacher, P., Glass, M., and van der Stelt, M. (2017) Cannabinoid CB2 receptor ligand profiling reveals biased signalling and off-target activity. Nature Communications 8, 13958

183. Havasi, A., and Borkan, S. C. (2011) Apoptosis and acute kidney injury. Kidney Int 80, 29-40

184. Linkermann, A., Chen, G., Dong, G., Kunzendorf, U., Krautwald, S., and Dong, Z. (2014) Regulated cell death in AKI. Journal of the American Society of Nephrology 25, 2689-2701

185. Lankadeva, Y. R., Cochrane, A. D., Marino, B., Iguchi, N., Hood, S. G., Bellomo, R., May, C. N., and Evans, R. G. (2019) Strategies that improve renal medullary oxygenation during experimental cardiopulmonary bypass may mitigate postoperative acute kidney injury. Kidney Int 95, 1338-1346

186. Hulse, M., and Rosner, M. H. (2019) Drugs in Development for Acute Kidney Injury. Drugs 79, 811-821

187. Pacher, P., Steffens, S., Haskó, G., Schindler, T. H., and Kunos, G. (2017) Cardiovascular effects of marijuana and synthetic cannabinoids: the good, the bad, and the ugly. Nature Reviews Cardiology 15, 151

188. Rosenbaum, D. M., Rasmussen, S. G., and Kobilka, B. K. (2009) The structure and function of G-protein-coupled receptors. Nature 459, 356

189. Mallipeddi, S., Janero, D. R., Zvonok, N., and Makriyannis, A. (2017) Functional selectivity at G-protein coupled receptors: Advancing cannabinoid receptors as drug targets. Biochemical pharmacology 128, 1-11

190. Przybyla, J. A., and Watts, V. J. (2010) Ligand-induced regulation and localization of cannabinoid CB1 and dopamine D2L receptor heterodimers. The Journal of pharmacology and experimental therapeutics 332, 710-719

191. Lohse, M. J., Nuber, S., and Hoffmann, C. (2012) Fluorescence/bioluminescence resonance energy transfer techniques to study G-protein-coupled receptor activation and signaling. Pharmacological reviews 64, 299-336

192. Priestley, R., Glass, M., and Kendall, D. (2017) Functional Selectivity at Cannabinoid Receptors. Advances in pharmacology (San Diego, Calif.) 80, 207221 
193. Járai, Z., Wagner, J. A., Varga, K., Lake, K. D., Compton, D. R., Martin, B. R., Zimmer, A. M., Bonner, T. I., Buckley, N. E., and Mezey, E. (1999)

Cannabinoid-induced mesenteric vasodilation through an endothelial site distinct from CB1 or CB2 receptors. Proceedings of the National Academy of Sciences 96, 14136-14141

194. Offertáler, L., Mo, F.-M., Bátkai, S., Liu, J., Begg, M., Razdan, R. K., Martin, B. R., Bukoski, R. D., and Kunos, G. (2003) Selective ligands and cellular effectors of a $\mathrm{G}$ protein-coupled endothelial cannabinoid receptor. Molecular pharmacology 63, 699-705

195. Kunos, G., Bátkai, S., Offertáler, L., Mo, F., Liu, J., Karcher, J., and HarveyWhite, J. (2002) The quest for a vascular endothelial cannabinoid receptor. Chemistry and Physics of Lipids 121, 45-56

196. Pertwee, R. G. (1997) Pharmacology of cannabinoid CB1 and CB2 receptors. Pharmacology \& therapeutics 74, 129-180

197. Atwood, B. K., and Mackie, K. (2010) CB2: a cannabinoid receptor with an identity crisis. British journal of pharmacology 160, 467-479

198. López, A., Aparicio, N., Pazos, M. R., Grande, M. T., Barreda-Manso, M. A., Benito-Cuesta, I., Vázquez, C., Amores, M., Ruiz-Pérez, G., and García-García, E. (2018) Cannabinoid CB 2 receptors in the mouse brain: relevance for Alzheimer's disease. Journal of neuroinflammation 15, 158 


\section{VITA}

Jeffrey Pressly was born in San Antonio, Texas in the year 1987. He obtained a Bachelor of Science degree on May 2009 from Texas A\&M University, College Station, TX and Master of Science in Biology on December 2011 from University of Texas at San Antonio, San Antonio, TX. He was matriculated in Pharmaceutical Sciences for doctoral studies at University of Tennessee Health Science Center, Memphis, TN, USA in August 2015. He anticipates completion of the requirements for doctorate degree by May 2020. 